\author{
Universidad Peruana Unión \\ Unidad de Posgrado de Teología
}

\title{
FACTORES ADMINISTRATIVOS, EVANGELÍSTICOS, PASTORALES Y ESTRUCTURALES QUE INFLUYERON EN EL CRECIMIENTO DE LOS DISTRITOS MISIONEROS DE TRUJILLO, AÑOS 2001-2009
}

\author{
Tesis \\ presentada en cumplimiento parcial \\ de los requerimientos para el grado académico de \\ Magíster en Teología
}

Por

Jorge Luis Reyes Aguilar

Noviembre 2015 
Copyright (C) 2015 Jorge Luis Reyes Aguilar Todos los derechos reservados 


\section{FACTORES ADMINISTRATIVOS, EVANGELÍSTICOS, PASTORALES Y ESTRUCTURALES QUE INFLUYERON EN EL CRECIMIENTO \\ DE LOS DISTRITOS MISIONEROS DE \\ TRUJILLO, AÑOS 2001-2009}

Tesis

presentada en cumplimiento parcial

de los requerimientos para el grado académico de

Magíster en Teología

\section{Por}

Jorge Luis Reyes Aguilar

\section{APROBADA POR LA COMISIÓN}

Asesor

Dr. Miguel Ángel Salomón Méndez

Profesor de Teología

Dr. Miguel Guillermo Bernuí Contreras

Profesor de Teología

Dr. Daniel William Richard Pérez

Profesor de Teología

Mg. Juan Marcelo Zanga Céspedes

Profesor de Teología
Unidad de Posgrado de Teología

Dr. Glúder Quispe Huanca

Director

Escuela de Posgrado

Dr. Erika Inés Acuña Salinas

Directora

Fecha de Aprobación 


\title{
RESUMEN DE TESIS
}

\author{
Universidad Peruana Unión \\ Unidad de Posgrado de Teología \\ Maestría en Teología
}

\section{TÍTULO: FACTORES ADMINISTRATIVOS, EVANGELÍSTICOS, PASTORALES Y ESTRUCTURALES QUE INFLUYERON EN EL CRECIMIENTO DE LOS DISTRITOS MISIONEROS DE TRUJILLO, AÑOS 2001-2009}

Nombre del investigador: Jorge Luis Reyes Aguilar

Grado y nombre del consejero: Dr. Miguel Ángel Salomón Méndez

Fecha de terminación: Noviembre de 2015

\section{Problema}

Se plantea la siguiente pregunta de investigación: ¿En qué medida los factores administrativos, evangelísticos, pastorales y estructurales han influido en el crecimiento de los distritos misioneros de Trujillo durante el período del 2001-2009?

\section{Propósito}

Los objetivos específicos en esta investigación son: (1) Identificar los factores administrativos que incidieron en el crecimiento de la IASD en la ciudad de Trujillo durante el periodo del 2001 al 2009. (2) Identificar los factores evangelísticos que influyeron en el crecimiento de la IASD en la ciudad de Trujillo durante el periodo del 2001 al 2009. (3) Identificar los factores pastorales que influyeron en el crecimiento de la 
IASD en la ciudad de Trujillo durante el periodo del 2001 al 2009. (4) Identificar los factores estructurales que influyeron en el crecimiento de la IASD en la ciudad de Trujillo durante el periodo del 2001 al 2009. (5) Relacionar todos estos factores con el crecimiento de la IASD en la ciudad de Trujillo durante el periodo del 2001 al 2009.

\section{Metodología}

La presente investigación es de tipo histórico sincrónico-descriptivo, pues tiene el objetivo de detallar los factores administrativos, evangelísticos, pastorales y estructurales (variables independientes) que contribuyeron al crecimiento de la IASD en la ciudad de Trujillo (variable dependiente), durante el período del 2001-2009.

\section{Conclusiones}

La expansión del adventismo en las diferentes regiones del Perú, y de manera particular en el norte peruano, fue el resultado del ímpetu misionero de los pioneros. El establecimiento de unidades administrativas en los nuevos territorios, facilitó el crecimiento y desarrollo de la iglesia adventista. También los especialistas en crecimiento señalan, entre otros factores que facilitan el desarrollo y expansión, a los administrativos, evangelísticos, pastorales y estructurales. 


\title{
THESIS ABSTRACT
}

\author{
Peruvian Union University \\ Graduate School of Theology \\ Master of Theology
}
Title: ADMINISTRATIVE FACTORS, EVANGELISTIC, PASTORAL AND STRUCTURAL INFLUENCE GROWTH MISSIONARIES DISTRICTS TRUJILLO, YEARS 2001-2009

Name of researcher: Jorge Luis Reyes Aguilar

Name and degree of faculty adviser: Miguel Ángel Salomón Méndez, Th.D.

Date completed: November 2015

\section{Problem}

The following research question arises: To what extent administrative, evangelistic, pastoral and structural factors have influenced to the growth of the missionary districts of Trujillo in the period 2001-2009?

\section{Purpose}

The specific objectives of this research are: (1) Identify the administrative factors affecting the growth of the SDA in the city of Trujillo between 2001 and 2009. (2) Identify the factors that influenced evangelistic growth in SDA Trujillo between 2001 and 2009. (3) Identify the pastoral factors that influenced the growth of the SDA in the city of Trujillo between 2001 and 2009. (4) To identify the structural factors that 
influenced the SDA growth in the city of Trujillo between 2001 and 2009. (5) all these factors relate to the growth of the SDA church in the city of Trujillo between 2001 and 2009.

\section{Methodology}

This research is descriptive historical synchronous type, for aims of administrative detail, evangelistic, pastoral and structural factors (independent variables) that contributed to the growth of the SDA church in the city of Trujillo (dependent variable) in the period specific 2001-2009.

\section{Conclusions}

The expansion of Adventism in the different regions of Peru, and especially so in northern Peru was the result of the missionary zeal of the pioneers. The establishment of administrative units in the New Territories facilitated the growth and development of the Adventist Church. Also, specialists in church growth among other factors indicate that facilitate the development and expansion, administrative, evangelistic, pastoral and structural. 


\section{TABLA DE CONTENIDO}

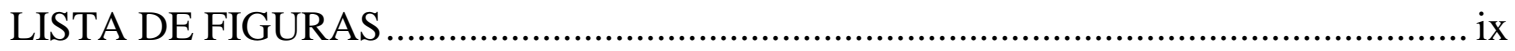

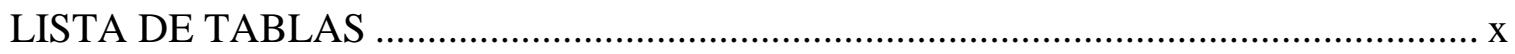

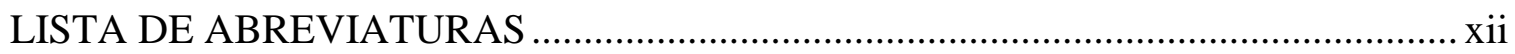

Capítulo

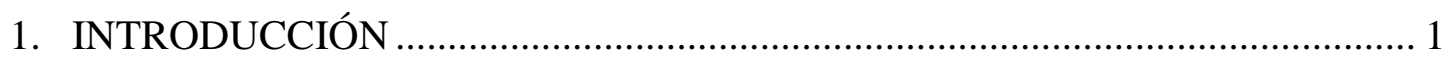

Trasfondo del problema ……………………………............................. 1

Planteamiento del problema....................................................................... 9

Objetivos de la investigación .................................................................... 9

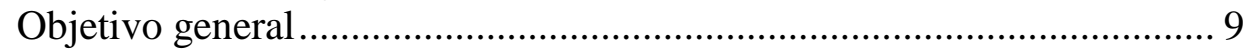

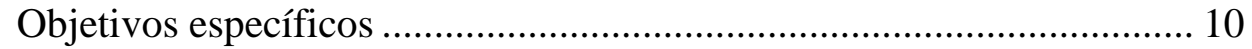

Hipótesis de la investigación...................................................................... 10

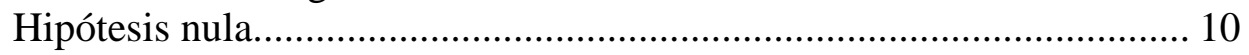

Justificación de la investigación .................................................................. 10

Delimitaciones de la investigación ............................................................. 11

Definición de términos............................................................................ 11

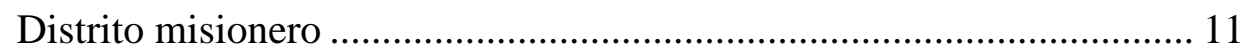

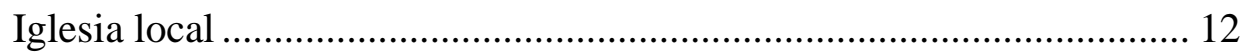

Asociación/Misión/Campo ................................................................... 12

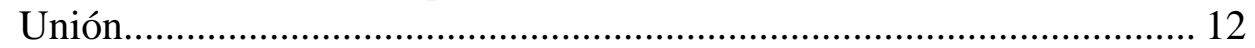

Asociación General ...................................................................... 12

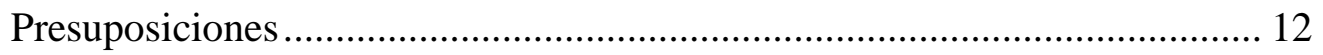

Organización del trabajo ......................................................................... 13

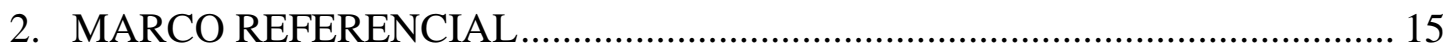

Datos referenciales de la ciudad de Trujillo................................................... 15

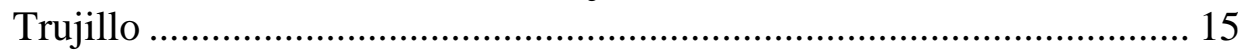

Geografía y clima de Trujillo........................................................ 17

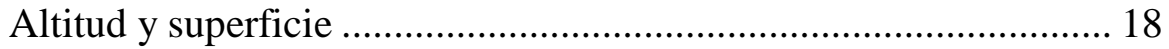

Organización Administrativa........................................................ 18

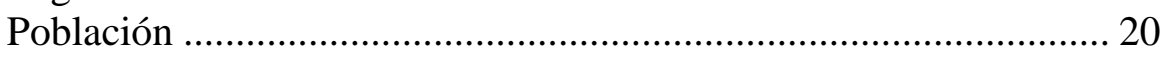

Estructura de edades ............................................................. 21

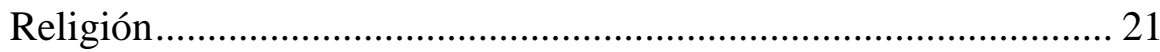

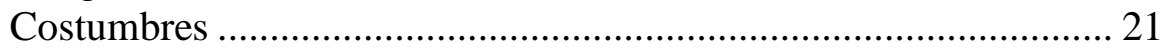




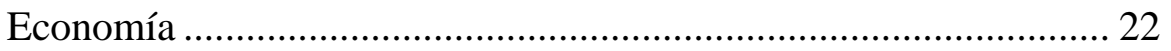

Servicios públicos y aprovisionamiento ………………………........ 23

Infraestructura energética ………………………………........ 23

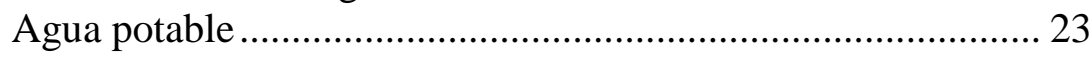

Educación ......................................................................... 23

Universidad Nacional de Trujillo ……………………….............. 26

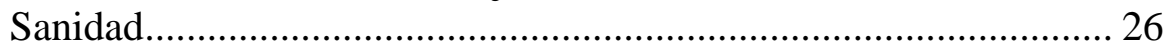

Historia y Cultura.............................................................................. 27

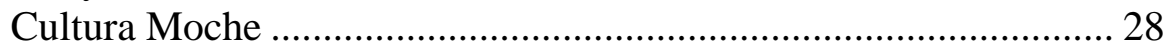

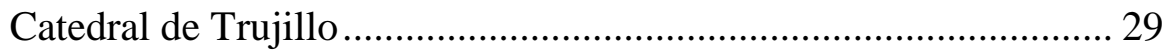

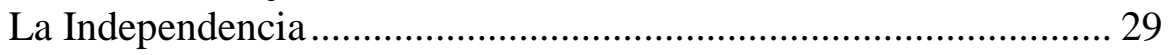

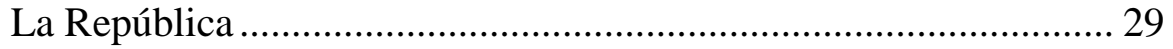

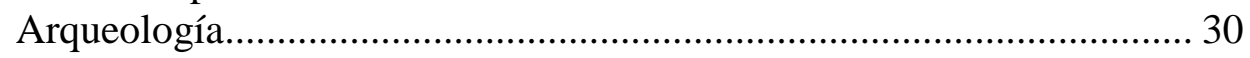

Ciudadela de Chan Chan............................................................... 30

Huaca El Dragón o Arco Iris ............................................................ 31

Huaca del Sol y Huaca de la Luna ................................................... 32

Huaca de la Luna ……………………………………....... 32

Huaca del Sol .................................................................. 33

Huaca La Esmeralda .................................................................... 33

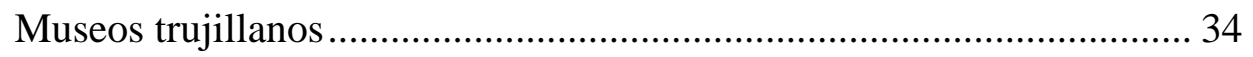

Museo Catedralicio ..................................................................... 34

Museo de Arqueología e Historia de la Universidad Nacional de

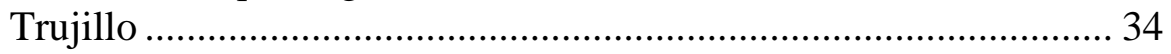

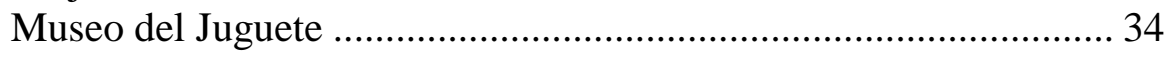

Museo de Zoología ........................................................................... 35

Datos referenciales de la Iglesia Adventista del Séptimo Día ......................... 35

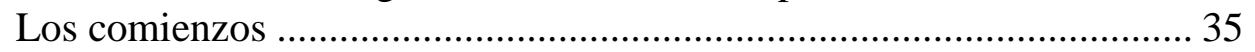

Despertar evangelístico y establecimiento administrativo....................... 37

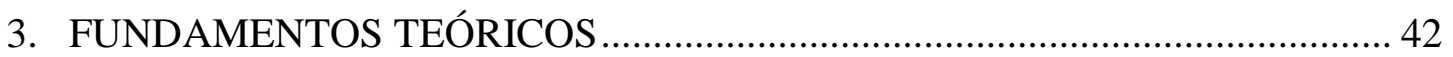

La Biblia y el crecimiento eclesiástico ......................................................... 42

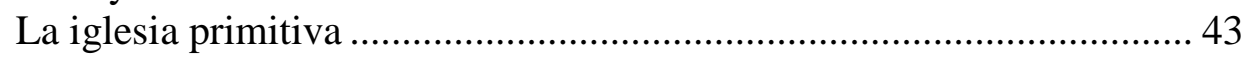

Epístolas paulinas.................................................................................. 44

El don de profecía y el crecimiento de iglesia ................................................ 45

El Espíritu Santo y el crecimiento ………………………..................... 45

Unidad para el crecimiento ……………............................................. 46

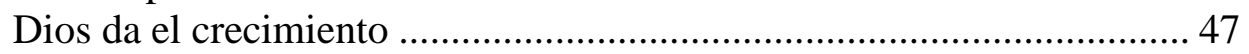

Autores contemporáneos y el crecimiento de iglesia...................................... 48

Factores de crecimiento particulares ........................................................... 52

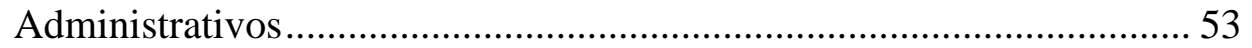

Los apóstoles................................................................................. 53

Los administradores de campo ..................................................... 54

Atribuciones del presidente ………………………………..... 54

Atribuciones del secretario ………………………………........ 55

Atribuciones del tesorero ......................................................... 55 


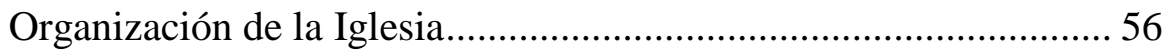

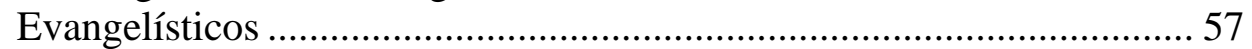

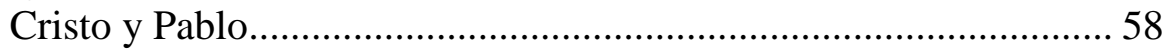

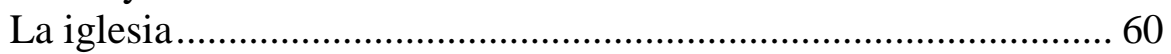

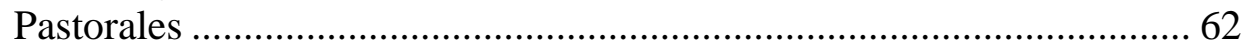

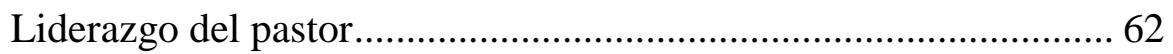

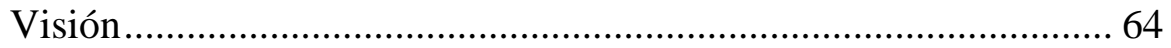

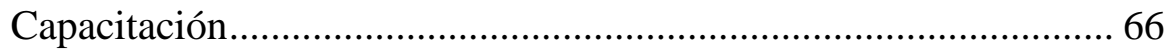

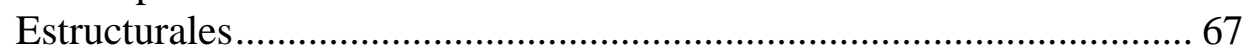

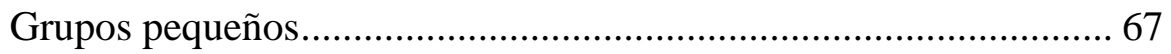

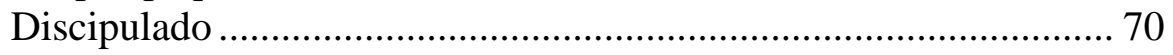

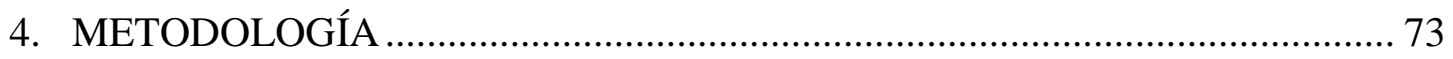

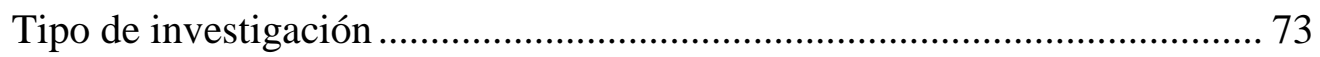

Diseño de la investigación .................................................................. 73

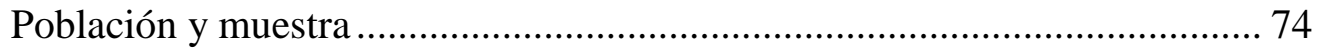

Unidades Intermedias................................................................. 75

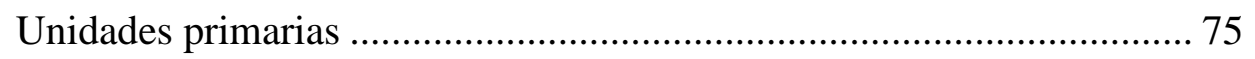

Descripción del instrumento ............................................................ 76

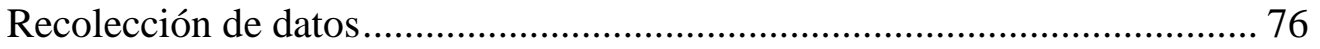

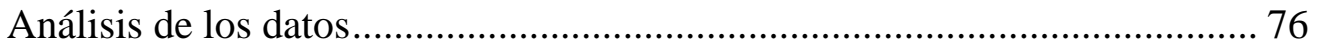

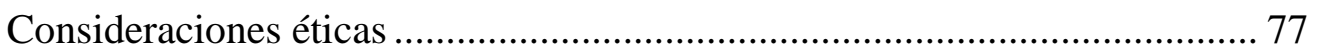

Definición y operacionalización de las variables....................................... 77

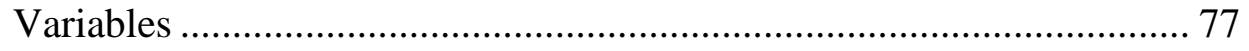

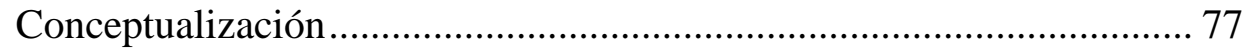

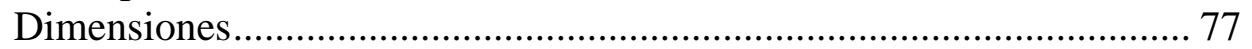

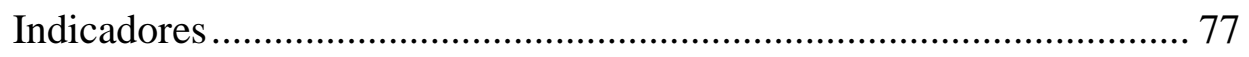

5. ANÁLISIS E INTERPRETACIÓN DE LOS RESULTADOS ............................ 79

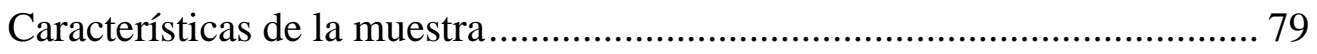

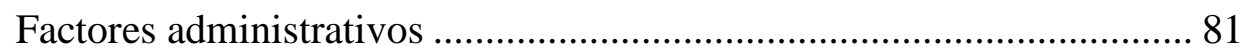

Factores económicos ................................................................ 83

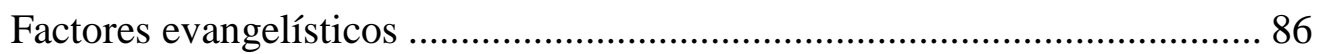

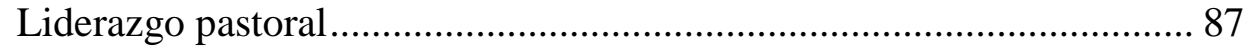

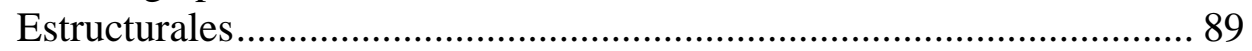

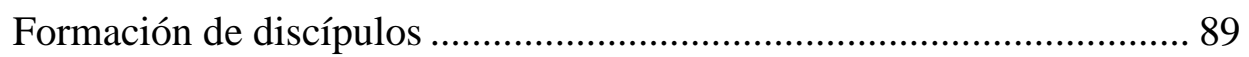

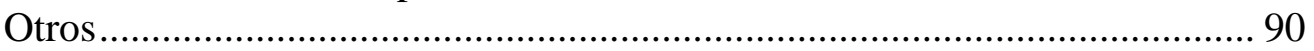

6. RESUMEN, CONCLUSIONES Y RECOMENDACIONES ........................... 95

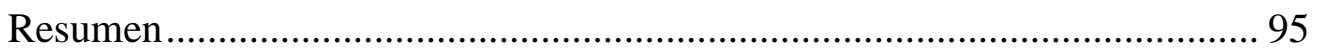

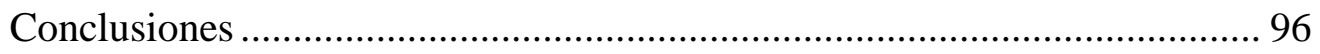

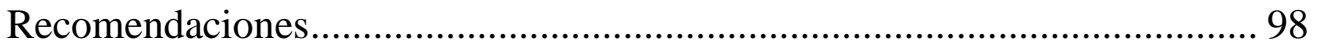


Apéndices

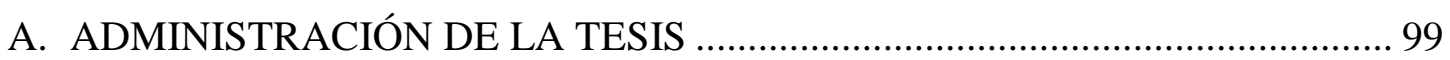

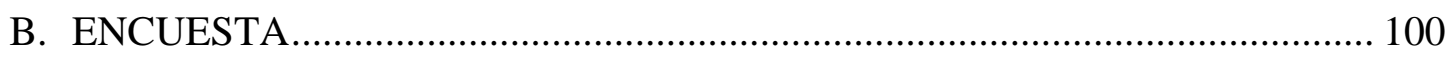

C. PRUEBA DE CONFIABILIDAD ALFA DE CRONBACH ............................ 104

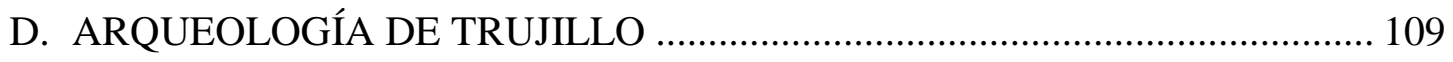

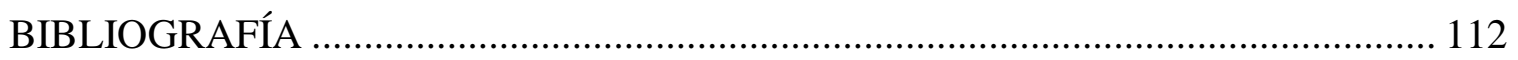




\section{LISTA DE FIGURAS}

1. Mapa de La Libertad - Ubicación de Trujillo .............................................................. 17

2. Plano ciudad de Trujillo centro............................................................................ 19

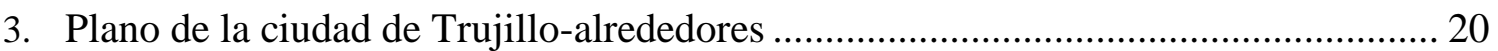

4. Sede de la Misión en Trujillo ¿Facilitó el crecimiento de los distritos misioneros? . 82

5. Acciones administrativas que influyeron más en el crecimiento de los distritos

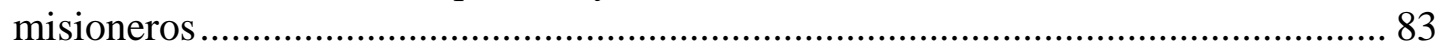

6. Cómo influyeron las condiciones económicas durante el período del 2001-2009 .... 85

7. ¿Considera usted que hubo énfasis evangelístico entre los años 2001-2009?............ 86

8. Campañas evangelísticas que se desarrollaron más durante el período del 2001-2009

9. ¿Del 1 al 5 en qué lugar ubicaría el liderazgo del pastor distrital como uno de los factores claves en el crecimiento de los distritos misioneros de Trujillo durante el período del 2001-2009?

10. ¿Qué característica en el liderazgo espiritual se manifestó mucho durante el período del 2001-2009?

11. ¿Considera usted que el rol que cumplieron los GP durante el período del 2001-2009 fueron fundamentales para el crecimiento de los distritos misioneros en la ciudad de Trujillo?

12. ¿Cree usted que la formación de nuevos discípulos contribuyó para el crecimiento de los distritos misioneros en Trujillo durante el período del 2001-2009?

13. ¿Cree usted que el ambiente social (estabilidad) contribuyó en el crecimiento de la iglesia durante el período del 2001-2009? 


\section{LISTA DE TABLAS}

1. Unión Peruana del Norte, informe mensual de la secretaría 2011, mes: diciembre .... 2

2. Bautismos Unión Peruana del Norte 2001-2009 ................................................... 5

3. Distritos, Iglesias y Miembros de la MNP, actualmente Asociación Nor Pacífico

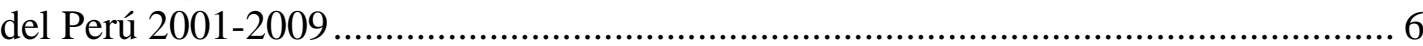

4. Porcentaje Crecimiento de la MNP, actualmente Asociación Nor Pacífico del

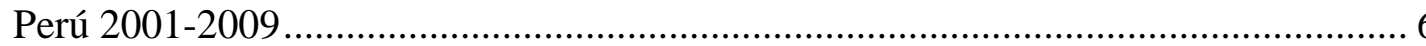

5. Distritos e Iglesias en la ciudad de Trujillo 2001-2009 ......................................... 7

6. Porcentaje de crecimiento de los distritos misioneros en la ciudad de Trujillo 2001-2009

7. Crecimiento en diezmos de la MNP, actualmente Asociación Nor Pacífico del Perú 2003-2009

8. Principales Colegios de la ciudad de Trujillo ............................................................. 24

9. Principales Universidades de la ciudad de Trujillo ............................................. 25

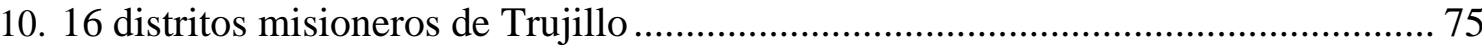

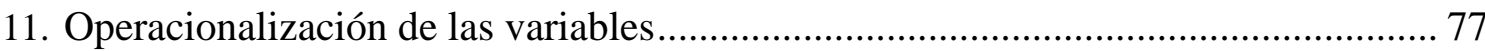

12. Información demográfica de los líderes de las Iglesias de la Ciudad de Trujillo...... 80

13. Muestra según distritos misioneros encuestados en la ciudad de Trujillo 81

14. ¿Cree usted que tener la sede de la Misión en Trujillo facilitó el crecimiento de los distritos misioneros?

15. ¿Cuál de las siguientes acciones administrativas considera usted que influyó más en el crecimiento de los distritos misioneros de Trujillo durante el período del 2001-2009? 105

16. Cómo influyeron las condiciones económicas en el período 2001-2009 106 
17. ¿Considera usted que hubo énfasis evangelístico entre los años 2001-2009?

18. ¿Qué tipo de campañas evangelísticas cree usted que dio mayor resultado en el crecimiento de la iglesia (se desarrolló más) durante el período del 2001-2009? ... 107

19. ¿Del 1 al 5 en qué lugar ubicaría el liderazgo del pastor distrital como uno de los factores claves en el crecimiento de los distritos misioneros de Trujillo durante el período del 2001-2009?

20. ¿Qué característica en el liderazgo espiritual se manifestó mucho durante el período del 2001-2009?

21. ¿Considera usted que el rol que cumplieron los GP durante el período del 2001-2009 fueron fundamentales para el crecimiento de los distritos misioneros en la ciudad de Trujillo?

22. ¿Cree usted que la formación de nuevos discípulos contribuyó para el crecimiento de los distritos misioneros en Trujillo durante el período del 2001-2009? 108

23. ¿Cree usted que el ambiente social (estabilidad) contribuyó en el crecimiento de la iglesia durante el período del 2001-2009? 


\section{LISTA DE ABREVIATURAS}

\begin{tabular}{ll} 
AG & Asociación General \\
ANoP & Asociación Nor Pacífico del Perú \\
APCE & Asociación Peruana Central Este \\
CBA & Comentario bíblico adventista \\
DSA & División Sudamericana \\
FMR & Fondo Manutención de Referencia \\
IASD & Iglesia Adventista del Séptimo Día \\
MICOP & Misión Centro Oeste del Perú \\
MNO & Misión Nor Oriental \\
MNP & Misión Nor Pacífico \\
MPN & Misión Peruana del Norte \\
RH & Review and Herald \\
UPN & Unión Peruana del Norte \\
UPS & Unión Peruana del Sur \\
\hline
\end{tabular}




\section{CAPÍTULO 1 \\ INTRODUCCIÓN}

\section{Trasfondo del problema}

La Iglesia Adventista del Séptimo Día (IASD) es un movimiento religioso a nivel mundial, sigue el mandato evangélico dado por Cristo según Mateo 28:18-20. Todos sus esfuerzos están centrados en el cumplimiento de la gran comisión. En la actualidad, según las estadísticas 2013 publicadas por la Asociación General (AG) de los adventistas del séptimo día, se pueden encontrar algunos datos ${ }^{1}$ que reflejan su crecimiento: Cuenta con 76,364 iglesias, $18.143,745$ miembros, 18,182 pastores ordenados y activos.

Durante el año 2013 ingresaron por medio del bautismo y profesión de fe 1.091,222 personas. De 232 países reconocidos por las Naciones Unidas, la IASD tiene obra establecida en 208. En su estructura organizativa tiene 13 Divisiones, 122 Uniones y 600 Asociaciones/Misiones. ${ }^{2}$

En la División Sudamericana (DSA), una subsede de la AG en Sudamérica, se puede observar los siguientes datos ${ }^{3}$ estadísticos generales 2013 en el cumplimiento de la

\footnotetext{
${ }^{1}$ Seven Day Adventist Church, Annual Statistical Report, 150th Report of the General Conference of Seventh-day Adventists ${ }^{\circledR}$ for 2012 and 2013 (Silver Spring, MD: Old Columbia Pike), 27 http://documents.adventistarchives.org/Statistics/ASR/ASR2014. pdf (consultado: 8 de noviembre, 2015).

${ }^{2}$ Ibíd., 27.

${ }^{3}$ Ibíd., 46.
} 
misión: 11,922 iglesias, 2’263,194 miembros, 2,846 pastores ordenados y activos.

Durante ese año ingresaron por medio del bautismo y profesión de fe 223,378 personas.

Asimismo en la Unión Peruana del Norte (UPN) ${ }^{4}$ de la IASD, en cumplimiento de

la Gran Comisión muestra los siguientes datos ${ }^{5}$ estadísticos en el 2011: 204 distritos

misioneros, 1068 iglesias, 170,044 miembros de iglesia y 23,639 bautismos. La siguiente

tabla contiene parte del informe que la UPN envió a la DSA en diciembre de 2011.

Tabla 1. Unión Peruana del Norte, informe mensual de la secretaría 2011, mes: diciembre $^{6}$

Unión Peruana del Norte

\begin{tabular}{lrrrrrr}
\hline Campos & MICOP & MPN & APCE & MNO & ANoP & Total UPN \\
\hline Bautismos & 61 & 340 & 115 & 391 & 329 & 1236 \\
Profesión de Fe & 42 & 2 & 2 & 34 & 3 & 83 \\
\hline Total & $\mathbf{1 0 3}$ & $\mathbf{3 4 2}$ & $\mathbf{1 1 7}$ & $\mathbf{4 2 5}$ & $\mathbf{3 3 2}$ & $\mathbf{1 3 1 9}$ \\
\hline Distritos & 31 & 39 & 58 & 31 & 45 & 204 \\
Iglesias & 176 & 261 & 122 & 225 & 284 & 1068 \\
$\begin{array}{l}\text { Congregaciones } \\
\begin{array}{l}\text { Nuevas congregaciones } \\
\text { organizadas este mes }\end{array}\end{array}$ & 179 & 478 & 138 & 331 & 558 & 1684 \\
\hline $\begin{array}{l}\text { Miembros al fin de mes } \\
\text { (Diciembre) }\end{array}$ & $\mathbf{2 4 . 6 1 4}$ & $\mathbf{4 1 . 6 5 1}$ & $\mathbf{1 8 . 6 4 6}$ & $\mathbf{3 2 . 1 8 0}$ & $\mathbf{5 2 . 9 5 3}$ & $\mathbf{1 7 0 . 0 4 4}$ \\
\hline
\end{tabular}

Por otro lado, es importante describir algunos antecedentes en la creación de la

ANoP: En el año 1960, el territorio de la Misión Peruana Central, con sede en Lima,

${ }^{4} \mathrm{La}$ UPN atiende la zona norte del Perú, en la actualidad comprende cinco campos: La Asociación Peruana Central Este (APCE) que abarca parte de Lima Norte y Huaraz. La Misión Centro Oeste del Perú (MiCOP) que abarca la provincia Constitucional del Callao, parte de Lima Norte y Chimbote. La Misión Peruana del Norte (MPN) que abarca Tumbes, Piura, Lambayeque y parte de Cajamarca. La Misión Nor Oriental (MNO) que abarca Amazonas y San Martín. Y la Asociación Nor Pacífico del Perú (ANoP) que abarca La Libertad y siete provincias de Cajamarca, como son: Cajamarca, Cajabamba, San Marcos, Celendín, San Pablo, San Miguel y Contumazá.

${ }^{5}$ Datos obtenidos de los archivos de secretaría de la UPN en abril de 2015. ${ }^{6}$ Ibíd. 
abarcaba toda la zona norte y oriente del Perú. Fue en este año cuando la junta de la Unión Incaica ${ }^{7}$ decidió dividir dicho territorio para crear la Misión del Amazonas, con sede en la ciudad de Pucallpa y la Misión Peruana del Norte, con sede en la ciudad de Chiclayo. Estos planes se concretaron el año 1961, cuando la Misión Peruana del Norte inicia oficialmente sus actividades. ${ }^{8}$

Se puede notar que en los siguientes 39 años de trabajo misional en el territorio de la MPN se experimentó un crecimiento significativo en número de feligreses, llegando a ampliar las fronteras geográficas con el establecimiento de nuevos grupos e iglesias. Por ejemplo, en el año 2000, la iglesia contaba con una feligresía de 110,887 personas, distribuidos en 285 iglesias y 737 grupos organizados, atendidos por 45 pastores. $^{9}$

Este desarrollo importante hizo necesario que los dirigentes de la institución, tomaran la decisión de crear un nuevo territorio eclesiástico para atender mejor dicha zona. De este modo, el 23 de noviembre del año 2000 se creó la Misión Nor Pacífico, cuyas instalaciones fueron inauguradas el 18 de marzo del 2001, en la ciudad de Trujillo. Este nuevo territorio se estableció con 25 distritos misioneros, 133 iglesias organizadas, 309 grupos organizados y 50,418 feligreses. ${ }^{10}$

Se puede observar que entre los años 2001 y 2009 la MNP continuó su desarrollo y crecimiento sostenido, tanto que las condiciones le permitieron cambiar su estatus de

${ }^{7}$ En aquella época, la Unión Incaica estaba conformada por tres países: Perú, Bolivia y Ecuador. En la actualidad, en el país se cuenta con dos Uniones: La Unión Peruana del Norte (UPN) y la Unión Peruana del Sur (UPS).

${ }^{8}$ Datos obtenidos de los archivos de secretaría de la ANoP en enero de 2010. ${ }^{9}$ Ibíd.

${ }^{10}$ Ibíd. 
Misión a Asociación. ${ }^{11}$ En ese sentido, el 01 de enero de 2010, con 43 distritos misioneros, 266 iglesias organizadas, 507 grupos organizados y 73,019 feligreses, ${ }^{12}$ se iniciaron las actividades de la flamante Asociación Nor Pacífico de la IASD.

Se observa un crecimiento significativo de la IASD en el territorio de la MNP. Cuando empezó sus actividades en el año 2001, la ciudad de Trujillo tenía 09 distritos misioneros. En la actualidad hay 18 distritos misioneros dentro de la zona urbana (ver tabla 5).

Se puede observar que el territorio eclesiástico de lo que hoy es la ANoP experimentó un crecimiento casi integral. Hubo aumento en número de miembros; por lo tanto, el número de iglesias aumentó y, por ende, también los distritos misioneros; del mismo modo, experimentó un crecimiento económico, reflejo del aumento de los diezmos. Todo esto finalmente repercutió con la creación de la nueva MNP (Misión Nor Pacífico) y su cambio de estatus en ANoP.

La administración entrante y las que siguieron han buscado llegar más a la feligresía, ya que antes desde Chiclayo las visitas eran menos frecuentes. Se han realizado y se siguen realizando, capacitaciones, encuentros, concentraciones,

\footnotetext{
${ }^{11} \mathrm{El}$ estatus de Misión indica que una organización puede recibir apoyo directo (financiero o administrativo) de la organización inmediata superior. Por otro lado, cuando los niveles de organización superiores consideran que una organización con estatus de Misión ha demostrado su capacidad para una mayor responsabilidad y participación en la vida global de la iglesia, se le puede conceder el estatus de Asociación. El estatus de Asociación le da derecho a la organización para identificarse como parte oficial de la Iglesia Adventista del Séptimo Día. Representa también el más alto nivel de autogobierno disponible para una organización. División Sudamericana de la Asociación General de los Adventistas del Séptimo Día, Reglamentos eclesiástico-administrativos (Buenos Aires: Asociación Casa Editora Sudamericana, 2012), 69-70.
}

${ }^{12}$ Datos obtenidos de los archivos de secretaría de la ANoP en enero de 2010. 
evangelismo personal y público. Atención más cercana y labor pastoral permanente.

La Misión Nor Pacífico (MNP) actualmente ANoP, era parte de los cuatro territorios eclesiásticos que conformaban en aquel entonces la UPN.

Las siguientes tablas muestran la realidad de los diferentes territorios eclesiásticos de la UPN y de la ANoP, cuando ésta era una Misión durante el período del 2001-2009:

La tabla permite observar los bautismos desde el inicio de la MNP hasta el 2009. Desde el 2010 se convierte en Asociación.

Los años con el mayor número de bautismos fueron computados del 2003 al 2006. Se mantienen sobre la base de 8000, y el número más elevado de bautismos fue el año 2005 con 8509 bautismos.

Tabla 2. Bautismos Unión Peruana del Norte 2001-2009 $9^{13}$

Unión Peruana del Norte

\begin{tabular}{lrrrrr}
\hline Campos & APCN & MNO & MNP & MPN & Total \\
\hline 2001 & 5352 & & 6795 & 7952 & 20099 \\
2002 & 6351 & & 6749 & 5744 & 18844 \\
2003 & 5783 & 4877 & 8249 & 8301 & 27210 \\
2004 & 6706 & 5539 & 8232 & 7340 & 27817 \\
2005 & 7695 & 6612 & 8509 & 9036 & 31852 \\
2006 & 5943 & 5004 & 8016 & 9064 & 28027 \\
2007 & 5088 & 5054 & 6241 & 8151 & 24534 \\
2008 & 5489 & 5748 & 6974 & 8162 & 26373 \\
2009 & 6018 & 5394 & 6242 & 6852 & 24506 \\
\hline Total & 54425 & 38228 & 66007 & 70602 & 229262 \\
\hline
\end{tabular}

${ }^{13}$ Datos obtenidos de los archivos de secretaría de la UPN en enero de 2010. 
Tabla 3. Distritos, Iglesias y Miembros de la MNP, actualmente Asociación Nor Pacífico del Perú 2001-2009 ${ }^{14}$

\begin{tabular}{lrrrrrrrrr}
\hline ANoP & $\mathbf{2 0 0 1}$ & $\mathbf{2 0 0 2}$ & $\mathbf{2 0 0 3}$ & $\mathbf{2 0 0 4}$ & $\mathbf{2 0 0 5}$ & $\mathbf{2 0 0 6}$ & $\mathbf{2 0 0 7}$ & $\mathbf{2 0 0 8}$ & $\mathbf{2 0 0 9}$ \\
\hline $\begin{array}{l}\text { Distritos } \\
\text { Iglesias y }\end{array}$ & 25 & 26 & 28 & 31 & 32 & 33 & 35 & 40 & 42 \\
Grupos & 563 & 596 & 620 & 674 & 680 & 736 & 745 & 766 & 773 \\
\hline Miembros & 57339 & 62164 & 68679 & 75225 & 80869 & 86582 & 82206 & 76650 & 73019 \\
\hline
\end{tabular}

Entre el 2001 y 2009 se incrementaron 17 distritos, equivale a un 68\% de aumento. Desde el 2007 hubo una disminución de miembros, de 82206 a 73019, debido al inicio del proceso de actualización de feligresía en todo el territorio.

Para el porcentaje de crecimiento según la tabla 4, se puede añadir que en el año 2,000 (cuando la MNP todavía formaba parte de la MPN), contaba con 23 distritos misioneros, 442 iglesias y grupos, y tenía 53,321 miembros.

Tabla 4. Porcentaje Crecimiento de la MNP, actualmente Asociación Nor Pacífico del Perú 2001-2009 $9^{15}$

\begin{tabular}{cccccccccc}
\hline ANoP & $\begin{array}{c}\mathbf{2 0 0 1} \\
\mathbf{\%}\end{array}$ & $\begin{array}{c}\mathbf{2 0 0 2} \\
\mathbf{\%}\end{array}$ & $\begin{array}{c}\mathbf{2 0 0 3} \\
\mathbf{\%}\end{array}$ & $\begin{array}{c}\mathbf{2 0 0 4} \\
\mathbf{\%}\end{array}$ & $\begin{array}{c}\mathbf{2 0 0 5} \\
\mathbf{\%}\end{array}$ & $\begin{array}{c}\mathbf{2 0 0 6} \\
\mathbf{\%}\end{array}$ & $\begin{array}{c}\mathbf{2 0 0 7} \\
\mathbf{\%}\end{array}$ & $\begin{array}{c}\mathbf{2 0 0 8} \\
\mathbf{\%}\end{array}$ & $\begin{array}{c}\mathbf{2 0 0 9} \\
\mathbf{\%}\end{array}$ \\
\hline $\begin{array}{c}\text { Distritos } \\
\text { Iglesias y }\end{array}$ & 8,69 & 4,00 & 7,69 & 10,71 & 3,23 & 3,13 & 6,06 & 14,28 & 5,00 \\
Grupos & 27,37 & 2,10 & 9,59 & 27,50 & 10,29 & 7,11 & 2,49 & 3,64 & 3,91 \\
\hline Miembros & 7,53 & 8,41 & 10,48 & 9,53 & 7,50 & 7,06 & $-5,05$ & $-6,76$ & $-4,74$ \\
\hline
\end{tabular}

En esta tabla se puede observar el crecimiento neto porcentual por año (entre el 2001 al 2009) de los distritos e iglesias, que se deriva del dato estadístico anterior. Como ya se ha mencionado, los miembros de iglesia decrecen durante los últimos tres años debido al proceso de actualización de feligresía.

\footnotetext{
${ }^{14}$ Datos obtenidos de los archivos de secretaría de la ANoP en enero de 2010. ${ }^{15}$ Ibíd.
} 
Tabla 5. Distritos e Iglesias en la ciudad de Trujillo 2001-2009 ${ }^{16}$

\begin{tabular}{lrrrrrrrrr}
\hline Trujillo & $\mathbf{2 0 0 1}$ & $\mathbf{2 0 0 2}$ & $\mathbf{2 0 0 3}$ & $\mathbf{2 0 0 4}$ & $\mathbf{2 0 0 5}$ & $\mathbf{2 0 0 6}$ & $\mathbf{2 0 0 7}$ & $\mathbf{2 0 0 8}$ & $\mathbf{2 0 0 9}$ \\
\hline Distritos & 9 & 10 & 10 & 11 & 14 & 15 & 16 & 17 & 18 \\
\hline Iglesias & 42 & 44 & 51 & 68 & 77 & 84 & 86 & 88 & 93 \\
\hline
\end{tabular}

Al iniciar la MNP, la ciudad de Trujillo tenía 9 distritos misioneros, al llegar al año 2009 ya tenía 18 distritos misioneros; es decir, experimentó un crecimiento del 100\% Tabla 6. Porcentaje de crecimiento de los distritos misioneros en la ciudad de Trujillo 2001-2009 ${ }^{17}$

\begin{tabular}{|c|c|c|c|c|c|c|c|c|c|c|}
\hline Trujillo & 2001 & $\begin{array}{r}2002 \\
\%\end{array}$ & $\begin{array}{r}2003 \\
\%\end{array}$ & $\begin{array}{r}2004 \\
\%\end{array}$ & $\begin{array}{r}2005 \\
\% \\
\end{array}$ & $\begin{array}{r}2006 \\
\% \\
\end{array}$ & $\begin{array}{r}2007 \\
\%\end{array}$ & $\begin{array}{r}2008 \\
\% \\
\end{array}$ & $\begin{array}{r}2009 \\
\%\end{array}$ & $\begin{array}{r}2001- \\
2009 \%\end{array}$ \\
\hline Distritos & - & 11,11 & - & 10,00 & 27,27 & 7,14 & 6,66 & 6,25 & 5,88 & 100 \\
\hline Iglesias & & 4.76 & 15.91 & 33.33 & 13.24 & 9.09 & 2.38 & 2.33 & 5.68 & 121,42 \\
\hline
\end{tabular}

Como se puede observar, los distritos misioneros de la ciudad de Trujillo se duplicaron al llegar al año 2009.

Tabla 7. Crecimiento en diezmos de la MNP, actualmente Asociación Nor Pacífico del Perú 2003-2009 ${ }^{18}$

\begin{tabular}{lrrr}
\hline ANoP & Diezmos & FMR & \% de crecimiento \\
\hline 2003 & $2,992,666.74$ & 1327.71 & \\
2004 & $3,542,885.03$ & 1571.82 & 18.40 \\
2005 & $3,890,593.06$ & 1726.08 & 9.82 \\
2006 & $4,275,184.75$ & 1896.71 & 9.87 \\
2007 & $4,922,866.61$ & 2184.06 & 15.16 \\
2008 & $5,846,187.56$ & 2593.69 & 18.75 \\
2009 & $6,666,755.61$ & 2957.74 & 14.04 \\
\hline
\end{tabular}

\footnotetext{
${ }^{16}$ Datos obtenidos de los archivos de secretaría de la ANoP en enero de 2010.

${ }^{17}$ Ibíd.

${ }^{18}$ Ibíd.
} 
No existen datos del año 2001 y 2002 en el sistema de tesorería, sólo se tiene desde el año 2003. Se puede observar que hubo cada año un crecimiento neto del diezmo. Del 2003 al 2009, el diezmo creció el 122.77\%.

El 100\% de la escala móvil, llamado Factor Manutención de Referencia (FMR), sirve de factor de referencia para fijar los porcentajes del FMR asignados a cada una de las funciones. ${ }^{19}$

Al comenzar la revisión bibliográfica se puede mencionar que hay por lo menos tres tesis que analizan algo parecido. Son trabajos de campo que han contribuido al desarrollo de la iglesia.

Uno de ellos es la tesis del Dr. Francisco Quinteros, titulada Nivel de impacto de los Grupos Pequeños en el crecimiento de la Iglesia Adventista de Lima metropolitana: un estudio cuantitativo comparativo entre los períodos 1991-1995 y 2001-2005. El autor ha analizado seis indicadores del crecimiento eclesiástico: cantidad de bautismos, incremento de los diezmos y ofrendas, surgimiento de nuevos líderes en las iglesias locales, surgimiento de instructores bíblicos, organización de nuevas iglesias y congregaciones y organización de nuevos distritos pastorales. Es un trabajo descriptivo correlacional, con diseño no experimental.

Se ha revisado la tesis del Dr. Bruno Raso, titulada "Un estudio de factores personales, eclesiásticos, pastorales y comunitarios que inciden sobre la misión de hacer discípulos”. El autor analiza el impacto de los factores que intervienen en la misión de cada miembro de iglesia para hacer discípulos y coloca sus estudios al servicio de la iglesia como una contribución al desafío de terminar la obra evangelizadora. Es un

${ }^{19}$ División Sudamericana, Reglamentos eclesiástico-administrativos, 528. 
trabajo descriptivo, del tipo ex post facto.

También se ha estudiado la investigación del Dr. Miguel Salomón, titulada “Estudio histórico de los factores que incidieron en el desarrollo de la Iglesia Adventista del Séptimo Día en Bolivia (1907-1977). Educación-obra médica-publicacionesevangelización-finanzas". Es un trabajo que tiene como fin brindar un conocimiento histórico de la IASD a través de sus actividades desarrolladas y, de ese modo, entender las estrategias que fueron empleadas para alcanzar su misión. Es también un material de consulta sobre la historia denominacional adventista de Bolivia y provee información bibliográfica. Asimismo, es un trabajo de carácter histórico-documental y descriptivo.

El presente trabajo también pretende ser un material de consulta para la IASD en el país. Contar con un estudio histórico de los factores que contribuyeron al crecimiento de la iglesia en la ciudad de Trujillo, puede ayudar a otras zonas a cumplir la misión.

\section{Planteamiento del problema}

Vistos los antecedentes arriba mencionados, se plantea la siguiente pregunta de investigación: ¿En qué medida los factores administrativos, evangelísticos, pastorales y estructurales influyeron en el crecimiento de los distritos misioneros de Trujillo durante el período del 2001-2009?

\section{Objetivos de la investigación}

Objetivo general

Determinar en qué medida los factores administrativos, evangelísticos, pastorales y estructurales influyeron en el crecimiento de la IASD en la ciudad de Trujillo durante el periodo del 2001 al 2009. 


\section{Objetivos específicos}

Identificar los factores administrativos que incidieron en el crecimiento de la IASD en la ciudad de Trujillo durante el periodo del 2001 al 2009.

Identificar los factores evangelísticos que influyeron en el crecimiento de la IASD en la ciudad de Trujillo durante el periodo del 2001 al 2009.

Identificar los factores pastorales que influyeron en el crecimiento de la IASD en la ciudad de Trujillo durante el periodo del 2001 al 2009.

Identificar los factores estructurales que influyeron en el crecimiento de la IASD en la ciudad de Trujillo durante el periodo del 2001 al 2009.

Relacionar todos estos factores con el crecimiento de la IASD en la ciudad de Trujillo durante el periodo del 2001 al 2009.

\section{Hipótesis de la investigación}

H1: Los factores administrativos, evangelísticos, pastorales y estructurales, influyeron significativamente en el crecimiento de la IASD en la ciudad de Trujillo, durante el período del 2001-2009.

\section{Hipótesis nula}

H0: Los factores administrativos, evangelísticos, pastorales y estructurales, no influyeron significativamente en el crecimiento de la IASD en la ciudad de Trujillo, durante el período del 2001-2009.

\section{Justificación de la investigación}

Los años 2001 - 2009 fueron muy importantes para la historia de la iglesia en Trujillo, para la ANoP, la UPN y por consiguiente para toda la Iglesia Adventista del 
Perú. En nueve años, el territorio que nació de la MPN ha tenido un desarrollo notable, lo que amerita realizar un estudio serio y prospectivo del fenómeno de crecimiento y desarrollo.

El presente estudio proporcionará información muy útil para la administración, los líderes de la iglesia y los feligreses en general, conducente a mejorar la calidad del crecimiento de la iglesia. Este trabajo contribuirá asimismo en el mejoramiento de la disciplina de crecimiento de iglesia y se constituirá en un material de consulta y referencia para futuras investigaciones. Este trabajo pretende ser un aporte para contribuir en las tareas de planificación, desarrollo del crecimiento eclesiástico en las grandes ciudades.

\section{Delimitaciones de la investigación}

Esta investigación estudió los factores que contribuyeron al aumento de los distritos misioneros de la IASD en la ciudad de Trujillo, departamento de La Libertad, Perú. Se circunscribirá al análisis de cuatro variables; es decir, administrativos, evangelísticos, pastorales y estructurales entre los años 2001y 2009. Este período va desde el inicio de la MNP y el año previo al cambio de estatus de Misión a Asociación.

\section{Definición de términos}

A continuación, se presentan algunos términos eclesiásticos que son necesarios definir con fines de una mejor lectura y comprensión de la tesis que se desarrolla.

\section{Distrito misionero}

Es el conjunto de iglesias y grupos organizados en una determinada zona, que atiende un pastor. Puede abarcar todo un distrito político o parte del mismo. 


\section{Iglesia local}

Es un cuerpo organizado y unido de creyentes individuales. ${ }^{20}$

\section{Asociación/Misión/Campo}

Es un cuerpo organizado y unido de iglesias en el territorio de un estado, una provincia o una región. ${ }^{21}$

\section{Unión}

Es un cuerpo unido de asociaciones, misiones o campos dentro de un territorio mayor. $^{22}$

\section{Asociación General}

Es la unidad mayor de la organización y abarca todas las uniones, en todas partes del mundo. La Asociación se manifiesta en el mundo a través de organismos denominadas divisiones, que son secciones de la Asociación General, con responsabilidad administrativa para una determinada zona geográfica. ${ }^{23}$

\section{Presuposiciones}

El autor acepta la autoridad de la Biblia, en la cual se encuentran claramente los principios y enseñanzas de crecimiento de iglesia en el cumplimiento de la misión, de manera especial en el Nuevo Testamento y los estudios de eruditos en la materia de

${ }^{20}$ Asociación General de la Iglesia Adventista del $7^{\circ}$ Día, Manual de la Iglesia (Buenos Aires: Asociación Casa Editora Sudamericana, 2000), 24.

${ }^{21}$ Asociación General, Manual de la Iglesia, 24

${ }^{22}$ Ibíd.

${ }^{23}$ Ibíd. 
iglecrecimiento que mencionan métodos y estrategias que están basados en esos principios.

Asimismo, el investigador tiene presente que el conductor de la historia de la Iglesia es Dios. En la actualidad, ese mismo Dios está en la completa dirección de su pueblo.

\section{Organización del trabajo}

El trabajo está estructurado de la siguiente manera. En la introducción se da un breve marco de referencia, que permite conocer el panorama general y específico de la IASD durante el período del 2001 al 2009, en la ciudad de Trujillo. Luego se presenta los antecedentes de la investigación y enseguida se plantea el problema de investigación, los objetivos de la investigación, la hipótesis, la hipótesis nula, la justificación, las delimitaciones de la investigación, la definición de términos, las limitaciones del estudio y las presuposiciones del trabajo.

El capítulo 2 describe el marco referencial de la investigación. Su centro es la ciudad de Trujillo, y se hace una breve referencia a su historia, cultura, realidad socioeconómica y religión. Asimismo, se presentan los datos referenciales de la Iglesia Adventista del Séptimo Día: los comienzos, el despertar evangelístico, el establecimiento administrativo y su realidad actual.

En el capítulo 3 se desarrollan los fundamentos teóricos. Se presenta lo que la Biblia enseña acerca del crecimiento eclesiástico. En segundo lugar, se habla del don de profecía y el crecimiento de la iglesia. En tercer lugar, lo que mencionan algunos autores

contemporáneos del tema. Finalmente, se describe los factores particulares considerados para el crecimiento en la zona de Trujillo. 
El capítulo 4 tiene relación con la metodología de la investigación: tipo de investigación, diseño, población y muestra, descripción del instrumento, recolección de datos, análisis de datos, consideraciones éticas y definición y operacionalización de las variables.

En el capítulo 5, se desarrolla los resultados de la investigación, después de haber aplicado el instrumento. Se analiza las características de la muestra, la relación entre las variables y la prueba de la hipótesis.

Finalmente, en el capítulo 6 se realiza un resumen de todo el trabajo, las respectivas conclusiones y las recomendaciones pertinentes. 


\section{CAPÍTULO 2}

\section{MARCO REFERENCIAL}

En este capítulo, se presenta en primer lugar datos referenciales de la ciudad de Trujillo: su ubicación y geografía, su historia y cultura, y otros aspectos importantes de la zona. En segundo lugar, se proporciona una breve reseña histórica de la Iglesia Adventista del Séptimo Día en el Perú.

\section{Datos referenciales de la ciudad de Trujillo}

A continuación, se encuentran algunos datos que brindan un vistazo general de una de las ciudades importantes del Perú, Trujillo.

\section{Trujillo}

Trujillo es una provincia de la costa norte del Perú, situada en la parte central y occidental del departamento de La Libertad, bajo la administración del Gobierno regional de La Libertad. Limita al norte con la provincia de Ascope, al este con la Provincia de Otuzco, al sur-este con la provincia de Julcán, al sur con la provincia de Virú y al oeste con el océano Pacífico. ${ }^{1}$

Desde una perspectiva histórica, Trujillo ha sido desde sus inicios una de las grandes ciudades del Perú. Si bien obtuvo su riqueza y esplendor coloniales gracias a la

${ }^{1}$ Gobierno Regional de La Libertad, "Plan estratégico regional de turismo de La Libertad 2011- 2021", http://www.regionlalibertad.gob.pe/sir/admin/docs/PERTU20 VERSIOVALIDAD.pdf (consultado: 1 de setiembre, 2014). 
explotación agrícola, fue también esta misma actividad la causante de un prolongado estancamiento y reducción. ${ }^{2}$

Sin embargo, durante los últimos años se ha ido afianzando un impulso renovador que está transformando a la ciudad de las casonas tradicionales en una metrópoli moderna e industrial, que conjuga las modernas líneas urbanas con los historiados muros del pasado. Diversos historiadores coinciden en señalar a don Diego de Almagro el fundador de esta ciudad. Se dice que, recorriendo los valles de la costa, al llegar al del río Moche, comprendió que sería ventajoso instalar allí una ciudad que sirviera de enlace entre Lima y San Miguel de Piura, y la estableció el 6 de diciembre de 1534 (en terrenos donados por el cacique Chimor) con el nombre de Trujillo, en honor de la tierra nativa de su socio, el gobernador Francisco Pizarro. Éste completó con posterioridad los detalles pendientes de la ceremonia de fundación e hizo oficial el nombre de la nueva población: “Ciudad de Trujillo de Nueva Castilla".3

Desde su fundación residieron en Trujillo muchos y notables conquistadores, entre ellos, el Capitán Diego de Mora, quien fue el primer Gobernador de la ciudad; don Juan Roldán y otros, troncos de ilustres familias trujillanas. ${ }^{4}$ Dada la nobleza y calidad de sus vecinos, el emperador Carlos V le otorgó el título de "Nobilísima Ciudad de Trujillo", por real cédula del 7 de diciembre de $1537 .^{5}$

${ }^{2}$ Gran Enciclopedia del Perú (Barcelona: Lexus Editores, 1998), 555.

${ }^{3}$ Ibíd., 555-56.

${ }^{4}$ Documental del Perú, Enciclopedia nacional básica (Barcelona: Cronion S.A. 1988), 13:11.

${ }^{5}$ Gran Enciclopedia del Perú (Barcelona: Lexus Editores, 1998), 556. 


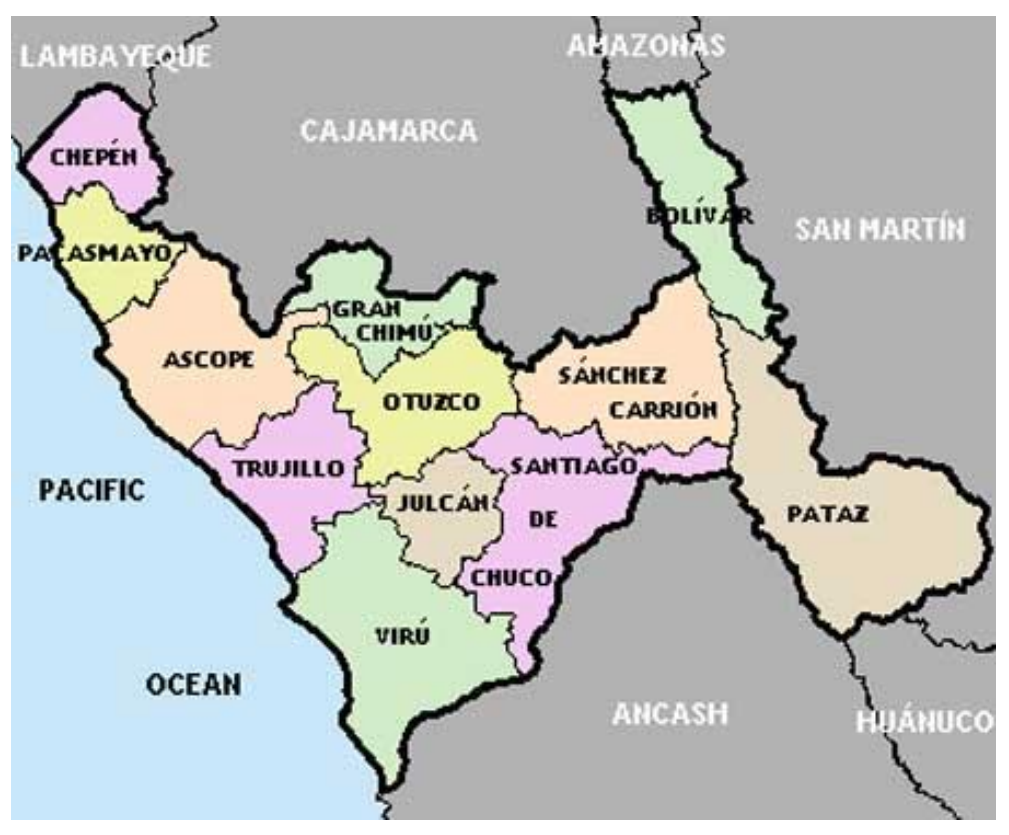

Figura 1. Mapa de La Libertad - Ubicación de Trujillo ${ }^{6}$

Trujillo funciona como centro comercial de la región La Libertad, donde se cultiva caña de azúcar y arroz. Es, además, un centro de distribución de mercancías y cuenta con establecimientos de los sectores textil y alimentario. ${ }^{7}$

\section{Geografía y clima de Trujillo}

La Región La Libertad presenta un relieve que va desde el litoral, pasa por la sierra (Andes) de Otuzco, Julcán y Santiago de Chuco, hasta la selva alta (Amazonía) en el límite con el Departamento de San Martín. La costa cuenta con playas y fecundos valles importantes para la producción agrícola nacional. La ciudad de Trujillo se identifica por su clima árido y semicálido, con una temperatura media máxima de $22,7^{\circ} \mathrm{C}$

6“Mapa de La Libertad", http://es.perutravelling.com/la-libertad-mapa (consultado: 17 de junio, 2013).

7“"Ciudad de la eterna primavera”, http://trujilloperu.com/region-la-libertad/lalibertad.html (consultado: 17 de junio, 2013). 
$\left(72,9^{\circ} \mathrm{F}\right)$ y una mínima de $15,8^{\circ} \mathrm{C}\left(60,4^{\circ} \mathrm{F}\right)$ con ausencia de lluvias durante todo el año.

No obstante, cuando se presenta el fenómeno de El Niño, el clima varía, aumenta el nivel de precipitaciones y la temperatura se puede elevar. ${ }^{8}$

\section{Altitud y superficie}

La provincia de Trujillo se encuentra a una altitud de 34 metros sobre el nivel del mar, y cuenta con una superficie de 1768,65 kilómetros cuadrados. ${ }^{9}$

\section{Organización Administrativa ${ }^{10}$}

La provincia de Trujillo está dividida en once distritos:

1. Trujillo

2. El Porvenir

3. Florencia de Mora

4. Huanchaco

5. La Esperanza

6. Laredo

7. Moche

8. Poroto

9. Salaverry

8“"Región la Libertad", http://trujilloperu.com/region-la-libertad/la-libertad.html. (Consultado el 17 de junio de 2013).

${ }^{9}$ Gobierno Regional de La Libertad, "Plan estratégico regional de turismo de La Libertad 2011 - 2021", http://www.regionlalibertad.gob.pe/sir/admin/docs/PERTU2 OVERSIOVALIDAD.pdf (consultado: 1 de septiembre, 2014).

${ }^{10}$ Ibíd. 
10. Simbal

11. Víctor Larco Herrera

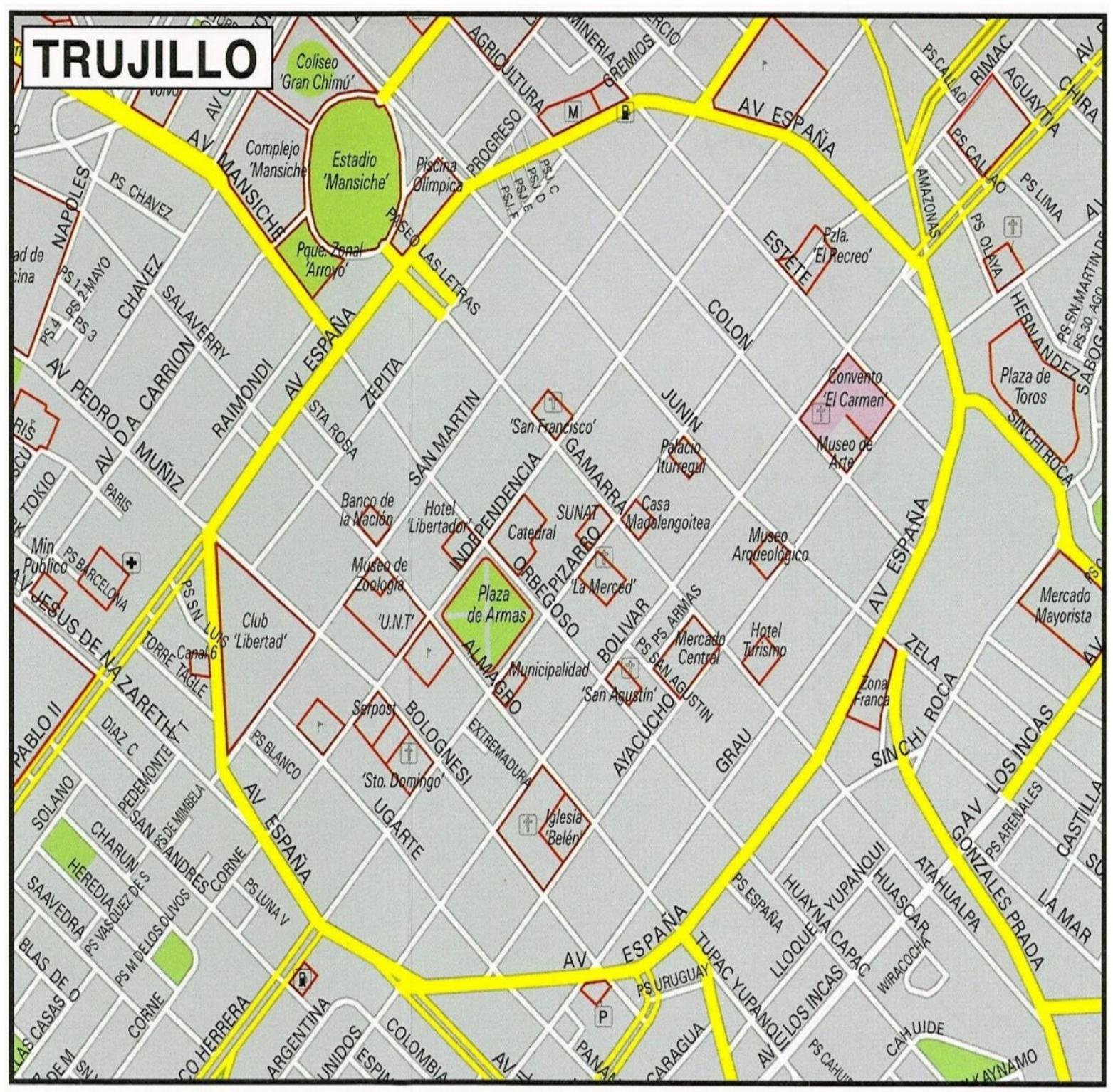

Figura 2. Plano ciudad de Trujillo centro ${ }^{11}$

11“Muralla de Trujillo", http://es.wikipedia.org/wiki/muralla_de_Trujillo. (consultado: 06 de julio, 2014). 


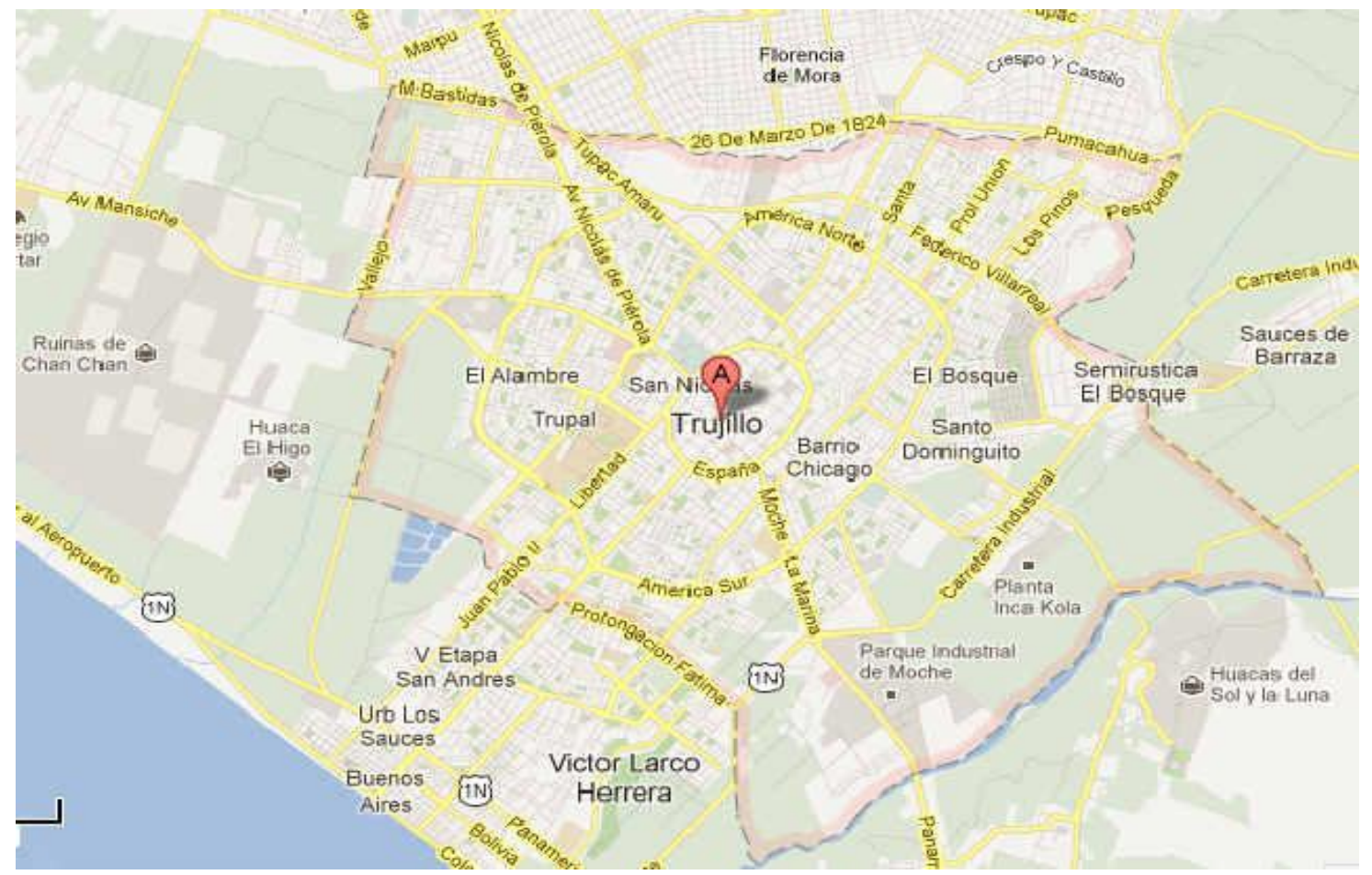

Figura 3. Plano de la ciudad de Trujillo-alrededores ${ }^{12}$

\section{Población}

Según los resultados del censo de población y vivienda del año 2007, la población de la provincia de Trujillo era de 811.979 habitantes, constituyéndose en la cuarta provincia más poblada de Perú.

Considerando esta cifra, la provincia de Trujillo, al año 2007, albergaba porcentualmente el 50,21\% de la población del Departamento de La Libertad y el 2,9\% de la población nacional de Perú. ${ }^{13}$

12“Mapa de Trujillo", http://www.para-viajar.com/mapas/mapa-de-trujilloperu.htm (consultado: 27 de mayo, 2014).

${ }^{13}$ Gobierno Regional de La Libertad, "Plan Estratégico Regional de Turismo de La Libertad 2011- 2021”, http://www.regionlalibertad.gob.pe/sir/admin/docs/PERTU2 OVERSIOVALIDAD.pdf (consultado: 1 de septiembre, 2014). 
Estructura de edades

La población de Trujillo se puede considerar “joven” (22 años como edad promedio). Su composición por edades se caracteriza por un mayor volumen poblacional de niños y jóvenes: los menores entre 0 y 9 años agrupan el $22 \%$ en tanto que los jóvenes, de 10 a 25 años alcanzan el 34\% (56\% entre ambos grupos), representando un gran reto para la sociedad en su conjunto, por las necesidades de atención en educación, salud, recreación y futuros puestos de trabajo. ${ }^{14}$

\section{Religión}

La religión predominante, en los distritos que componen la ciudad, es el catolicismo, de acuerdo con los datos del censo realizado el año 2007. En la ciudad, el 76,9 \% de la población mayor de 12 años es católica, el 15,1 \% es evangélica, el 3,9 \% profesa otras religiones y el 4,1\% no se vincula a ninguna religión de un universo de 541056 personas. ${ }^{15}$

\section{Costumbres}

En la ciudad de Trujillo una de las tradiciones más antiguas, representativas y de gran impacto es el cuidado y la crianza de caballos de paso. Este caballo es considerado el mejor caballo de silla del mundo, por ser el de andar más suave. En la localidad de Buenos Aires Norte en el distrito de Víctor Larco se ubica el local de la Asociación de Propietarios y Criadores de caballos de paso de La Libertad. En la ciudad existe el

\footnotetext{
${ }^{14}$ Municipalidad Provincial de Trujillo, Atlas ambiental de la ciudad de Trujillo
} (Trujillo: Municipalidad Provincial de Trujillo, 2002), 61.

${ }^{15}$ Gobierno Regional de La Libertad, "Plan estratégico regional de turismo de La Libertad 2011 - 2021", http://www.regionlalibertad.gob.pe/sir/admin/docs/PERTU 20VERSIOVALIDAD.pdf (consultado: 1 de setiembre, 2014). 
monumento denominado "El Mural de caballos de paso", el cual se encuentra ubicado en Víctor Larco y rinde homenaje a los tradicionales jinetes trujillanos y de la región denominada chalana. El caballo de paso peruano es considerado oriundo del norte del Perú y ha sido declarado Patrimonio Cultural de la Nación por el Instituto Nacional de Cultura (INC) del gobierno peruano. ${ }^{16}$

Asimismo, en las afueras de la ciudad, en el distrito de Huanchaco, se aprecian a los caballitos de totoras, estas embarcaciones de origen preinca de proa levantada, hechas de totora prensada, miden de tres a cuatro metros de largo y en ellas los pescadores huanchaqueros continúan haciéndose a la mar, poniendo en práctica técnicas ancestrales de pesca.

\section{Economía}

Está orientada principalmente a la producción de alimentos, muebles y enseres, textiles, productos metálicos y materiales de construcción. Un rubro floreciente es el calzado. La extracción de recursos pesqueros se realiza a través de los puertos de Chicama y Salaverry. ${ }^{17}$

La caña de azúcar es el cultivo predominante en la agricultura de Trujillo, ubicada en Laredo. Asimismo, un rubro importante de exportación está constituido por el espárrago y el tomate. El Perú exporta pasta de tomate a Japón, Costa Rica, Venezuela, Colombia y Ecuador, en base a la producción procesada por el complejo agroindustrial de

${ }^{16}$ Gobierno Regional de La Libertad, "Plan estratégico regional de turismo de La Libertad 2011 - 2021", http://www.regionlalibertad.gob.pe/sir/admin/docs/PERTU 20VERSIOVALIDAD.pdf (consultado: 1 de septiembre, 2014).

${ }^{17}$ Gran Enciclopedia del Perú (Barcelona: Lexus Editores, 1998), 586. 
Chao, construido y equipado en 1990 en el marco del proyecto Chavimochic. ${ }^{18}$

\section{Servicios públicos y aprovisionamiento ${ }^{19}$}

Infraestructura energética

La distribución de la energía eléctrica en la ciudad está a cargo de Hidrandina. La tasa de electrificación alcanza el orden del 91\% siendo el distrito de Trujillo el de mayor cobertura y el de El Porvenir el de menor con 82\%. El 2010 en la ciudad se consumió un total de 428159 MWh de energía eléctrica, correspondiendo a los distritos de Trujillo y La Esperanza las tasas más altas de consumo.

Agua potable

La principal fuente de abastecimiento proviene de la planta de tratamiento de Salaverry, la planta tiene una capacidad de producción de 1,25 m³/s. La empresa encargada de la distribución de agua potable es SEDALIB S.A. la que adquiere el agua del proyecto especial CHAVIMOCHIC y a la vez explota 33 pozos tubulares del acuífero del valle de Santa Catalina.

La producción per cápita de agua es de 210 litros por persona, y una demanda anual de $899 \mathrm{mil} \mathrm{m}^{3}$ /año. La cobertura del servicio del agua potable en la ciudad es de $91,74 \%$.

Educación $^{20}$

La ciudad de Trujillo muestra una tasa de analfabetismo reducida de 5,7\% en

${ }^{18}$ Gran Enciclopedia del Perú (Barcelona: Lexus Editores, 1998), 587.

${ }^{19}$ Instituto Nacional de Estadística e Informática, Compendio Estadístico del Perú, julio 2012.

${ }^{20}$ Gobierno Regional de La Libertad, Gerencia Regional de Educación La Libertad, Alcanzando las metas educativas 2010, enero 2012. 
comparación con la de la región $(13,0 \%)$ y otras ciudades del país.

\section{Educación primaria y secundaria}

En la ciudad existen más de 833 centros educativos, el $83 \%$ de planteles se concentra en el continuo urbano, correspondiendo el 50\% al distrito de Trujillo. La concentración de establecimientos educativos en el distrito de Trujillo corresponde principalmente a los del nivel secundario (53\%) donde se produce una mayor presencia del sector privado. La ampliación de la infraestructura educativa estatal y creciente participación del sector privado en la educación, ha permitido el progreso de la cobertura educativa en la ciudad.

Tabla 8. Principales Colegios de la ciudad de Trujillo

\begin{tabular}{|c|c|c|}
\hline Colegio & Fundada & Ubicación \\
\hline Colegio Nacional de San Juan & 23 Junio 1854 & \\
\hline $\begin{array}{l}\text { Escuela de Artes y Oficios } \\
\text { "Marcial Acharán y Smith" }\end{array}$ & \multirow[t]{2}{*}{12 Enero 1913} & $\begin{array}{l}\text { Centro histórico de Trujillo, en } \\
\text { el Jr. Colón } N^{\circ} 467 \text {. }\end{array}$ \\
\hline $\begin{array}{l}\text { Colegio Centro de Educación y } \\
\text { Capacitación Técnica (CECAT) } \\
\text { Politécnico Marcial Acharán }\end{array}$ & & \multirow[t]{4}{*}{ Centro de Trujillo. } \\
\hline $\begin{array}{l}\text { Colegio Seminario de San } \\
\text { Carlos y San Marcelo }\end{array}$ & $\begin{array}{l}\text { Tiene más de } 386 \\
\text { años de presencia } \\
\text { formativa en la } \\
\text { región }\end{array}$ & \\
\hline $\begin{array}{l}\text { Colegio Pedro Mercedes Ureña } \\
\text { (Centro Viejo) }\end{array}$ & Fundado en 1878. & \\
\hline $\begin{array}{l}\text { Gran Unidad Escolar José } \\
\text { Faustino Sánchez Carrión }\end{array}$ & & \\
\hline Colegio Santa Rosa & & Centro histórico de Trujillo. \\
\hline $\begin{array}{l}\text { Colegio Rafael Narváez } \\
\text { Cadenillas }\end{array}$ & \multirow[t]{2}{*}{$\begin{array}{l}\text { Fue fundado en } \\
1992\end{array}$} & $\begin{array}{l}\text { Su local se ubica en los } \\
\text { espacios de la Universidad } \\
\text { Nacional de Trujillo. }\end{array}$ \\
\hline Colegio Modelo & & $\begin{array}{l}\text { Esquina de la avenida España } \\
\text { con la avenida El Ejército } \\
\text { frente a la Plaza Bolognesi. }\end{array}$ \\
\hline
\end{tabular}




\section{Educación superior}

Existe un considerable número de universidades, entre la pública, la Universidad Nacional de Trujillo (UNT) y privadas. Y un conjunto de institutos superiores y centros ocupacionales, que sirven a un sector importante del norte peruano para la formación de recursos humanos profesionales y la provisión de los cuadros técnicos para el servicio regional y nacional. En 1998, la población universitaria alcanzó un total de 26,805 alumnos, incrementando en la última década en casi un 100\%. En Trujillo, muchos de los estudiantes universitarios (55.43\%) son foráneos, provenientes principalmente de otras ciudades del interior de la Región La Libertad, así como de otras regiones del norte del país.

Tabla 9. Principales Universidades de la ciudad de Trujillo ${ }^{21}$

\begin{tabular}{lrr}
\hline Universidad & Estudiantes & Instalación \\
\hline Universidad Nacional de Trujillo & 17305 & 1824 \\
Universidad Antenor Orrego & 9710 & 1988 \\
Universidad César Vallejo & 10960 & 1989 \\
Universidad Privada del Norte & 4807 & 1996 \\
Universidad Católica de Trujillo & 589 & 2010 \\
Universidad Privada de Trujillo & 479 & 2010 \\
Universidad Privada Leonardo Da Vinci & - & 2012 \\
\hline
\end{tabular}

También se pueden mencionar algunos institutos de educación superior entre los cuales se encuentra la Escuela Superior Indoamérica, donde se han formado profesores de primaria y secundaria desde 1965. Asimismo, algunos otros institutos que también se encuentran en la ciudad: el Instituto Nueva Esperanza, Instituto Tecnológico Trujillo, Instituto Pedagógico Santo Tomás De Aquino e Instituto Tecnológico del Norte.

\footnotetext{
${ }^{21}$ Fuentes: Censo 2007, II Censo Nacional Universitario 2010.
} 
Además de los centros de formación superior universitaria y tecnológica la ciudad también cuenta con centros superiores de formación artística: el Conservatorio Regional de Música Carlos Valderrama, el cual tiene rango universitario presentando carreras profesionales de formación musical y otorgando grados de bachiller y títulos de licenciado a nombre de la nación en sus respectivas carreras.

También es un centro superior de formación artística en la ciudad la Escuela Superior de Bellas Artes de Trujillo Macedonio de la Torre, fundada por el pintor indigenista Pedro Azabache Bustamante, donde se forman artistas en diversos campos de las bellas artes: la escultura, la pintura, etc.

\section{Universidad Nacional de Trujillo}

Es la única universidad nacional de la ciudad, fundada en 1824 por el libertador Simón Bolívar y por José Faustino Sánchez Carrión, es la cuarta más antigua de Perú y fue la primera republicana del país; dada su importancia y calidad recibió varios premios. De sus aulas egresaron poetas: Carlos Hugo Garrido Chalén, César Vallejo integrante del Grupo Norte, Alejandro Romualdo; filósofos e ideólogos políticos: Antenor Orrego, Víctor Raúl Haya de la Torre (APRA), Luciano Castillo (Partido Socialista del Perú); economistas: Luis Alva, Pacífico Huamán, César Liza, Jaime Verástegui; escritores: Ciro Alegría, Eduardo González Viaña, Juan Morillo Ganoza.

\section{Sanidad $^{22}$}

Respecto a los servicios de salud en Trujillo existen un total de 97 establecimientos entre hospitales, centros materno infantil, centros de salud, clínicas,

${ }^{22}$ Gobierno Regional de La Libertad, Gerencia Regional de Salud, Avances de la Gestión Regional en Salud 2007-2012. 
policlínicos, postas médicas; de éstos el $66 \%$ pertenece al sector público y $34 \%$ al sector no público, siendo el Ministerio de Salud del gobierno peruano el que cuenta con mayor cantidad de establecimientos (50\%), brinda mayor atención en consulta externa (44\%), en servicios de laboratorio y rayos X (68\%) e internamiento (56\%). EsSalud cuenta con 3 hospitales, 3 centros médicos y 2 postas y los privados son 10 clínicas y 5 centros médicos. El continuo urbano de Trujillo concentra el 75\% de los establecimientos de salud; en el distrito capital se ubica el $40 \%$ de establecimientos. Algunos de los establecimientos de salud importantes son: EsSalud, Nivel III: Hospital Regional Docente, Nivel IV: Hospital Víctor Lazarte Echegaray, Hospital de Florencia de Mora, Ministerio de Salud, Hospital Belén, Hospital Vista Alegre, Hospital Albrecht, Hospital, La Noria, Institutos Regionales, Instituto Regional de enfermedades Neoplásicas (IREN) y Instituto Regional de Oftalmología (IRO).

\section{Historia y Cultura ${ }^{23}$}

Trujillo es la ciudad más poblada del norte del Perú, la tercera ciudad más importante del país, eje cultural y económico de la costa norte. El centro de la ciudad presenta hermosos edificios que datan de la época colonial: la Catedral, el Monasterio El Carmen, así como también numerosas iglesias y mansiones. Se le conoce en el Perú como la "Ciudad de la Eterna Primavera", capital Nacional de la Marinera y como la capital de la cultura. En ella, se conjugan tradiciones y modernidad.

En la localidad donde actualmente se extiende la ciudad de Trujillo se desarrollaron varias culturas pre hispánicas como los Cupisnique, los Mochicas y los

23،Así es mi Tierra: Trujillo (Perú) - Newport”, http://trujillonewport.wordpress.c om/trujillo-su-historia (consultado: 25 de marzo, 2013). 
Chimúes. Es por ello que se encuentran numerosos restos arqueológicos que atestiguan el desarrollo de esos pueblos. Sin embargo, el principal emplazamiento urbano de la zona se debe a la Cultura Chimú, cuyos restos se encuentran en la ciudadela de Chan Chan, su capital, donde se calcula que habitaron en su época de mayor expansión 100.000 personas, y se encuentra a cuatro kilómetros del centro de la ciudad de Trujillo. Sin embargo, a pesar de estos emplazamientos urbanos, no podemos hablar con propiedad de la existencia de la ciudad de Trujillo antes de la llegada de los conquistadores españoles.

Los ceramistas de la cultura Moche, pueblo que existió entre los siglos I a VIII de nuestra era, llevaron a su más alta expresión una tradición que se había iniciado más de mil años antes. Sus ceramios, llamados "huacos", ya sean esculpidos, grabados o decorados, son obras de arte que, por su perfección, son sólo comparables con las esculturas griegas o egipcias. Así, la cerámica Moche está despertando admiración e interés en todo el mundo.

\section{Cultura Moche}

Esta cultura inicia su desarrollo en el valle de Moche, cerca de Trujillo en el Período de los desarrollos Regionales (años 100 a 800 d.C.). Coexiste con culturas regionalizadas, con mucho prestigio religioso, con notable avance tecnológico en la cerámica, la arquitectura y la agricultura. Es notable asimismo su avance en la metalurgia, con fundiciones de oro, plata y cobre y sus respectivas aleaciones como el repujado, el martillado y el soldado a presión.

La cultura Moche ha recibido varios nombres. Max-Uhle la llamó Proto-Chimú, Mochica. Julio C. Tello la denominó Muchik. Y los norteamericanos de los años 60 la bautizaron Early Chimú. 


\section{Catedral de Trujillo}

A nivel religioso, desde la fundación de la ciudad, Trujillo acogió las más diversas órdenes católicas. En consecuencia, en el año 1577 se crea el Obispado de Trujillo mediante bula papal emitida por Gregorio XIII. Luego de ello, durante todo lo que restaba del siglo XVI e incluso hasta inicios del siglo XVII, la construcción de templos tuvo un gran auge en la ciudad, los mismos que se mantienen hasta la actualidad. En 1616 se termina la construcción de la Iglesia Catedral.

\section{La Independencia}

Luego del desembarco del General José de San Martín en Paracas en septiembre de 1820, el intendente de la ciudad, José Bernardo de Torre Tagle encabezó un movimiento independentista que culminó con la declaración de la independencia el mismo 24 de diciembre de 1820 ante un cabildo abierto reunido en la Plaza de Armas de la ciudad.

Para esta oportunidad se confeccionó una de las primeras banderas peruanas según el modelo ideado por San Martín, el mismo que fue velado la noche anterior, por estudiantes seminaristas (Del Colegio Seminario) en la histórica Casa del Márquez de Falcalá. El 29 de diciembre, se proclamó dicha declaración y Trujillo se convirtió en la primera ciudad del Perú en declarar la independencia del nuevo país.

\section{La República}

Durante la guerra de la independencia, Trujillo tuvo un papel preponderante tanto a nivel económico como político. Ya en 1820 había sido establecida como capital del departamento de La Libertad y, en 1823, luego de la creación de la República del Perú y el final del protectorado de José de San Martín, y ante el contraataque de las tropas 
realistas que tomaron la ciudad de Lima, Trujillo asumió la capital del país durante el gobierno de José de la Riva Agüero, quien fuera el primer Presidente del Perú.

En 1824 la ciudad recibió al ejército libertador de Simón Bolívar quien asumió el gobierno del país.

Bolívar, secundado por José Faustino Sánchez Carrión, creó importantes instituciones en la ciudad de Trujillo: la Corte de Justicia del Norte y la Universidad Nacional de Trujillo, para la cual asignó antiguos claustros de órdenes religiosas.

$$
\text { Arqueología }{ }^{24}
$$

\section{Ciudadela de Chan Chan}

A cinco $\mathrm{Km}$ al noroeste de Trujillo, en el valle de Moche (10 minutos en auto). Este centro urbano prehispánico representa la más grande ciudad de barro de América prehispánica. Fue declarada Patrimonio Cultural de la Humanidad por la UNESCO en 1986.

Chan Chan habría sido la capital del reino Chimú, abarcando originalmente más de $20 \mathrm{~km} 2$ desde las proximidades del puerto de Huanchaco hasta el Cerro Campana. Los arqueólogos estiman que albergó a más de 100 mil personas. En su estructura se distinguen plazas, viviendas, depósitos, talleres, calles, murallas y templos piramidales. Sus enormes muros están profusamente decorados con relieves de figuras geométricas, estilizados zoomorfos y seres mitológicos. El recorrido por el sitio arqueológico se complementa con la visita al Museo de Sitio.

Chan-Chan. Metrópoli capital del extenso y poderoso reino Chimú, la de mayor

\footnotetext{
${ }^{24}$ Rotary Club de Trujillo, Monografía Geográfica e Histórica del Departamento de La Libertad, Trujillo.
} 
importancia en el litoral, cuya extensión se calcula en 18 km. cuadrados. Es hoy un inmenso laberinto de enormes paredes, muchas de ellas labradas con belleza, donde aún se puede apreciar sus bien trazadas calles que se cruzan en ángulo recto.

Estas obras hidráulicas aún son visibles y son el asombro de la ingeniería moderna; cementerios y otros recintos que quizá eran mercados, talleres o cuarteles.

Chan-Chan estaba formada por diez grandes unidades generalmente rectangulares. Cada unidad se encontraba rodeada de altos muros de altura superior a los nueve metros, encerrando en ellos un emparrillado de calles, casas grandes y pequeñas, grandes pirámides, depósitos de víveres y agua.

Entre los distintos barrios parece que existieron zonas de cultivo pertenecientes a la comunidad, donde se observan pequeñas construcciones aisladas, tales como habitaciones de bajos techos y una sola entrada.

Estas unidades o barrios miden hasta $335 \mathrm{~m}$. por $480 \mathrm{~m}$., es decir, más de 16 has. Entre ellas podemos citar los siguientes: Velarde Laberinto, Rivero, Schudi, Uhle, Bandelier, del Gran Chimo, Martínez Compañón, Tello, O’Donovan.

\section{Huaca El Dragón o Arco Iris}

A cuatro $\mathrm{km}$ de la ciudad de Trujillo (10 minutos en auto), esta pirámide de adobe es especialmente importante, porque su construcción había sido realizada al inicio de la cultura Chimú y al final de la cultura Tiahuanaco-Wari entre los siglos X-XI d.C. Se calcula que su antigüedad es de 1100 años.

La edificación tiene una base de forma cuadrangular y paredes decoradas por altos relieves con representaciones zoomorfas y antropomorfas. El nombre de Dragón se debe a una de estas figuras, un ser bicéfalo con incontables patas, similar a un dragón. 
Los investigadores consideran que una de las funciones de este lugar fue ceremonial (estaría vinculado a rituales en honor del arco iris y otros fenómenos naturales relacionados con la fertilidad).

Fue descubierta por un buscador de tesoros el año 1943 y limpiada por el Instituto de Antropología de la Universidad Nacional de Trujillo, en los años 1947 y 1948, labor que puso al descubierto tres muros exteriores y dos muros interiores con magníficas decoraciones en relieve de patente intención mitológica.

\section{Huaca del Sol y Huaca de la Luna}

A ocho km al sur de la ciudad de Trujillo (15 minutos en auto). La Huaca del Sol funcionó como el centro político-administrativo y la Huaca de la Luna, como centro ceremonial. Entre ambas, se ubica la Zona Urbana compuesta por viviendas, grandes avenidas, callejones, corredores y plazas. Estos componentes que confirman la alta organización política, religiosa, económica y social de los Moches.

La Huaca de la Luna está compuesta por templos superpuestos de acuerdo con distintas etapas del poderío mochica. En algunas paredes se pueden observar hermosos murales polícromos, cuyas figuras claramente definidas representan al dios Ai-apaec.

En el templo, los arqueólogos han descubierto una tumba con más de 40 guerreros sacrificados. La visita turística comprende por el momento la Huaca de la Luna.

En la huaca de La Luna (vecina a la Del Sol) paralelo a los descubrimientos arqueológicos se ha puesto en valor para que el turista visite sus corredores, plazas y gigantescas pinturas murales.

Huaca de la Luna

Esta Huaca es atribuida a la Cultura Proto-Chimu (Mochica). Está dentro de la 
jurisdicción del distrito de Moche, recostada a una colina rocosa de forma piramidal llamada "Cerro Blanco".

Tiene tres planos escalonados adheridos al declive del cerro y la plataforma es más pequeña que la Huaca del Sol, con $80 \mathrm{~m}$. por $60 \mathrm{~m}$. de base y $21 \mathrm{~m}$. de altura.

En lo alto quedan restos de unas habitaciones cuyos muros representan rastros de pintura tipo "fresco", con figuras de guerreros y simbología del mismo carácter. Los colores empleados fueron: negro, blanco, azul, rojo, amarillo, rosa y color pardo.

Huaca del Sol

También atribuida a la cultura Proto-Chimu (Mochica). Está en la margen izquierda del río Moche y a poca distancia de la Huaca de la Luna; formada por plataformas escalonadas, todas ellas construidas con adobes en un número incontable.

La plataforma que sirve de base mide $228 \mathrm{~m}$. de largo por $136 \mathrm{~m}$. de ancho; y tiene cinco terrazas que se elevan a una altura total de $18 \mathrm{~m}$.

Un desmonte de $6 \mathrm{~m}$. de ancho y cerca de $90 \mathrm{~m}$. de longitud conduce al extremo Norte, y una pirámide escalonada de $103 \mathrm{~m}$. por lado y $23 \mathrm{~m}$. de altura, remata el extremo Sur de la plataforma. Se ha calculado que tiene 130 millones de adobes.

\section{Huaca La Esmeralda}

A $3 \mathrm{~km}$ de la ciudad de Trujillo en el caserío de Mansiche, a kilómetro y medio al Oeste, en la cooperativa de producción El Cortijo (8 minutos en auto).

Este sitio arqueológico está asociado a la cultura Chimú y fue construido vinculado a Chan Chan. La edificación tiene base rectangular (65 metros de largo y 41 metros de ancho) y dos plataformas con rampas centrales. Las paredes de adobe están decoradas con altorrelieves con motivos zoomorfos y geométricos. 
Fue descubierta después de las grandes lluvias de 1925. Se le considera un templo con diversos compartimientos y terrazas, con riquísimos e interesantes decorados en relieve modelados en barro.

$$
\text { Museos trujillanos }{ }^{25}
$$

\section{Museo Catedralicio}

Ubicado dentro de la catedral de Trujillo. Conserva objetos vinculados a la liturgia, tallas y pinturas del período colonial, entre los que destacan dos lienzos: "La negación de San Pedro" y el retrato de San Juan Bautista. Caracterizan a este edificio el techo decorado con vigas policromadas y la cripta adornada con pinturas murales de los apóstoles.

\section{Museo de Arqueología e Historia de la Universidad Nacional de Trujillo}

Se exponen restos arqueológicos vinculados a las distintas culturas prehispánicas que se desarrollaron en la Región La Libertad. El museo se encuentra en la casa Risco, famosa por sus patios decorados con murales. Destacan objetos de cerámica, orfebrería, tejidos y arte plumario.

\section{Museo del Juguete}

Muestra la transformación del juguete a través del tiempo, desde la época prehispánica hasta el decenio de 1950. Se puede apreciar juguetes de distintas partes del mundo, donde se refleja costumbres, modas y parámetros socioculturales.

25“Región La Libertad”, http://trujilloperu.com/region-la-libertad/la-libertad.html (consultado: 19 de junio, 2013). 


\section{Museo de Zoología}

Presenta diversas especies de la fauna de la Región y del Perú, aves, peces, reptiles, insectos y camélidos.

\section{Datos referenciales de la Iglesia Adventista del Séptimo Día}

Seguidamente se encuentran algunos detalles de la Iglesia Adventista del Séptimo Día: los comienzos, el despertar evangelístico, el establecimiento administrativo y la realidad actual.

\section{Los comienzos}

El 26 de junio de 1898, la Foreign Mission Board de la Asociación General de la Iglesia Adventista del Séptimo Día votó la adición de los territorios de Bolivia, Perú y Ecuador a la Misión Chilena, lo cual fue determinante para que la Misión Chilena extendiese sus actividades al territorio peruano. ${ }^{26}$

En el año 1900, un grupo reducido de creyentes recibe la visita del presidente de la Misión de la Costa Occidental, el pastor G.H. Baber, quien experimentó la intolerancia religiosa de algunas personas en Lima, las cuales lo desprecian y también al grupo reunido en el culto de oración. ${ }^{27}$

En 1901, el pastor Enrique Balada llegó desde Chile y atendió la nueva iglesia por un período de un año. Cerca de finalizar el año 1902, el pastor Balada realizó un pedido

\footnotetext{
${ }^{26}$ Asociación General de la Iglesia Adventista del Séptimo Día, Historia de la Iglesia Adventista del Séptimo Día en el Perú, la primera década 1898-1907, 1.

${ }^{27}$ Jorge P. Maquera Sosa, Operación andes libres: Construyendo la "utopía" (Lima: Editorial Imprenta Unión, 2014), 84.
} 
de mil ejemplares de la Revista Señales de los Tiempos, ${ }^{28}$ para evangelizar Lima y el Callao. $^{29}$

Del vecino país del sur salieron misioneros decididos a establecer la obra adventista en el Perú. Liborio y José Osorio llegaron hasta Arequipa. José Luis Escobar, acompañado por otros creyentes, trabajó en Lima, como obrero de sostén propio. Ellos celebraron reuniones a puerta cerrada y distribuyeron publicaciones. El grupo de adventistas habría de convertirse en iglesia con la llegada del pastor Franklyn Lelan Perry. $^{30}$

Perry persuadió a un maestro de escuela, quien enseñaba en la región del Lago Titicaca, a distribuir algunas publicaciones adventistas. Es probable que haya sido una de éstas la que cayó en manos del cacique Camacho, quien había aprendido a leer en el Ejército, el cual encontró también una Biblia y había aprendido a amarla. Pronto comenzó a guardar el sábado y así se inició la historia de las misiones entre los nativos de aquellas regiones. ${ }^{31}$

La obra adventista en el Perú había comenzado en los últimos años del siglo XIX. Misioneros norteamericanos, como el ya mencionado Franklyn Lelan Perry y A.N. Allen

\footnotetext{
${ }^{28}$ La obra de publicaciones fue de vital importancia en los comienzos de la Iglesia Adventista. Las primeras revistas de la Iglesia Adventista no solamente estimularon la evangelización, sino también proveyeron un sentido de comunidad espiritual entre los primeros creyentes. Véase http://www.interamerica.org

${ }^{29}$ Maquera, 84.

${ }^{30}$ Daniel Oscar Plenc, Misioneros en Sudamérica (Buenos Aires: Asociación Casa Editora Sudamericana, 2008), 68-69.
}

${ }^{31}$ Aldo D. Orrego, Nuestra herencia: Historia de la Iglesia Adventista para el Ministerio Joven (Buenos Aires: Asociación Casa Editora Sudamericana, 2005), 153. 
dieron forma a la organización e iniciaron la Misión Peruana en 1906. La Unión Incaica se organizaría en 1914, incluyendo Bolivia, Ecuador y Perú. La presencia de Fernando y Ana Sthal consolidó la obra en lo que habría de llamarse la Misión del Lago Titicaca, entre 1911 y 1919 . Después, entre 1921 y 1939, se convertirían en pioneros de la predicación adventista, esta vez entre los indígenas campas de la Amazonía peruana en el Alto Perené y luego en la Misión del Alto Amazonas, con sede en Iquitos. ${ }^{32}$

El 13 de junio de 1907, se informaba en la Review and Herald, la organización formal de la primera Iglesia Adventista en el Perú, casi 10 años después de la llegada del evangelio a costas peruanas. Luego de un bautismo de 5 hermanos, el pastor Perry organizó esta iglesia con 17 hermanos en total. ${ }^{33}$

\section{Despertar evangelístico y establecimiento administrativo}

Se puede notar un despertar evangelístico en la iglesia, cuando ella se organiza para el cumplimiento de la misión. Desde Bolivia, Fernando Stahl había estado haciendo visitas a la región de Puno, en el Perú, entre 1910 y 1911. Entonces pidió a la administración de la iglesia permanecer en Platería, a 40 kilómetros de la ciudad de Puno, e iniciar la misión entre los aimaras de la zona.

Stahl se interesó por el bienestar y atención a su prójimo. Parte de su ministerio lo dedicó a orientar en los principios básicos de la salud a los campesinos. Impulsó temas de temperancia. Les enseñó la limpieza, la importancia de beber agua pura y prácticas

\footnotetext{
${ }^{32}$ Plenc, 84.
}

${ }^{33}$ F. H. Westphal, "The Opening of Our Work in Western South America”, RH, 16 de mayo de 1907. 
sencillas que ayudaron considerablemente en el mejoramiento de la salud de los campesinos. $^{34}$

Asimismo, surgió la primera escuela adventista promovida por el cacique Manuel Zuñiga Camacho, apoyado por el pastor Allen, de Lima y los esposos Stahl. ${ }^{35}$

La obra educativa fue fundamental en el inicio y la consolidación de la iglesia. De eso estaban convencidos Camacho y Stahl. Una escuela diurna abrió sus puertas para acoger a 150 alumnos, muchos de ellos adultos de más de 40 años. La Biblia era la base del programa educativo. Bartolomé Rojas y su esposa Hilalia llegaron de Argentina para dirigir la escuela durante un año, pero por circunstancias adversas no pudieron continuar. Ana Stahl entonces asumió el liderazgo de la escuela y muchos de los cultos de los sábados a los que concurrían unas 800 personas. $^{36}$

Desde Platería se iniciaron los incesantes viajes exploratorios y misioneros de Sthal por toda la región que circundaba el lago Titicaca tanto en Perú como en Bolivia. Su crónica registra lugares como Juli, Lampa Putuma (Pomata), Puna, Occopampa, Paru, y otros. Se realizaron los oportunos contactos con las autoridades civiles y con los líderes aborígenes. Desde muchos lugares se solicitaban estaciones misioneras, escuelas y dispensarios médicos. Manuel Z. Camacho y Juan Huanca fueron muchas veces los compañeros de viaje de Fernando Stahl en estas giras a lomo de mula y a caballo. ${ }^{37}$ En cada lugar donde se iniciaba la obra educativa, se tenía el apoyo de los
${ }^{34}$ Maquera, 99.
${ }^{35}$ Plenc, 86.
${ }^{36}$ Ibíd., 87.
${ }^{37}$ Plenc, 87. 
campesinos, también hubo diversos grados de oposición que generalmente eran motivados por intereses económicos. Aun así, la obra adventista fue avanzando. Se puede mencionar que hasta 1916 alrededor del Lago Titicaca se fundaron unas 19 escuelas para indios, visitadas por más de 2200 escolares. Desde la primera Escuela Adventista de Platería en 1913 hasta aquí se veían resultados significativos. ${ }^{38}$

El éxito en esta etapa radicaba en que los misioneros, encabezados por Fernando Stahl, vivían en las mismas chozas de los indios, los ayudaban en sus trabajos, perfeccionaban sus pequeñas industrias, les sanaban sus enfermedades y, lo más admirable, les hablaban en aymara. "Cada lugar visitado, cada choza y cada persona atendida recibía siempre el aprecio y cariño sincero de cada misionero, poco a poco comenzaba a consolidarse la obra evangelística y educativa de los adventistas". ${ }^{39}$

La obra educacional ha sido una llave de entrada para comenzar y afirmar otras fases de las actividades adventistas. Hoy se tiene en el Perú una extensa red de escuelas primarias y colegios secundarios, además de la Universidad Peruana Unión en la localidad de Naña, cerca de Lima. ${ }^{40}$

A los dos años de haber llegado al Perú, el pastor Maxwell ya había participado en muchos bautismos, así como de sufrimientos de manos del populacho azuzado por su párroco. Bautismos en Arequipa, Junín, Contumazá, Supe y el Norte, contribuían a que el número de miembros de iglesia para 1916 fuera de 490 hermanos.

El profesor Fernando Osorio, profesor de la escuela de la iglesia de Lima, Perú, escribió al pastor Maxwell que de diversas partes llegaban noticias del avance de la causa

\footnotetext{
${ }^{38}$ Maquera, 168-69.

${ }^{39}$ Ibíd., 169.

${ }^{40}$ Orrego, $153-154$.
} 
adventista. Desde Mala llega un joven para llevar a un pastor para bautizar a treinta personas, el pastor L. D. Minner, sin conocer mucho el español, bautizó en dos viajes misioneros al centro y norte del Perú a cincuenta personas (en su segundo viaje, cuando visita Trujillo, Ascope y Contumazá (él bautiza a 39 personas en este recorrido). En la región del Titicaca, 200 bautismos. En ese año, en el Perú se bautizaron más de quinientas personas. El presidente del comité para la implementación de la educación pública, Dr. Vicente Villarán, con la recomendación del Sr. Encinas de Puno, invita al pastor E. F. Peterson, al hermano H. B. Lundquist y al hermano F. C. Varney para explicar el método empleado en las escuelas de Platería que eran reconocidas escuelas modelos para el Perú. La misión de Platería ejerció una influencia notable en todo el territorio peruano. ${ }^{41}$

Los misioneros que llegaron al Perú en 1918 fueron el pastor E. F. Peterson y esposa, el señor y la señora Lundquist y el pastor F. A. Stahl retornó luego de haber vuelto a los Estados Unidos. ${ }^{42}$ El pastor L. D. Minner, superintendente de la Misión Peruana, regresó de un viaje por el interior del Norte del Perú, y fue acompañado del pastor E. H. Wilcox, secretario misionero. Fueron realizando bautismo en Trujillo, Ascope y Contumazá. En este viaje se organizaron dos iglesias, Ascope con 29 miembros y Contumazá con $25 .{ }^{43}$ Entre 1920 y 1930, se establece la iglesia en Ascope, Cascas y Contumazá. Por aquel entonces los hermanos recibieron la visita del pastor Fernando Stahl, quien llegó por razones de salud. En esas circunstancias llega el mensaje a la

\footnotetext{
${ }^{41}$ Fernando Osorio, "In the Inca Union", $R H, 26$ de diciembre, 1918, 23.

${ }^{42}$ J. L. Shaw, "To the fields in 1918", $R H, 16$ de enero, 1919, 11.

${ }^{43}$ E. F. Peterson, “Inca Union Mission”, $R H, 20$ de febrero, 1919, 17.
} 
ciudad de Trujillo, comenzando sus reuniones de hogares en el Jirón Unión, para que luego bajo el liderazgo del primer pastor, Agustín Alva Alva, se alquilara en 1942 la casona ubicada en el Jirón San Martín 880. En 1943 se organiza la primera iglesia en la ciudad de Trujillo y en este mismo año se compra el lote ubicado en Independencia 871. El templo se construyó con mucho esfuerzo y se llegó a dedicar en el año $1951 .{ }^{44}$

Los pastores de la iglesia central de Trujillo han sido: Agustín Alva (1942-1944), Merardo León (1945-1946), Agustín Alva (1947-1950), Juan Ramos (1951-1952), Gonzalo Alva (1952-1955), Raúl Álvarez (1956-1958), Licinio Bendezú (1959-1960), Raúl Alarcón (1961-1964), Norberto Franco (1961-1968), Víctor Mestanza (1969-1970), Leonardo Pinedo (1971-1972), Pedro Flores (1973-1975), Rodrigo Gutiérrez (19761979), Claudio Huamán (1980-1982), Vosler García (1983-1985), Vladimiro Silva (1986-1987), Pedro Villanueva (1988-1991), Vladimiro Silva (1992-1993), Saúd Elías (1994-4 meses), Julio Godoy (1994-8 meses), Jaime Vaca (1995), Abner Tello (19961997), Eleuterio Guerrero (1998-2002), Arnulfo Chico (2003), Francisco Gonzáles (2004), Eberth Durand (2005-2007), Jorge Reyes (2008), Gerardo Medina (2009), Santos Corrales (2010-2013), y desde el año 2014 es el pastor Ever Rojas.

En síntesis, se ha visto un panorama breve de la ciudad de Trujillo, mostrando su fundación, ubicación, organización administrativa, población, educación, costumbres y cultura. Asimismo, se han destacado datos referenciales de la Iglesia Adventista del Séptimo Día, sus inicios en el Perú, su despertar evangelístico y establecimiento administrativo. Cada detalle muestra como Dios conduce su obra en medio de una sociedad creciente y desafiante.

\footnotetext{
${ }^{44}$ Datos proporcionados por el pastor Ever Rojas el 10 de noviembre de 2015.
} 


\section{CAPÍTULO 3 FUNDAMENTOS TEÓRICOS}

Este capítulo desarrolla algunos conceptos bíblicos de crecimiento de iglesia, del mismo modo, un breve análisis del don de profecía sobre crecimiento de iglesia. También se da algunos conceptos de autores contemporáneos sobre este tema de investigación. Finalmente, se describen factores particulares que probablemente dieron crecimiento a la iglesia de Trujillo en el período de estudio: administrativos, evangelísticos, pastorales y estructurales.

\section{La Biblia y el crecimiento eclesiástico}

Las Escrituras mencionan claramente la misión que Cristo dejó a la iglesia cristiana: "Por tanto, id, y haced discípulos a todas las naciones, bautizándolos en el nombre del Padre, del Hijo y del Espíritu Santo; enseñándoles que guarden todas las cosas que os he mandado; y he aquí yo estoy con vosotros todos los días, hasta el fin del mundo" (Mt 28:19,20). Los cristianos a través del tiempo han tratado de cumplir esta gran comisión, llevando el evangelio a diferentes partes del mundo. "La iglesia primitiva funcionaba dentro del estricto cumplimiento de la Gran Comisión" y lo que ellos realizaron brinda claras enseñanzas de iglecrecimiento, pues dependieron, en todo momento, de los designios de Dios. ${ }^{1}$

\footnotetext{
${ }^{1}$ Juan Carlos Miranda, Manual de iglecrecimiento (Miami, FL: Editorial Vida, 1985), 14 .
} 


\section{La iglesia primitiva}

Se puede encontrar en la iglesia primitiva por lo menos cuatro elementos básicos para el desarrollo saludable de una iglesia. "En primer lugar, encontramos en el capítulo 2 del libro de los Hechos, que existía un crecimiento espiritual". ${ }^{2}$ No puede haber otro tipo de crecimiento si no le precede la base espiritual. El énfasis no está puesto sólo en los números sino "en todo aspecto del individuo y de la iglesia. La madurez cristiana y la relación vertical con Dios son la base de todo crecimiento". ${ }^{3}$

En segundo lugar, se puede mencionar un crecimiento corporativo. Tiene que ver con el "cuerpo de Cristo", los hermanos estaban juntos (Hch 2:44). Tiene que reinar la unidad y no la división entre los feligreses. ${ }^{4}$

En tercer lugar, había un crecimiento social, pues "tenían favor con todo el pueblo" (Hch 2:47). No estaban ocupados sólo en la predicación, sino que también estaban interesados en atender sus necesidades. ${ }^{5}$

En cuarto lugar, Hechos menciona un crecimiento numérico. El versículo 47 dice: "Y el Señor añadía cada día a la iglesia los que habían de ser salvos". Dios bendijo el trabajo de la iglesia. "Como resultado efectivo de las actividades individuales y colectivas de esa iglesia, de lo que ellos estaban sembrando, el Señor les daba el crecimiento". 6

\footnotetext{
${ }^{2}$ Miranda, 14.

${ }^{3}$ Ibíd., 15.

${ }^{4}$ Ibíd.

${ }^{5}$ Ibíd.

${ }^{6}$ Ibíd., 16.
} 
A la luz de lo analizado, se puede señalar que el crecimiento de la Iglesia es integral y siempre está asociado al cumplimiento de la misión.

\section{Epístolas paulinas}

Uno de los textos significativos del apóstol Pablo respecto a este tema se encuentra en 1 Co 3:6: "Yo planté, Apolos regó; pero el crecimiento lo ha dado Dios". Pablo predicó el evangelio en Corinto y estableció la iglesia allí. Dios le había asignado esta obra tan importante. Apolos llegó después para regar la semilla sembrada, complementando el trabajo del apóstol. Se puede observar que "el verbo plantar como regar están en tiempo aoristo, indicando una acción pasada y terminada. El tercer verbo, ha dado, está en tiempo imperfecto, indicativo de una acción continuada, o un proceso que continúa todo el tiempo. De modo que era Dios quién estaba produciendo el crecimiento". ${ }^{7}$ En la tarea que se realiza para Dios, los seres humanos son instrumentos que van y vienen. Cada uno contribuye en el proceso de plantar y cultivar. Pero el que obra, en todo el proceso, es Dios. ${ }^{8}$

Los términos agrícolas que se usan en este pasaje, muestran "el carácter limitado y subordinado de lo que Pablo y Apolos han hecho". ${ }^{9}$ Cada líder y miembro de iglesia tienen una función en la iglesia, asignada por Dios. Pero siempre hay que recordar que el crecimiento lo da Dios. "No es el poder humano, sino el divino, el que obra la

\footnotetext{
${ }^{7}$ William M Greathouse, Donald S Metz y Frank G Carver, eds., Comentario bíblico Beacon (Kansas City, MO: Casa Nazarena de Publicaciones, 1968), 357.

${ }^{8}$ Greathouse, et al., 357 .

${ }^{9}$ D Guthrie; J.A. Motyer ed. Nuevo comentario bíblico (Buenos Aires: Casa Bautista de Publicaciones, 1977), 783.
} 
transformación del carácter. Los que plantan y los que riegan, no hacen crecer la semilla; trabajan bajo la dirección de Dios, como sus agentes señalados, y cooperan con él en su obra. Al Artífice maestro pertenecen el honor y la gloria del éxito". ${ }^{10}$ Todo líder y todo feligrés deben recordar este principio.

Queda claro entonces, cada líder o miembro de iglesia puede contribuir de alguna manera en la predicación de la Palabra de Dios, pero el único que da el crecimiento y obra, en todo el proceso, es Dios.

\section{EI don de profecía y el crecimiento de iglesia}

Elena G. de White da detalles interesantes del crecimiento de iglesia. Ella complementa muy bien lo que se encuentra en las Sagradas Escrituras. Las citas que a continuación vienen, refuerzan el estudio bíblico.

\section{El Espíritu Santo y el crecimiento}

En la Biblia se destaca la persona del Espíritu Santo en el crecimiento espiritual y eclesiástico. El Espíritu Santo tuvo y tiene una obra especial para los creyentes. Dios prometió el derramamiento de su Espíritu y en eso debemos pensar. Elena G. de White dice:

La promesa del Espíritu es algo en lo cual se piensa poco; y el resultado es tan sólo lo que podría esperarse: sequía, tinieblas, decadencia y muerte espirituales. Los asuntos de menor importancia ocupan la atención y, aunque es ofrecido en su infinita plenitud, falta el poder divino que es necesario para el crecimiento y la prosperidad de la iglesia y que traería todas las otras bendiciones en su estela. ${ }^{11}$

\footnotetext{
${ }^{10}$ Elena G. de White, Hechos de los apóstoles (Buenos Aires: Asociación Casa Editora Sudamericana, 1977), 225.

${ }^{11}$ Elena G. de White, Joya de los testimonios (Miami, FL: Publicaciones Interamericanas, 1953), 3:211.
} 
Asimismo, se destaca la influencia del Espíritu en el progreso de la obra. Ella expresa que "se necesita la influencia del Espíritu Santo para que la obra quede debidamente equilibrada, y que pueda progresar sólidamente en todo ramo". ${ }^{12}$

Por otro lado, así como el derramamiento del Espíritu fue clave para la iglesia apostólica, para la iglesia cristiana de hoy igualmente es necesaria. Hay que tener en cuenta el énfasis que se da: "El derramamiento del Espíritu en los días de los apóstoles fue el comienzo de la lluvia temprana, y gloriosos fueron los resultados. Hasta el fin del tiempo, la presencia del Espíritu ha de morar con la iglesia fiel". ${ }^{13}$

\section{Unidad para el crecimiento}

Algo que se destaca en Hechos de los Apóstoles, que es indispensable para el avance de la predicación, es la unidad. Sin unidad, no se puede esperar resultados. Elena G. de White manifiesta:

A la iglesia primitiva se le había encomendado una obra de crecimiento constante: el establecer centros de luz y bendición dondequiera hubiese almas honestas dispuestas a entregarse al servicio de Cristo. La proclamación del Evangelio había de tener alcance mundial, y los mensajeros de la cruz no podían esperar cumplir su importante misión a menos que permanecieran unidos con los vínculos de la unidad cristiana, y revelaran así al mundo que eran uno con Cristo en Dios. ${ }^{14}$

En estos tiempos, como lo fue en la época de Jesús, es indispensable que se haga realidad su oración a favor de la unidad. Sin ella la obra no puede avanzar. La siguiente cita se encarga de mostrar en forma elocuente esta necesidad:

${ }^{12}$ Elena G. de White, Joya de los testimonios (Miami, FL: Publicaciones Interamericanas, 1953), 2:529.

${ }^{13}$ Elena G. de White, Eventos de los últimos días (Buenos Aires: Asociación Casa Editora Sudamericana, 1992), 189.

${ }^{14}$ Elena G. de White, Hechos de los Apóstoles (Buenos Aires: Asociación Casa Editora Sudamericana, 1977), 74. 
Dios tiene una obra especial que los hombres de experiencia deben hacer. Han de guardar la causa de Dios. Han de cuidar de que la obra de Dios no se confíe a hombres que crean que es su privilegio avanzar de acuerdo con su propio juicio independiente, para predicar lo que les plazca, no haciéndose responsables ante nadie de las instrucciones que imparten o del trabajo que realizan. Si este espíritu de suficiencia propia gobierna en nuestro medio, no habrá armonía de acción, ni unidad de espíritu, ni seguridad para la obra, ni habrá saludable crecimiento en la causa. Habrá falsos maestros, malos obreros que, insinuando el error, apartarán a las almas de la verdad. Cristo oró porque sus seguidores fueran uno, como él era uno con el Padre. Los que desean ver esta oración contestada, deben tratar de desanimar la más leve tendencia a la división, y tratar de obtener el espíritu de unidad y amor entre los hermanos. ${ }^{15}$

\section{Dios da el crecimiento}

Otro aspecto de este estudio, destacado en la Biblia y el crecimiento de la iglesia,

es que Dios es el único que da el crecimiento. Lo expresan claramente los escritos de Pablo en su epístola a los Corintios (1 Co 3:6). Y Elena G. de White reafirma la enseñanza de la Palabra de Dios cuando indica lo siguiente:

Pablo fue quien predicó primero el Evangelio en Corinto y quien había organizado la iglesia allí. Esta era la obra que el Señor le había asignado. Más tarde, por la dirección de Dios, otros obreros fueron enviados allí, para que ocuparan su debido lugar. La semilla sembrada debía regarse, y esto debía hacerlo Apolos. Siguió a Pablo en su obra, para dar instrucción adicional y ayudar al crecimiento de la semilla sembrada. Conquistó los corazones del pueblo, pero era Dios el que daba el crecimiento. No es el poder humano, sino el divino, el que obra la transformación del carácter. Los que plantan y los que riegan, no hacen crecer la semilla; trabajan bajo la dirección de Dios, como sus agentes señalados, y cooperan con él en su obra. Al Artífice maestro pertenecen el honor y la gloria del éxito. ${ }^{16}$

Asimismo, siempre en el contexto de 1 Corintios 3:6, destaca que el hombre es sencillamente un cooperador en su causa, porque únicamente Dios puede realizarla y nadie más.

${ }^{15}$ Elena G. de White, El evangelismo (Buenos Aires: Asociación Casa Editora Sudamericana, 1975), 158.

${ }^{16}$ Elena G. de White, Hechos de los Apóstoles (Buenos Aires: Asociación Casa Editora Sudamericana, 1977), 222. 
Un Pablo puede plantar, y Apolo regar, pero Dios da el crecimiento. Con sencillez y mansedumbre, el hombre ha de cooperar con los agentes divinos, haciendo en todo momento lo mejor que pueda, aunque comprendiendo siempre que Dios es el gran Artífice maestro. El hombre no debe sentir confianza en sí mismo; porque con ello agotaría su fuerza de reserva y destruiría sus facultades mentales y físicas. Aunque fuesen puestos a un lado todos los obreros que ahora llevan las cargas más pesadas, la obra de Dios seguiría adelante. Por lo tanto, dejemos que nuestro celo en el trabajo esté templado por la razón y suspendamos nuestros esfuerzos por hacer lo que el Señor solo puede realizar. ${ }^{17}$

En resumen, la persona del Espíritu Santo es clave en el crecimiento espiritual y eclesiástico. La unidad es indispensable para lograr resultados y avanzar en la predicación. Y reconocer en todo momento que al Artífice maestro le pertenecen el honor y la gloria del crecimiento.

\section{Autores contemporáneos y el crecimiento de iglesia}

Entre los principales investigadores contemporáneos sobre iglecrecimiento, se pueden citar:

Peter Wagner, ${ }^{18}$ define crecimiento de iglesia como "todo lo que está implicado en llevar a hombres y mujeres que no tienen ninguna relación personal con Jesucristo a la comunión con Él y a una membresía responsable en la iglesia”. ${ }^{19}$ El autor también realiza

${ }^{17}$ Elena G. de White, Joyas de los testimonios (Buenos Aires: Asociación Casa Editora Sudamericana, 1975), 2:354.

${ }^{18}$ C. Peter Wagner sirvió como misionero en Bolivia bajo la Misión y Andes Misión Evangélica Sudamericana (ahora SIM Internacional) de 1956 a 1971. Luego se desempeñó durante 30 años (1971-2001) como profesor de Crecimiento de Iglesia en la Facultad Mundial del Seminario Teológico Fuller Misiones hasta su jubilación en 2001. Es autor de más de 70 libros. Él era el presidente de Global Harvest Ministries 1993-2011 y actualmente es el emérito canciller del Instituto de Liderazgo Wagner, que sirve para entrenar a los líderes a unirse en un movimiento conocido como la Nueva Reforma Apostólica, una organización que Wagner también ayudó a fundar. Actualmente es el vicepresidente de Global Spheres, Inc.

${ }^{19}$ C. Peter Wagner, Su iglesia puede crecer (Barcelona: Editorial Clie, 1980), 14. 
un estudio de los dones espirituales y su relación con el crecimiento de iglesia. En su libro Sus dones espirituales pueden ayudar a crecer a su iglesia, muestra cómo los dones espirituales pueden hacer posible que los cristianos participen de modo más efectivo en la ejecución de la Gran Comisión de Jesús de ir y hacer discípulos en todas las naciones (Mateo 28:19,20). ${ }^{20}$

El enfoque de David Yonggi Cho ${ }^{21}$ es interesante. En los primeros capítulos de su libro se dirige a los pastores y laicos. Sus consejos son para todo líder. Expresa, por ejemplo, que no puede ocurrir crecimiento de iglesia sin el activo liderazgo del pastor. "Si usted es líder de una congregación cristiana, tiene que participar activamente en su crecimiento, o de lo contrario, buscar a otra persona para que la dirija". ${ }^{22}$

Para Yonggi Cho "el crecimiento de la iglesia se basa en algo más que una serie de ideas y principios que al ponerlos en práctica hacen que la iglesia crezca en número automáticamente". ${ }^{23}$ Menciona que es básica la filosofía espiritual, de manera particular la condición del corazón del líder, "pues es allí donde tiene que comenzar el crecimiento de la iglesia". ${ }^{24}$

${ }^{20} \mathrm{C}$. Peter Wagner, Sus dones espirituales pueden ayudar a crecer a su iglesia (Barcelona: Editorial Clie, 1980), 7.

${ }^{21}$ David Yonggi Cho, ha gastado más de 44 años haciendo hincapié en la importancia del ministerio de células, lo que él cree que es la clave del crecimiento de la iglesia, así como equipo ministerial. En noviembre de 1976, Cho fundó Crecimiento de la Iglesia Internacional, una organización dedicada a la enseñanza de los principios de la evangelización y crecimiento de la iglesia a los pastores de todo el mundo. 11.

${ }^{22}$ David Yonggi Cho, Mucho más que números (Miami, FL: Editorial Vida, 1985),

\section{${ }^{23}$ Ibíd., 7.}

${ }^{24}$ Cho, 7 . 
Asimismo, menciona que la iglesia puede crecer de manera dinámica si el pastor o líder "considera a los laicos como asociados potenciales capaces de dar testimonio y de constituirse en extensiones de su propio ministerio". ${ }^{25}$

Rick Warren ${ }^{26}$ enfoca su estudio en el propósito de la iglesia, aunque parte de un enfoque humanista de iglecrecimiento. La iglesia debe tener un propósito, de lo contrario no habrá crecimiento. "No hay nada que preceda al propósito. El punto de partida para todas las iglesias debe ser la pregunta: ¿Para qué existimos? Hasta no saber para qué existe su iglesia, usted no tiene fundamento, ni motivación, ni dirección en su ministerio". ${ }^{27}$ Es importante tener claro el fundamento correcto de una nueva iglesia que después modificarlo cuando la iglesia ya existe por años.

Christian Schwarz, ${ }^{28}$ después de un estudio minucioso, realizado en cinco continentes, comprobó que existen ocho características de una iglesia saludable: Liderazgo capacitador, ministerios según dones, espiritualidad ferviente, estructuras

\section{${ }^{25}$ Cho, 34 .}

${ }^{26}$ Rick Warren, es el fundador y actual autoridad pastoral de la Iglesia Saddleback Church, localizada en Lake Forest, California, siendo esta una de las ocho congregaciones más grandes de los Estados Unidos en la actualidad. Él es también uno de los autores de libros cristianos mejor vendidos, incluyendo su guía de evangelismo y ministerio de la iglesia "Una iglesia con propósito", que ha desencadenado una serie de conferencias sobre evangelismo y ministerios cristianos.

${ }^{27}$ Rick Warren, Una iglesia con propósito (Miami, FL: Editorial Vida, 1998), 88.

${ }^{28}$ La iglesia occidental ha estado expuesta a las teorías de iglecrecimiento, cuyo proponente principal ha sido C. Peter Wagner. Los principios que propone son el fruto de la observación de algunas "super" mega-iglesias alrededor del mundo, las cuales no representan siquiera $0,1 \%$ de la totalidad de congregaciones sobre la faz de la tierra. Es precisamente esta anomalía la que llevó a Christian Schwarz a un exhaustivo estudio de más de 1.000 iglesias, de una gran diversidad de grupos y denominaciones, en treinta y dos países a lo largo y ancho de los cinco continentes. Los principios que descubrió echan por tierra muchas de las teorías de iglecrecimiento. Su estudio contempla el crecimiento en calidad y no solamente numérico. 
funcionales, culto inspirador, células integrales, evangelismo según las necesidades y relaciones afectivas. ${ }^{29}$ Estas ocho características, según su investigación, serían los principios del iglecrecimiento.

Bruce Grubbs $^{30}$ habla de crecimiento de iglesia a través de diferentes aspectos. Menciona el crecimiento a través del Liderazgo pastoral, del establecimiento de prioridades, por medio de la predicación y adoración eficaces, de un ministerio evangelizador, entre otros. ${ }^{31}$ En su introducción menciona claramente que los hermanos que anhelan ver crecer a la iglesia deben tener visión de lo que Dios espera, "visión de las ricas posibilidades dentro de la congregación actual y visión de lo que puede llegar a ser en el futuro". ${ }^{32}$

Asimismo, Juan Wagenveld ${ }^{33}$ habla de un crecimiento integral de la iglesia. Su definición es interesante: "El iglecrecimiento es el estudio de los principios bíblicos que

${ }^{29}$ Christian A. Schwarz, Desarrollo natural de la iglesia: Ocho características básicas de una iglesia saludable (Barcelona: Editorial Clie, 1996), 79.

${ }^{30}$ Bruce Grubbs, utiliza su pasión para ayudar a las iglesias a descubrir y perseguir la visión de Dios para su ministerio. Trabaja con el liderazgo de la iglesia para articular, desarrollar y lograr su visión del reino y la gloria de Dios.

${ }^{31}$ Bruce Grubbs, Mi iglesia puede crecer (Buenos Aires: Casa Bautista de Publicaciones, 1985), 3.

${ }^{32}$ Grubbs, 4.

${ }^{33}$ Juan Wagenveld, estudió Teología en Dordt College, Misiones e Iglecrecimiento en Calvin Theological Seminary y cursó sus estudios de doctorado de ministerio en misiología en Trinity Evangelical Divinity School, Chicago. Fue profesor de Iglecrecimiento y Misiones en un seminario teológico de San Juan y forma parte del profesorado internacional de FLET. Wagenveld cree que el crecimiento o estancamiento de la iglesia ocurre en el contexto de las dinámicas que influyen en el desarrollo de una congregación. En su libro Iglecrecimiento integral, nos guía a fin de que podamos comprender esas dinámicas y así ponerlas en práctica para el crecimiento integral de la Iglesia local. Sin embargo, no solo escribe acerca del tema como resultado de sus estudios e investigaciones, sino que plasma en esta obra su propia experiencia pastoral. 
conducen al crecimiento integral de la iglesia según los propósitos de Dios. Partiendo de la Biblia y usando toda disciplina disponible". ${ }^{34}$ La Biblia es el punto de partida y se arraiga en los propósitos de Dios para su iglesia. El crecimiento que se busca "debe de ser integral en el sentido más amplio de la palabra". ${ }^{35}$

Pedro Larson ${ }^{36}$ destaca que crecimiento de iglesia es una dinámica espiritual de la vida en Cristo, “en la cual Dios es el autor y el actor principal. Él hace, mueve y produce vidas transformadas". ${ }^{37}$ Además menciona que el crecimiento es una estructura bíblicoteológica con praxis misionera. Que es una ciencia misiológica "a la cual llamamos iglecrecimiento". Y que finalmente es un fenómeno socio-institucional, "en el cual se estudian las iglesias como instituciones humanas". ${ }^{38}$

\section{Factores de crecimiento particulares}

En esta sección, se considera cuatro factores que pueden estar impactando a la iglesia y produciendo un crecimiento significativo. Los factores a definir son: Los administrativos, evangelísticos, pastorales y estructurales.

${ }^{34}$ Juan Wagenveld, Iglecrecimiento integral (Miami, FL: Editorial Unilit, 2000), 20.

${ }^{35}$ Ibíd., 21.

${ }^{36}$ Pedro Larson, profesor de Iglecrecimiento y Misiones, Seminario Teológico Bautista Mexicano, 1978 a 1999. Miembro del equipo de VELA (Visión Evangelizadora de América Latina), 1986 al 1999. Coordinador de la filial de IMDELA/MEXICO (Instituto Misionológico de las Américas) en su programa de maestría en misionología urbana, 1996 a 1999.

${ }^{37}$ Pedro A. Larson, Crecimiento de la iglesia (Buenos Aires: Casa Bautista de Publicaciones, 1989), 22.

${ }^{38}$ Ibíd. 


\section{Administrativos}

La elección de los siete diáconos fue una característica notable del desarrollo de la organización de la iglesia (Hch 6:1-7). "Hasta ese momento había funcionado bajo la dirección de hombres que se distinguían por tener dones del Espíritu”, ${ }^{39}$ pero ahora los apóstoles convocan a la multitud de discípulos para distribuir responsabilidades y atender mejor a la iglesia. Es decir, dotar a la iglesia de una estructura administrativa inicial.

\section{Los apóstoles}

Los apóstoles estaban a la cabeza de todos aquellos hombres que habían sido elegidos y trabajaban en la misión de la iglesia. Se puede decir que los líderes de la organización en aquellos días eran los apóstoles. Se ve el ejercicio de su autoridad en el reproche a Ananías y Safira (Hch 5:1-10), en la elección de los siete que ya se ha mencionado y "el envío de Felipe, Pedro y Juan y la forma en que fueron supervisados". ${ }^{40}$ (Hch 8:5,14). Estos siervos de Dios cumplían una obra administrativa en la iglesia y eran llamados ancianos pues se desempeñaban de esa manera (Hch 11:29, 30; $15: 2)$.

El liderazgo de los apóstoles es reconocido e inequívoco. En el sentido más restringido, los apóstoles fueron los doce designados por el mismo Jesús (Mt 10:1-4), Matías, que reemplazó a Judas, y Pablo. En el sentido más amplio también se aplica a Bernabé (Hch 14:1), Santiago (Gá 2:9), Andrónico y Junias (Ro 16:7). En la organización en desarrollo que era la iglesia, los doce y también Pablo ocupan una posición singular de

${ }^{39}$ Francis D. Nichol, ed. Comentario bíblico adventista (Buenos Aires: Asociación Casa Editora Sudamericana, 1996), 6:28; en adelante CBA.

${ }^{40}$ Nichol, ed. $C B A, 6: 28$. 
autoridad. Ellos, junto con los profetas, son el cimiento sobre el cual se edifica la iglesia, siendo Jesús la piedra angular (Ef 2:20). ${ }^{41}$

\section{Los administradores de campo}

En la actualidad, los líderes de una zona geográfica de la iglesia son llamados administradores de campo. Está conformado por el presidente, el secretario y el tesorero. Ellos “deben llevar adelante la obra en consulta mutua, conforme a los planes, reglamentos y programas votados por la Junta Directiva de la Unión, por el congreso y/o por la Junta Directiva de la Asociación”. ${ }^{42}$ Ellos tomarán decisiones importantes, basados en el propósito que tiene la iglesia:

Comunicar el evangelio eterno del amor de Dios, en el contexto del mensaje de los tres ángeles de Apocalipsis 14:6 al 12, conforme está revelado en la vida, muerte, resurrección y ministerio sacerdotal de Jesucristo, invitándolas a aceptar a Jesús como su Salvador personal y a unirse a su iglesia, asistiéndolas y edificándolas espiritualmente en preparación para su pronto retorno. ${ }^{43}$

Asimismo, ellos tienen ciertas atribuciones que cumplir, que el Reglamento

Eclesiástico específica:

Atribuciones del presidente

El presidente de la Asociación será un ministro ordenado de experiencia. Es el primer administrador, el representante oficial responsable por mantener el tono espiritual en toda la Asociación. Trabajará en armonía con la Junta Directiva de la Unión y en

${ }^{41}$ Raoul Dederen, ed. Teología: Fundamentos bíblicos de nuestra fe, (Miami, FL: Asociación Publicadora Interamericana, 2007), 5:224-225.

${ }^{42}$ División Sudamericana, Reglamentos eclesiástico-administrativos, 218.

${ }^{43}$ Ibíd., 224. 
estrecho consejo con sus administradores. ${ }^{44}$

Atribuciones del secretario

El secretario es responsable ante la Junta Directiva de la Unión y la Junta

Directiva y el congreso de la Asociación, en consulta y juntamente con el presidente y el tesorero. Preparará la agenda para las sesiones de la Junta Directiva y del congreso de la Asociación, así como los informes estadísticos que le sean requeridos. Coordinará la redacción y conservación de las actas de los congresos de la Asociación, de las sesiones de la Junta Directiva y enviará copia a los miembros y administradores de la Unión. ${ }^{45}$

Atribuciones del tesorero

Es responsable ante la Junta Directiva de la Unión y de la Junta Directiva y el congreso de la Asociación, en consulta y juntamente con el presidente y el secretario. Será el responsable de imprimir la debida dirección financiera a la Asociación, lo cual incluye, pero no se limita a recibir, salvaguardar y distribuir todos los fondos en armonía con los votos de la Junta Directiva; enviará a la Unión o División, en tiempo y forma, todos los fondos requeridos en armonía con el reglamento de la División; proveerá al presidente y a la Junta Directiva toda la información que le sea solicitada. ${ }^{46}$

Por otro lado, se puede manifestar que de la prudente y acertada conducción de los administradores depende mucho el avance de la iglesia en la zona que les toca conducir. Como misioneros, no han olvidado que su sagrada responsabilidad es predicar

\footnotetext{
${ }^{44}$ División Sudamericana, Reglamentos eclesiástico-administrativos, 218.

${ }^{45}$ Ibíd., 219.

${ }^{46}$ Ibíd.
} 
el evangelio y ser protagonistas del crecimiento de la iglesia. El ambiente de cordialidad, amistad y compañerismo cristiano con los pastores distritales y la feligresía, contribuyen para que la obra prospere y se tenga iglesias saludables con miembros dispuestos a colaborar en la evangelización de estos tiempos.

Una administración involucrada en el trabajo misionero, tan igual como los apóstoles en la época de la iglesia primitiva, redundará en la motivación del pastor. Sus feligreses serán guiados a cumplir la misión y la iglesia crecerá producto de la bendición de Dios.

También es importante mencionar lo que destaca Veloso: "la administración de los distintos niveles de la iglesia debe mantener siempre presente la necesidad de proveer los medios necesarios para el desarrollo espiritual de los miembros de iglesia". ${ }^{47}$ Entre los elementos que se pueden utilizar para el desarrollo espiritual corporativo de la iglesia, están los congresos, los retiros espirituales, las reuniones campales y otras. ${ }^{48}$

\section{Organización de la Iglesia}

La IASD funciona como una entidad con ramificaciones en el mundo entero. Las iglesias locales están agrupadas en asociaciones o misiones. A su vez las asociaciones o misiones forman uniones, generalmente creadas en función de alineamientos nacionales, étnicos o lingüísticos. Las uniones están agrupadas en divisiones, las que funcionan como extensión de la Asociación General de los Adventistas del Séptimo Día. ${ }^{49}$

${ }^{47}$ Mario Veloso, Teología de la administración eclesiástica (Brasilia: Seminario Adventista Latinoamericano de Teología, 1982), 57.

${ }^{48}$ Veloso Teología de la administración eclesiástica, 57.

${ }^{49}$ Raoul Dederen, ed. Teología: Fundamentos bíblicos de nuestra fe (Miami, FL: 
La Asociación General de la Iglesia Adventista tiene las siguientes 13 divisiones: $:^{50}$ (1) División Africana Occidental, (2) División Asia Pacífico del Norte, (3) División Asia Pacífico del Sur, (4) División África-Océano Índico, (5) División África Central Oriental, (6) División Pacífico Sur, (7) División Euroafricana, (8) División Euroasiática, (9) División Interamericana, (10) División Norteamericana, (11) División Sudamericana, (12) División Sudasiática, (13) División Transeuropea.

El gobierno de la Iglesia es representativo en todos los niveles. Las iglesias locales envían representantes a los congresos de la Asociación o Misión. Los representantes de Asociación o Misión contribuyen en las decisiones a nivel de Unión. Las juntas de divisiones tienen representación de las uniones que las componen. La junta de la Asociación General cuenta con representación de las divisiones. ${ }^{51}$

Las decisiones que se efectúan en cada nivel, es a través de juntas integradas por los administradores (presidente, secretario y tesorero), representantes de los departamentos e instituciones de la iglesia y miembros de iglesia. ${ }^{52}$

Se puede decir que la estructura administrativa y organizativa de la iglesia fue provista por Dios para el crecimiento de la misma en todas sus áreas.

\section{Evangelísticos}

La feligresía de la iglesia cumple la predicación del evangelio a través del evangelismo personal y el evangelismo público. Uno está ligado al otro, no pueden estar

Asociación Publicadora Interamericana, 2005), 1:77.

50“'Office of Archives, Statistics, and Research", http://www.adventiststatistics.org (consultado: 10 de mayo, 2015).

${ }^{51}$ Raoul Dederen, ed. Teología: Fundamentos bíblicos de nuestra fe, 1:77.

${ }^{52}$ Dederen, 78. 
separados. Esta obra debe realizarse teniendo en cuenta lo que menciona las Sagradas

Escrituras.

\section{Cristo y Pablo}

Los evangelios muestran la obra personal que realizaba Jesús (Lc 19:10), incluso en la atención a las multitudes (Mt 5:1). Su método es el más eficaz y con certeza los que trabajan siguiendo su ejemplo tendrán gran éxito.

Jesús llegó al contacto personal con los hombres. Él no se mantenía alejado y apartado de los que necesitaban su ayuda. Entró en los hogares de los hombres, confortando al doliente, sanando al enfermo, elevando al despreciado, yendo aquí y allá haciendo el bien. Y si nosotros seguimos en las pisadas de Jesús, debemos hacer lo que él hizo. Debemos dar a los hombres la misma clase de ayuda que él les dio. ${ }^{53}$

Es muy importante el trabajo de casa en casa, razonando y explicando la Palabra.

Los obreros que sigan los métodos de Cristo ganarán almas como salario. ${ }^{54}$ La obra de Cristo se realizaba mayormente por medio de entrevistas personales. Eximía una fiel consideración al auditorio de un alma. Por medio de un alma, a menudo el evangelio se extendía a millares de personas. ${ }^{55}$

El método que usó Cristo para presentar la verdad no se puede mejorar. El obrero que trata de introducir diversos métodos para llegar a los de mentalidad mundana, suponiendo que así logrará evitar las objeciones para aceptar la cruz, debilita su influencia. Se debe perseverar en la sencillez de la piedad y Dios bendecirá su obra. ${ }^{56}$

${ }^{53}$ Elena G. de White, El ministerio de la bondad (Buenos Aires: Asociación Casa Editora Sudamericana, 1976), 64.

${ }^{54}$ White, El ministerio de la bondad, 64.

${ }^{55}$ Ibíd., 64-65.

${ }^{56}$ Elena G. de White, Cada día con Dios (Buenos Aires: Asociación Casa Editora 
Es importante destacar también textualmente lo que menciona Elena G. de White respecto a esto: "Sólo el método de Cristo será el que dará éxito para llegar a la gente. El Salvador trataba con los hombres como quien deseaba hacerles bien. Les mostraba simpatía, atendía a sus necesidades y se ganaba su confianza. Entonces les decía: "Seguidme". 57

Rick Warren menciona que una de las características impresionantes del ministerio de Jesús era que atraía a las multitudes. Su ministerio tenía una cualidad magnética. ${ }^{58}$ Él amaba a los perdidos y le gustaba pasar tiempo con ellos. Disfrutaba más estar con ellos, que con los líderes religiosos. La gente percibía que a Jesús le encantaba estar con ellos. Incluso los niños pequeños querían estar cerca de él. "Amar a los incrédulos como lo hizo Jesús, es la llave para el crecimiento de la iglesia que más se pasa por alto". 59

Asimismo, se puede observar en el ministerio del apóstol Pablo, el evangelismo personal y público. Hch 20:20 expresa lo siguiente: “y cómo nada que fuera útil he rehuido de anunciaros y enseñaros, públicamente y por las casas”. Este siervo de Dios tenía claro que "la obra personal no ocupaba el lugar del evangelismo público, sino que era su compañera indispensable". ${ }^{60}$

Sudamericana, 1979), 185.

${ }^{57}$ Elena G. de White, Consejos sobre el régimen alimenticio (Buenos Aires: Asociación Casa Editora Sudamericana, 2008), 551.

${ }^{58}$ Rick Warren, Una iglesia con propósito (Miami, FL: Editorial Vida, 1998), 215.

${ }^{59}$ Warren, Una iglesia con propósito, 216.

${ }^{60}$ Nichol, ed., $C B A, 6: 386$. 
Pablo seguía de cerca el modelo de Jesús, definido por el profeta: "No quebrará la caña cascada" (Isa 42:1-3). La adaptabilidad es una de las cualidades más útiles que puede cultivar un siervo de Dios. "Le ayuda a trabajar como Jesús trabajaba: en los hogares de los pobres e ignorantes, entre los mercaderes y comerciantes en los lugares públicos, en los banquetes y diversiones de los ricos, y en su conversación con los sabios". ${ }^{61}$

Pablo realizó sus viajes misioneros siguiendo la instrucción de Cristo de ir de dos en dos. A veces iban Pablo, Bernabé y Marcos, otras veces se lo encuentra con Silas. Ellos no sólo querían discipular individuos sino también querían llegar a toda una comunidad. "La iglesia primitiva practicaba el ministerio en equipo. No había obreros solos en las iglesias del siglo I, porque la evangelización siempre se hacía en comunidad, como Jesús ordenó”. ${ }^{62}$

\section{La iglesia}

Cuando la iglesia no descuida ninguna de las dos obras, entonces con certeza Dios bendecirá sus esfuerzos evangelísticos. La iglesia primitiva creció así, obra personal y obra pública. Hubo un proceso interesante y significativo, luego vinieron los resultados. Pedro predicó y se bautizaron como tres mil personas (Hch 2:41). Después cinco mil hombres (Hch 4:4), y Lucas sigue narrando que "aumentaban más, gran número de hombres y mujeres" (Hch 5:14). Una es la consecuencia de la otra. Los corazones son tocados en las casas y confirmados en el evangelismo público.

${ }^{61}$ Nichol, ed., $C B A, 6: 386$.

${ }^{62}$ Russell Burrill, La iglesia revolucionada del siglo XXI (Buenos Aires: Asociación Casa Editora Sudamericana, 2007), 71. 
La iglesia debe proclamar el mensaje en los grandes caminos de la vida, como en los senderos perdidos. Los miembros deben hacer obra de evangelización entre sus vecinos, llegar a aquellos que todavía no han conocido la verdad para estos tiempos. ${ }^{63}$

Hay que tener en cuenta que, así como el padre envió al hijo al mundo, así él envió a sus discípulos (Jn 20:21). La tarea principal siempre ha sido llevar el evangelio de Jesucristo hasta el último rincón del mundo. A los miembros de iglesia se los ha llamado a salir del mundo, para ser enviados nuevamente al mundo con una misión y un mensaje. “El llamamiento a la evangelización surge del mandato inequívoco del Señor de la iglesia". ${ }^{64}$

Por otro lado, Stedman agrega que la humildad, la paciencia, el amor, la unidad y la paz son las verdaderas huellas de Jesús. La iglesia no tiene por qué hablar de sí misma, sino que tiene que ser humilde y no presumida. "La iglesia no puede salvar al mundo, pero el Señor de la iglesia sí puede hacerlo”. Asimismo la iglesia tiene que ser paciente y comprensiva, conociendo que las semillas de la verdad toman su tiempo antes de florecer, de crecer y de estar listas para la cosecha. ${ }^{65}$

Es importante también destacar lo que cita Mario Veloso de Elena G. de White, mencionando que la iglesia es una comunidad misionera: "la iglesia es el medio señalado por Dios para la salvación de los hombres. Fue organizada para servir, y su misión es la de anunciar el evangelio al mundo. Desde el principio fue el plan de Dios que su iglesia

${ }^{63}$ Elena G. de White, Testimonios selectos (Buenos Aires: Casa Editora Sudamericana, 1932), 5:149.

${ }^{64}$ Dederen, ed. Teología: Fundamentos bíblicos de nuestra fe, 5:218.

${ }^{65}$ Ray C. Stedman, La iglesia resucita (Barcelona: Editorial Clie, 1978), 31. 
reflejase al mundo en su plenitud y suficiencia". ${ }^{66}$

\section{Pastorales}

En esta parte se vieron tres aspectos significativos que todo pastor debe considerar en su trabajo, para el crecimiento de la iglesia. Pueden existir más aspectos, pero se describirá en esta sección solamente el liderazgo del pastor, la visión que debe tener y la importancia de la capacitación.

\section{Liderazgo del pastor}

El Espíritu Santo ha constituido líderes en su iglesia, "a fin de perfeccionar a los santos para la obra del ministerio" (Ef 4:11, 12). Del correcto uso de los dones otorgados por Dios, la iglesia será edificada saludablemente. No todos pueden ejercer la misma función, pero todos contribuyen para perfeccionar el cuerpo.

Aquí es oportuno destacar el trabajo pastoral. El desarrollo de una iglesia dependerá de la activa participación del pastor. "Sin el activo liderazgo del pastor, el crecimiento de la iglesia nunca puede ocurrir en realidad". ${ }^{67}$ Todo líder de congregación debe tener injerencia en el crecimiento de su iglesia, de lo contrario debe buscar otra persona que lo dirija. ${ }^{68}$ Por eso, debe empezar en él la obra de crecimiento que Dios produce en el corazón. Su actitud debe cambiar. “¿Cómo puede uno cambiar la actitud de su corazón? Tiene que examinar su visión. Si usted tiene una visión equivocada, o si la misma es demasiado reducida en relación con la capacidad que Dios le ha concedido, la

\footnotetext{
${ }^{66}$ Veloso, Teología de la administración eclesiástica, 27.

${ }^{67}$ Cho, 11 .

${ }^{68}$ Ibíd., 11.
} 
actitud de su corazón también será incorrecta, y usted se sentirá desanimado, perplejo y deprimido". 69

Peter Wagner, teólogo evangélico egresado de la Escuela de Misiones del Fuller Theological Seminary, añade respecto a este asunto lo siguiente: "El signo vital número uno de una iglesia sana y próspera es un pastor que es un pensador posibilista y cuyo liderazgo dinámico ha sido usado para catalizar la iglesia en masa en acción para el crecimiento". 70

Schuller destaca que la dirección del pastor es primordial y requiere mucha responsabilidad. No se la puede considerar a la ligera, ni dejar "en manos de quienes no estén dispuestos a considerar a la iglesia como el asunto más importante de su vida". ${ }^{71}$ Como sucede para el encendido de un motor, el pastor debe ser la bujía de encendido. "El capitán y estratega que conduzca a las tropas monte arriba". ${ }^{72}$

Asimismo, los hombres de crecimiento de iglesia, "son gente que tiene la capacidad de generar entusiasmo. Estos líderes son agentes de cambio con un don especial para vislumbrar las necesidades de la iglesia y la comunidad, y tienen la habilidad de visualizar los ministerios que pueden atender esas necesidades y utilizar los dones que tiene la iglesia para implementar esos ministerios". ${ }^{73}$ Son siervos que brindan

${ }^{69}$ Cho, 12 .

${ }^{70}$ Wagner, Su iglesia puede crecer, 71.

${ }^{71}$ Robert H. Schuller, Su iglesia tiene posibilidades (Barcelona: Editorial Clie, 1976), 72 .

${ }^{72}$ Schuller, 72.

${ }^{73}$ Isabel y Daniel Rode, Crecimiento: Claves para revolucionar su iglesia (Buenos Aires: Asociación Casa Editora Sudamericana, 2003), 20. 
permanente formación a los miembros de iglesia, con el propósito de lograr su desarrollo y ellos puedan cumplir sus objetivos de misión. ${ }^{74}$

En muchos lugares, los pastores son claves para el crecimiento de la iglesia. Dios puede usar poderosamente a estos hombres en el cumplimiento de la misión. Para esto, ellos deben tomar en cuenta la feligresía de la congregación, "la población o sociedad que les rodea, los problemas prioritarios, los programas que llegan a llenar necesidades sentidas, los propósitos específicos de la congregación y luego buscan las soluciones que permiten su crecimiento". ${ }^{75}$

\section{Visión}

Los ministros que desean que sus iglesias se desarrollen y avancen de manera sistemática, necesitan tener visión. Abraham es un buen ejemplo bíblico de esto (Gn 13: 14, 15). Él tuvo que llegar al punto de ver lo que Dios le estaba prometiendo. "Antes que Abraham comenzara a andar en conformidad con la promesa de Dios, él tenía que ver su cumplimiento. Antes que usted entre en una nueva dimensión de éxito en su vida y en su ministerio, tiene que tener ojos para ver ese éxito". ${ }^{76}$

Dios está muy interesado en conceder este éxito. El problema está en la visión equivocada que se ha tenido, una visión que no ha sido la adecuada, por cuanto no se ha entrado "en una profunda y amorosa comunión con el Espíritu Santo" ${ }^{77}$ Él debe cambiar la actitud del corazón, del fracaso al éxito. Al mirar con sus ojos sólo veremos victoria,

\footnotetext{
${ }^{74}$ Rode, Crecimiento, 20.

${ }^{75}$ Larson, 81.

${ }^{76}$ Cho, 18 .

${ }^{77}$ Ibíd, 20.
} 
nunca derrota. Se entenderá que el crecimiento es integral, es completo, no es sólo un área, es todo un conjunto de cosas. No se limita a lo numérico, es mucho más que números.

Todo líder debe saber a dónde quiere ir y contagiar su sueño a los demás. “Cuando el líder llega a entender la visión que Dios le ha dado para su congregación y la hace propia, viviendo, respirando y soñando la visión, entonces empieza la tarea de transicionar su estilo de liderazgo y su enfoque de guiar a sus líderes y su congregación hacia su propia transición". 78

Por otro lado, es importante destacar lo que menciona el Dr. Daniel Rode, teólogo adventista, en su libro: Estrategias para crecimiento de iglesia, habla de las características de la visión de Dios según Hemphill, que son muy importantes para todo líder que desea ver a su iglesia, misión o asociación crecer. Menciona lo siguiente: ${ }^{79}$ (1) la visión se origina en Dios, (2) la visión de Dios estará centrada en su Palabra y será apoyada por ella, (3) para traer una visión a la realidad tenemos que experimentar la investidura sobrenatural de poder, (4) La visión de Dios estará fundamentada en la gran comisión, (5) la visión guiará a la iglesia a exaltar a Cristo, (6) la visión requiere obediencia radical, (7) la visión lleva al crecimiento natural, (8) La visión demanda una disposición para cambiar, (9) la visión requiere la unidad familiar.

${ }^{78}$ Samuel Santana, Renovación, transición y fortalecimiento de las iglesias hispanas en Norte América (Connecticut: Fiel, 2007), 7.

${ }^{79}$ Daniel Julio Rode, Estrategias de crecimiento de iglesia (Buenos Aires: Seminario Adventista Latinoamericano de Teología, 1998), 56. 


\section{Capacitación}

La capacitación es una parte importante en este asunto de crecimiento de iglesia. Los ministros deben preocuparse de capacitar a sus feligreses, de tal manera que los motiven y los lleven a la acción. Ef 4:12 dice: "a fin de perfeccionar a los santos para la obra del ministerio, para la edificación del cuerpo de Cristo.” Es clara la tarea que menciona el apóstol Pablo aquí. Se debe “equipar a los demás para que éstos hagan la obra del ministerio. ¡Qué hermoso! El ministerio no es para unos pocos que puedan ser escogidos, sino que el ministerio es patrimonio de todos los discípulos. ¡Ninguno queda excluido! ¡Ninguno es demasiado inútil! ¡Ninguno está marginado!” ${ }^{80}$

Christian Schwarz, fundador y director del Instituto para el Desarrollo Natural de la Iglesia en Alemania, menciona que los responsables de crecimiento de iglesia, centralizan su trabajo en capacitar a otros para el servicio. Estos hombres "capacitan, apoyan, motivan a cada uno para que llegue a ser aquello que Dios ha previsto para él'" ${ }^{81}$ Estas capacitaciones demandan tiempo, esfuerzo y sacrificio, pero son grandemente recompensadas. El ministro debe estar dispuesto a entregarse con todas sus fuerzas.

De la misma manera, Miranda dice que "el pastor debe querer que la iglesia crezca, y estar dispuesto a pagar el precio". ${ }^{82}$ El ministro que desea ver a su iglesia crecer, debe trabajar fuertemente en este sentido. Tener una mente optimista y estar dispuesto a aprovechar todas las oportunidades que se presentan para crecer. ${ }^{83} \mathrm{Se}$

\footnotetext{
${ }^{80}$ Larson, 77.

${ }^{81}$ Schwarz, 22.

${ }^{82}$ Miranda, 52.

${ }^{83}$ Ibíd., 53.
} 
requiere invertir mucho tiempo en capacitar a la feligresía, esto significa pagar el precio.

Otro detalle muy importante que destacar en este asunto, es lo que menciona LeRoy Eims, director de evangelismo mundial para los Navegantes. Él habla del principio de la instrucción en el ministerio de Cristo. “Además de convertir a sus hombres en sus discípulos por medio de su compañía en la obra diaria del ministerio, Jesús también tuvo con ellos momentos especiales de instrucción”. ${ }^{84}$ (Mr 4:11).

Jesús los preparó para toda situación, para enfrentar la oposición y el rechazo $(\mathrm{Mr}$ 6:11). "Su entrenamiento ocurría donde la batalla escarnecía. En ciertas ocasiones, él apartaba a sus hombres para tener algunos momentos especiales juntos, pero su entrenamiento era mayormente en la práctica “mientras trabajaban”. Ellos estaban en el ministerio con él". ${ }^{85}$

\section{Estructurales}

En la actualidad, la IASD realiza evangelismo personal y público a través de los Grupos Pequeños. Cree firmemente que la obra de la predicación del evangelio terminará de la misma manera como comenzó. Asimismo, considera que el discipulado es un elemento muy importante en el cumplimiento de la gran comisión.

\section{Grupos pequeños}

Las Sagradas Escrituras presentan la organización del pueblo de Israel en grupos. Jetro, observó cómo atendía Moisés al pueblo. Todos venían delante de él y terminaba muy cansado. “¿Qué es esto que haces tú con el pueblo?” (Ex 18:14) fue la expresión del

${ }^{84}$ LeRoy Eims, El arte perdido de discipular (El Paso, TX: Editorial Mundo Hispano, 2008), 35.

${ }^{85}$ Eims, 36. 
suegro. Después de una breve conversación, el consejo que dio fue oportuno: "además escoge tú de entre todo el pueblo a hombres virtuosos, temerosos de Dios, hombres veraces, que aborrezcan la avaricia, y ponlos sobre el pueblo como jefes de mil, de cien, de cincuenta y de diez" (Ex 18:21).

La IASD cree también que la mejor manera de atender a las personas es organizándolas en grupos. El Grupo Pequeño es la expresión mínima de su organización y tiene claros objetivos: discipular y enviar a predicar (Mc 3:14).

Estos grupos están conformados por un promedio ${ }^{86}$ de ocho a doce personas que se reúnen una vez a la semana en los hogares, para confraternizar, testificar, estudiar la Biblia y orar. Han sido organizados en algunos casos de manera geográfica, otros por afinidad, por edad, o algún detalle especial según lo hayan decidido en la iglesia.

Algunos escritores consideran muy importante la organización de estos grupos para el crecimiento de la iglesia. Yonggi Cho, pastor de la iglesia protestante más grande del mundo, los llama grupos hogareños. Él dice: “Un grupo hogareño es el elemento básico de nuestra iglesia. No es otro programa de la iglesia; es el programa de nuestra iglesia. Tiene un tamaño limitado, que por lo general no pasa de quince familias. Tiene una meta definida" ${ }^{87} \mathrm{Y}$ los líderes de estos grupos reciben por escrito los planes bien específicos y son preparados en su instituto bíblico.

Por otro lado, Jean-Pierre Besse, teólogo francés, considera a los grupos pequeños como células. Menciona que "la estructura celular forma la base de toda la iglesia local, como una integración total en el funcionamiento de la iglesia. Se transforma en el

\footnotetext{
${ }^{86}$ Este es un promedio que se maneja en la ANoP.

${ }^{87}$ Cho, 44-45.
} 
tejido..." ${ }^{88}$ Y sus líderes son conscientes de que su iglesia es como un cuerpo compuesto por células.

Asimismo, Emilio Abdala, otro teólogo adventista, opina que la principal justificación para los grupos pequeños es un retorno a las prácticas de la iglesia primitiva. Dice que los grupos pequeños florecerán debido a un sistema de valores y base teológica que da sustento a su programa. Adoptar una estructura de grupos pequeños por razones meramente organizacionales es perder el foco. De la misma forma, hay que tener en cuenta que los grupos pequeños ofrecen ventajas para el cumplimiento de la gran comisión y la salvación de las personas. ${ }^{89}$

Por otro lado, el Dr. Juan Carlos Miranda, fundador y director, desde 1976, del Departamento Hispano del Instituto de Evangelismo e Iglecrecimiento Charles E. Fuller, menciona que los grupos pequeños han significado para él la razón del crecimiento de su iglesia. Testificando de lo que ocurrió en Pasadena, destaca lo siguiente: "Estos grupos pequeños han sido la razón de nuestro crecimiento aquí en Pasadena. Es por medio de ellos que hemos ganado a nuevas personas para nuestra iglesia. Un 90\% de nuestra congregación ha llegado así. La mayoría se ha decidido por Cristo en los lugares que se reúnen estos grupos hogareños". ${ }^{90}$

${ }^{88} \mathrm{Jean}$-Pierre Besse, Células en casa para la iglesia en misión (Barcelona: Editorial Clie, 2001), 55.

${ }^{89}$ Emílio Abdala, "Os pequenos grupos na história do cristianismo". Pequenos grupos, grandes solucoes (Brasilia: Seminaro Adventista Latinoamericano de Teología, 2007), 37.

${ }^{90}$ Miranda, 63. 


\section{Discipulado}

Jesús manifestó claramente en la gran comisión la consigna de "hacer discípulos" (Mt 28:19). El centro de la misión de la iglesia es discipular, que la gente llegue a imitar a Jesús. Es la razón básica del trabajo misionero de la iglesia.

Craig Keener, profesor de estudios bíblicos del Seminario Teológico de Palmer en la Universidad de Eastern, dice que "la manera de hacer discípulos aquí tiene dos aspectos: (1) Bautizándolos. Debido a que el bautismo era un acto de conversión (usado para los gentiles que se convertían al judaísmo), significa iniciar a las personas en la fe. (2) Enseñándoles los mandamientos de Jesús registrados en Mateo. ${ }^{91}$

El Dr. Isidro Goma Civit, teólogo graduado en la Universidad Gregoriana, opina que "haced discípulos" tiene que ver con el resultado completo de la misión, no sólo con un aspecto de ella. Lo expresa de la siguiente manera: "Hacer discípulos señala el resultado completo de la Misión; no como otros términos del vocabulario misional que indican sólo un aspecto, o una fase incoactiva ("proclamar", "dar testimonio", “evangelizar”, etc.). Hacer discípulos es hacer Comunidad cristiana, hacer iglesia". 92

Otras de las cosas que se debe destacar del texto bíblico ya mencionado, es que en estos últimos años se ha reconocido que "ir" no es el verbo principal. "En realidad el único imperativo en Mt. 28:19 es el "haced discípulos", y las demás formas verbales son participios. Esto significa que la misión llega a ser fundamentalmente el "hacer

${ }^{91}$ Craig S. Keener, Comentario del contexto cultural de la Biblia (El Paso, TX: Editorial Mundo Hispano, 2006), 126, 127.

${ }^{92}$ Isidro Goma Civit, El evangelio según San Mateo (Madrid: Ediciones Marova, 1976), 2:715. 
discípulos". 93

Para David J. Bosch, erudito sudafricano de tradición reformada, "llegar a ser discípulo implica volverse decisiva e irrevocablemente hacia Dios y hacia el prójimo. A partir de allí es un peregrinaje que, en realidad, nunca termina en esta vida, un peregrinaje continuo de descubrir nuevas dimensiones del amor para con Dios y el prójimo, en la medida en que se va revelando el reino de Dios...".94 Asimismo, él manifiesta que "el llamado a los discípulos es a proclamar la victoria final de Jesús sobre el poder de la maldad, a testificar de su presencia permanente y a llevar al mundo hacia el reconocimiento del amor de Dios". 95

Según Bruno Raso, actual vicepresidente de la DSA, el “hacer discípulos” tiene que ver con el centro mismo del cometido misional. Está establecido en tono imperativo y tiene un sentido de urgencia. Las expresiones traducidas como "id", "bautizándolos" y “enseñándoles”, manifiestan acciones en ascenso, dependientes y simultáneas con el verbo principal: "haced discípulos". 96

El discipulado es un concepto clave en el libro de Mateo. De los evangelios sinópticos, el que más utiliza esta palabra es Mateo, unas 73 veces. En Marcos se lo encuentra unas 46 veces y en Lucas 37. Se puede notar que Mateo está interesado en

${ }^{93}$ John Corrie, "Mateo 28:16-20: La misión y el discipulado”, Kairós, juliodiciembre 2002, 28.

${ }^{94}$ David J. Bosch, Misión en transformación: Cambios de paradigma en la teología de la misión (Grand Rapids, MI: Libros Desafío, 2000), 111.

${ }^{95}$ Bosch, Misión en transformación, 112.

${ }^{96}$ Bruno Raso, “Un estudio de factores personales, eclesiásticos, pastorales y comunitarios que inciden sobre la misión de hacer discípulos" (Tesis doctoral, Seminario Adventista Latinoamericano de Teología, 2004), 19. 
definir quién es un discípulo de Jesucristo. Y los discípulos "son todos los que siguen la enseñanza de Jesús".97

Este capítulo ha presentado las diferentes perspectivas de crecimiento de iglesia. Cada autor presenta la esencia de sus estudios realizados, y en algunos casos muestran la experiencia por la cual pasaron. Asimismo, se han destacado algunos conceptos bíblicos de iglecrecimiento que son la base del desarrollo de la iglesia. Y se han desarrollado los posibles factores de crecimiento en la ciudad de Trujillo: administrativos, evangelísticos, pastorales y estructurales.

${ }^{97}$ Raso, 19. 


\section{CAPÍTULO 4 METODOLOGÍA}

\section{Tipo de investigación}

La presente investigación es de tipo histórico sincrónico-descriptivo y explicativo, pues tuvo el objetivo de verificar los factores administrativos, evangelísticos, pastorales y estructurales (variables independientes) que influyeron en el crecimiento de la IASD en la ciudad de Trujillo (variable dependiente), durante el período del 2001-2009.

Es histórico, porque buscó revisar el pasado de la manera más objetiva y exacta posible. De manera sistemática se verificó y sintetizó evidencias que permitieron obtener conclusiones válidas, derivadas de la hipótesis.

Es sincrónico-descriptivo, porque puntualizó los factores que influyeron en el crecimiento de la iglesia en Trujillo, en un momento dado, en un tiempo concreto.

Es explicativo, porque no sólo persiguió describir o acercarse al problema, sino que intentó encontrar las causas del mismo.

\section{Diseño de la investigación}

Para concretar este estudio se utilizó el diseño no experimental, transversal o transeccional, que involucró recolectar datos en un tiempo determinado sin intervenir en la labor pastoral en sus respectivas iglesias. Para ello, se tomó en cuenta los informes y cuadros comparativos que tiene secretaría y tesorería de la ANoP entre el 2001-2009. 


\section{Población y muestra}

La población estuvo compuesta por 522 miembros de las juntas directivas de 16 distritos misioneros escogidos de los 18 de la ciudad de Trujillo, con sus respectivos pastores. La muestra de este estudio fue representativa, no probabilístico, conformado por 244 feligreses. La selección de la muestra se hizo de manera directa a los que participaron en la encuesta, de las principales iglesias de Trujillo, miembros representativos (integrantes de junta directiva) que antecedieron y vivieron durante el período de estudio, pastores del período en estudio, administradores y ex administradores, por ajustarse mejor a los objetivos de la presente investigación. La muestra fue de 244 personas, que se determinó según la fórmula propuesta por Munich, Lourdes y Ángeles, Ernesto. ${ }^{165}$

La presente fórmula se utiliza para calcular el tamaño de la muestra en trabajos de investigación educacional y en ciencias sociales:

$$
n=\frac{N * Z_{\alpha}^{2} * p * q}{(N-1) * e^{2}+Z_{\alpha}^{2} * p * q}
$$

En donde:

Z= Nivel de confianza (1,96 tabla de distribución normal para el 95\% de confiabilidad).

$\mathrm{N}=$ Población

$\mathrm{p}=$ Probabilidad a favor $(0.10)$

$q=$ Probabilidad en contra (0.90)

${ }^{165}$ Lourdes Munich, Ernesto Ángeles, Métodos y técnicas de investigación (México: Trillas, 1990), 166. 
$\mathrm{e}=$ Error de estimación $(4,5 \%=0,045)$

$\mathrm{n}=$ Tamaño de la muestra

Realizando las operaciones tenemos:

$$
\mathrm{n}=\frac{522 * 1,96^{2} * 0,5 * 0,5}{521 * 0,0459^{2}+1,96^{2} * 0,10 * 0,90} \quad n=243,59 \approx 244
$$

Unidades Intermedias

Las unidades intermedias están compuestas por 16 distritos misioneros de los 18 de la ciudad de Trujillo. La tabla 10 describe las unidades intermedias escogidas aleatoriamente.

Tabla 10. 16 distritos misioneros de Trujillo

\begin{tabular}{lll}
\hline $\mathrm{N}^{\mathrm{o}}$ & DISTRITO & MIEMBROS JUNTAS DIRECTIVAS \\
\hline 1 & Trujillo Central & 37 \\
2 & Trujillo Chimú & 33 \\
3 & Trujillo Florencia de Mora & 35 \\
4 & Trujillo Santa Isabel & 29 \\
5 & Trujillo Quintanas & 33 \\
6 & Trujillo Esperanza "A" & 35 \\
7 & Trujillo Esperanza "B" & 31 \\
8 & Trujillo Esperanza "C" & 33 \\
9 & Trujillo Porvenir "A" & 35 \\
10 & Trujillo Porvenir "B" & 33 \\
11 & Trujillo Laredo & 31 \\
12 & Trujillo Platanar & 29 \\
13 & Trujillo Palermo & 33 \\
14 & Trujillo Víctor Larco & 31 \\
15 & Trujillo Moche & 33 \\
16 & Trujillo Virú & 31 \\
\hline & TOTAL GENERAL & 522 \\
\hline
\end{tabular}

Unidades primarias

Las unidades primarias están formadas por las 244 personas seleccionadas entre miembros de juntas directivas de las principales iglesias de Trujillo, miembros de iglesia 
activos por lo menos cinco años antes del período en estudio y durante el período, pastores del período en estudio, administradores y ex administradores.

\section{Descripción del instrumento}

Se elaboró una encuesta para obtener información básica y fidedigna de los feligreses, en cuanto al crecimiento de la iglesia en los períodos ya mencionados. Asimismo, se aplicó la prueba de confiabilidad de Alfa de Cronbach y se obtuvo un índice de 0.7. Esto indica que el instrumento es confiable (ver apéndice 3).

\section{Recolección de datos}

Las encuestas se realizaron entre los meses de junio y julio del 2013, con la ayuda de los pastores distritales. Ellos reunieron a los miembros de la junta directiva de su iglesia principal en su respectivo templo y les aplicaron la encuesta preparada. Además, se realizó un estudio de los datos estadísticos de la ANoP, relacionados con cantidad de pastores, misioneros, bautismos, feligresía, número de distritos, etc., que obran en los archivos de la Secretaría.

\section{Análisis de los datos}

El análisis de los datos es de tipo cuantitativo, a través de la estadística descriptiva (frecuencia de cada pregunta y la revisión de los datos registrados por la secretaría de la ANoP). Además, para conocer el resultado de este análisis se utilizó el programa SPSS, que permite al investigador realizar análisis y gráficos estadísticos sin tener que conocer la mecánica de los cálculos ni la sintaxis de los comandos del sistema.

Asimismo, se realizó análisis con tablas de frecuencias, tablas porcentuales, tablas comparativas, gráficos de series de tiempo, gráficos de barras y gráficos de sectores. 


\section{Consideraciones éticas}

Este trabajo cumple las características de una investigación de carácter

académico; por lo tanto, guarda la debida confidencialidad de las personas y entidades

involucradas.

\section{Definición y operacionalización de las variables}

Tabla 11. Operacionalización de las variables

\begin{tabular}{|c|c|c|c|}
\hline Variables & Conceptualización & Dimensiones & Indicadores \\
\hline $\begin{array}{l}\text { Crecimiento de } \\
\text { los distritos } \\
\text { misioneros en la } \\
\text { ciudad de } \\
\text { Trujillo durante } \\
\text { el período del } \\
2001-2009 .\end{array}$ & $\begin{array}{l}\text { Determinar en qué medida } \\
\text { los factores } \\
\text { administrativos, } \\
\text { evangelísticos, pastorales y } \\
\text { estructurales influyeron en } \\
\text { el crecimiento de la IASD } \\
\text { en la ciudad de Trujillo } \\
\text { entre los años } 2001 \text { al } \\
2009 \text {. }\end{array}$ & $\begin{array}{l}\text { 1. Número de } \\
\text { distritos } \\
\text { 2. Número de } \\
\text { bautismos } \\
\text { 3. Diezmos y } \\
\text { ofrendas }\end{array}$ & $\begin{array}{ll}\text { 1. } & \text { Registro de } \\
\text { secretaría de la } \\
\text { ANoP } \\
\text { 2. Registro de } \\
\text { tesorería de la } \\
\text { ANoP }\end{array}$ \\
\hline $\begin{array}{l}\text { Factores: } \\
\text { Administrativos } \\
\text { Evangelísticos } \\
\text { Pastorales } \\
\text { Estructurales }\end{array}$ & $\begin{array}{l}\text { Administrativos: } \\
\text { 1. La sede de la MNP en } \\
\text { Trujillo facilitó o no el } \\
\text { crecimiento de los } \\
\text { distritos misioneros } \\
\text { entre el 2001-2009. } \\
\text { 2. Acciones } \\
\text { administrativas que } \\
\text { influyeron en el } \\
\text { crecimiento de los } \\
\text { distritos misioneros en } \\
\text { Trujillo. } \\
\text { Evangelísticos: } \\
\text { 1. Énfasis evangelístico } \\
\text { entre el 2001 y } 2009 . \\
\text { 2. Tipos de campañas } \\
\text { evangelísticas que dio } \\
\text { mayor resultado en el } \\
\text { crecimiento de la } \\
\text { iglesia en Trujillo. } \\
\text { Pastorales: } \\
\text { 1. Liderazgo del pastor } \\
\text { como factor clave en el } \\
\text { crecimiento de los }\end{array}$ & $\begin{array}{l}\text { La contribución } \\
\text { de estos factores } \\
\text { en el crecimiento } \\
\text { de la IASD en la } \\
\text { ciudad de } \\
\text { Trujillo. }\end{array}$ & $\begin{array}{l}\text { Cuestionario sobre } \\
\text { los factores de } \\
\text { crecimiento } \\
\text { distrital de la IASD } \\
\text { en la ciudad de } \\
\text { Trujillo durante el } \\
\text { período del 2001- } \\
2009\end{array}$ \\
\hline
\end{tabular}


distritos de Trujillo

entre 2001-2009.

2. Características del

liderazgo espiritual que

se manifestó mucho

durante el período del

2001-2009.

Estructurales:

1. El rol que cumplieron

los GP durante el

período del 2001-2009

para el crecimiento de

la iglesia en Trujillo.

2. La formación de

nuevos discípulos

contribuyó o no para el

crecimiento de los

distritos de Trujillo

entre el 2001-2009. 


\section{CAPÍTULO 5}

\section{ANÁLISIS E INTERPRETACIÓN DE LOS RESULTADOS}

\section{Características de la muestra}

Se observa, en la tabla 12, información que describe la participación de las personas quienes formaron parte de la muestra para el estudio descriptivo de la investigación realizada. Con respecto al género de los entrevistados, el 43,9\% fueron mujeres y el 56,1\% fueron varones, líderes de las diferentes iglesias de los distritos misioneros encuestados. Las edades varían entre los 17 años y los 84 años y la mayoría está en el grupo de 17 a 30 años de edad con un 26,6\%.

El estado civil también fue una característica importante para el estudio, los casados representan el $62,3 \%$, los solteros el $32,8 \%$ y sólo el 4,9\% representado por otros.

Otra característica demográfica es la ocupación de los feligreses líderes en los distritos encuestados, el $21,7 \%$ son empleados por el estado, mientras que el $17,6 \%$ son comerciantes, el 10,7\% trabajan de profesores en el Ministerio de Educación, así mismo el 5,3\% son empresarios y solo el 2,0\% son misioneros de la Iglesia Adventista del Séptimo Día, y finalmente el 42,6\% tiene otra ocupación. 
Tabla 12. Información demográfica de los líderes de las Iglesias de la Ciudad de Trujillo

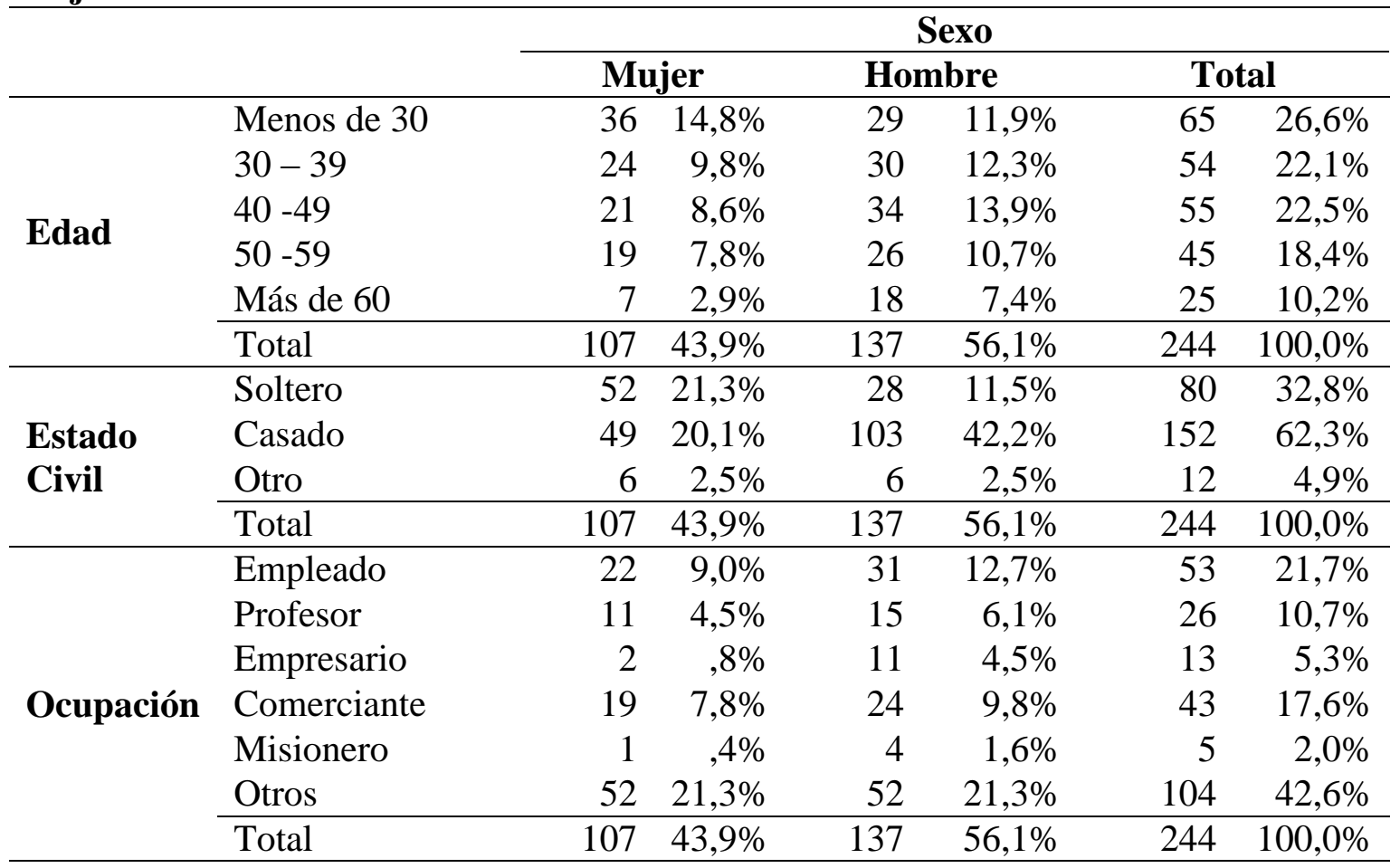

En la tabla 13 se puede observar como la muestra se distribuyó según los distritos encuestados para los resultados de la investigación realizada, Se encuestaron 16 distritos los cuales demuestran el crecimiento exponencial de la iglesia durante la última década.

Estos 16 distritos se encuentran en la ciudad de Trujillo, se consideró tanto a hombres como mujeres. En estos distritos encuestados, se tuvo como mayor población de encuestados a varones con un total de 137 y a mujeres con un total de 107. Esto hace a un total de 244 encuestados. De los cuales la iglesia de las Quintanas tuvo una mayor participación con un total de 23 encuestados. 
Tabla 13. Muestra según distritos misioneros encuestados en la ciudad de Trujillo

\begin{tabular}{lrrrrrr}
\hline \multirow{2}{*}{ Distrito } & \multicolumn{2}{c}{ Sexo } \\
\cline { 2 - 7 } & \multicolumn{2}{c}{ Mujer } & \multicolumn{2}{c}{ Hombre } & \multicolumn{2}{c}{ Total } \\
\hline Trujillo Central & 7 & $50,0 \%$ & 7 & $50,0 \%$ & 14 & $100,0 \%$ \\
Trujillo Chimú & 11 & $73,3 \%$ & 4 & $26,7 \%$ & 15 & $100,0 \%$ \\
Trujillo Florencia de Mora & 4 & $23,5 \%$ & 13 & $76,5 \%$ & 17 & $100,0 \%$ \\
Trujillo Santa Isabel & 9 & $56,3 \%$ & 7 & $43,8 \%$ & 16 & $100,0 \%$ \\
Trujillo Quintanas & 10 & $43,5 \%$ & 13 & $56,5 \%$ & 23 & $100,0 \%$ \\
Trujillo Esperanza A & 5 & $35,7 \%$ & 9 & $64,3 \%$ & 14 & $100,0 \%$ \\
Trujillo Esperanza B & 11 & $55,0 \%$ & 9 & $45,0 \%$ & 20 & $100,0 \%$ \\
Trujillo Esperanza C & 8 & $44,4 \%$ & 10 & $55,6 \%$ & 18 & $100,0 \%$ \\
Trujillo Porvenir A & 11 & $57,9 \%$ & 8 & $42,1 \%$ & 19 & $100,0 \%$ \\
Trujillo Porvenir B & 7 & $46,7 \%$ & 8 & $53,3 \%$ & 15 & $100,0 \%$ \\
Trujillo Laredo & 7 & $41,2 \%$ & 10 & $58,8 \%$ & 17 & $100,0 \%$ \\
Trujillo Platanar & 5 & $33,3 \%$ & 10 & $66,7 \%$ & 15 & $100,0 \%$ \\
Trujillo Palermo & 2 & $25,0 \%$ & 6 & $75,0 \%$ & 8 & $100,0 \%$ \\
Trujillo Víctor Larco & 2 & $16,7 \%$ & 10 & $83,3 \%$ & 12 & $100,0 \%$ \\
Trujillo Moche & 7 & $58,3 \%$ & 5 & $41,7 \%$ & 12 & $100,0 \%$ \\
Trujillo Virúy & 1 & $11,1 \%$ & 8 & $88,9 \%$ & 9 & $100,0 \%$ \\
\hline Total & 107 & & 137 & & 244 & $100,0 \%$ \\
\hline
\end{tabular}

Factores administrativos

Sobre los factores administrativos han sido medidos por los ítems 5 y 6 del instrumento, el cual arrojó los siguientes resultados:

La pregunta 5 de la encuesta menciona si la sede de la Misión en Trujillo facilitó el crecimiento de los distritos misioneros. E1 53,28\% opina que está "De acuerdo" con esta afirmación, mientras que un 29,51\% corrobora esta opinión con un "Totalmente de acuerdo", seguido de un 8,61\% que no está "Ni de acuerdo ni en desacuerdo", y un leve 4,92\% opinan "En desacuerdo". Finalmente, solo el 3,69\% está en "Totalmente en desacuerdo". 


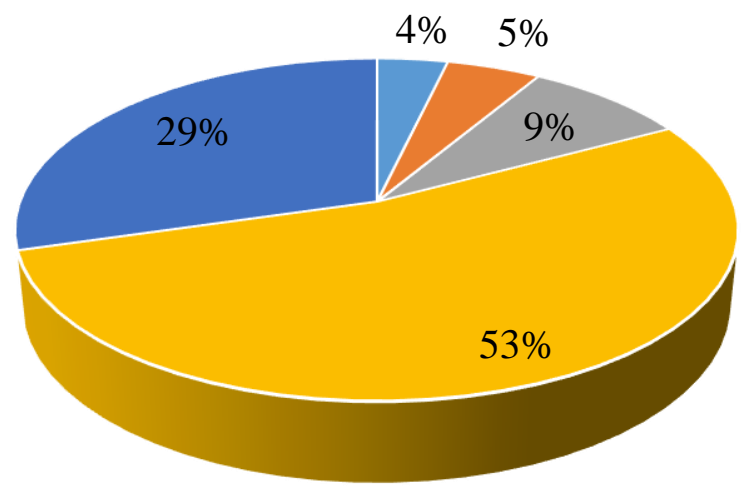

- Totalmente en desacuerdo

- En desacuerdo

- Ni de acuerdo ni en desacuerdo

- De acuerdo

- Totalmente de acuerdo

Figura 4. Sede de la Misión en Trujillo ¿Facilitó el crecimiento de los distritos misioneros?

El ítem 6 consideró cuál de las acciones administrativas fueron las que más influyeron en el crecimiento de los distritos misioneros de Trujillo en el periodo 2001 2009. Las respuestas nos dan un claro panorama de lo que los feligreses creen y opinan sobre el crecimiento de los distritos en la ciudad de Trujillo, por acciones administrativas: “Trabajo armonioso con hermanos y pastores" un 34,4\%, seguido del "Liderazgo espiritual" con un 34,0\%, luego de un" Énfasis misionero y evangelístico" con un 22,5\%. Los tres mencionados tienen el $90 \%$ de la opinión de la iglesia y creen que fue por esos motivos que crecieron los distritos en la ciudad de Trujillo, mientras que el "Apoyo económico" y la "Pronta solución de problemas" tienen un porcentaje de 4,9\% y 4,1\% respectivamente. 


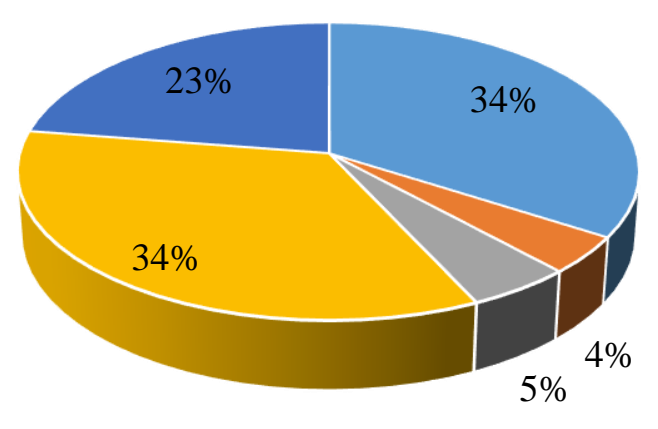

- Liderazgo espiritual

- Pronta solución de problemas

- Apoyo económico

- Trabajo armonioso con hermanos y pastores

- Énfasis misionero y evangelístico

Figura 5. Acciones administrativas que influyeron más en el crecimiento de los distritos misioneros

\section{Factores económicos}

En relación con los factores económicos, se plantearon 4 ítems que pudieron medir la opinión de los líderes con respecto a este asunto. En el ítem 7, se preguntó ¿Cree usted que las condiciones económicas de la región en los años 2001 - 2009 contribuyeron al crecimiento de la iglesia? Se consiguió el siguiente resultado: 45,1\% opinó que está “De acuerdo", el 21,7\% “Ni de acuerdo ni en desacuerdo", el 14,8\% opinó que está “Totalmente de acuerdo", mientras que el 11,1\% y el 7,4\% están en la posición de "En desacuerdo" y en "Totalmente en desacuerdo" respectivamente.

El ítem 8 recolectó la opinión si ¿considera que la situación económica de la región en los años 2001 - 2009 ayudó a los miembros a ser más fieles en la devolución de los diezmos? Los resultados son los siguientes: el 36,5\% opina que está "De acuerdo", mientras que el 23,8\% opinó que está "Ni de acuerdo ni en desacuerdo", el 18,9\% mencionó que está "En desacuerdo”, por otro lado el 11,1\% está "Totalmente de 
acuerdo" y el 9,8\% está "Totalmente en desacuerdo".

El ítem 9 pregunta ¿Considera que los miembros de la iglesia fueron más fieles en la devolución de los diezmos en ese período? El resultado de las opiniones son las siguientes: el 40,6\% está "De Acuerdo", seguido de un 28,3\% que no está "Ni de acuerdo ni en desacuerdo", mientras que el 18,9\% opinó que está "En desacuerdo" y por otro lado el 12,7\% opinó que está "Totalmente de acuerdo" y un pequeño sector que es el 4,5\% dijo que está "Totalmente en desacuerdo".

El ítem 10 mide si las pocas oportunidades laborales impidieron a los hermanos apoyar económicamente a la iglesia en el período 2001 - 2009. Los resultados son los siguientes: El 36,1\% opina que está "De acuerdo", el 28,7\% está "En desacuerdo", seguido de un 20,9\% que opinó que no está "Ni de acuerdo ni en desacuerdo", mientras que un 8,6\% está "Totalmente en desacuerdo" y finalmente el 5,7\% está "Totalmente de acuerdo". 


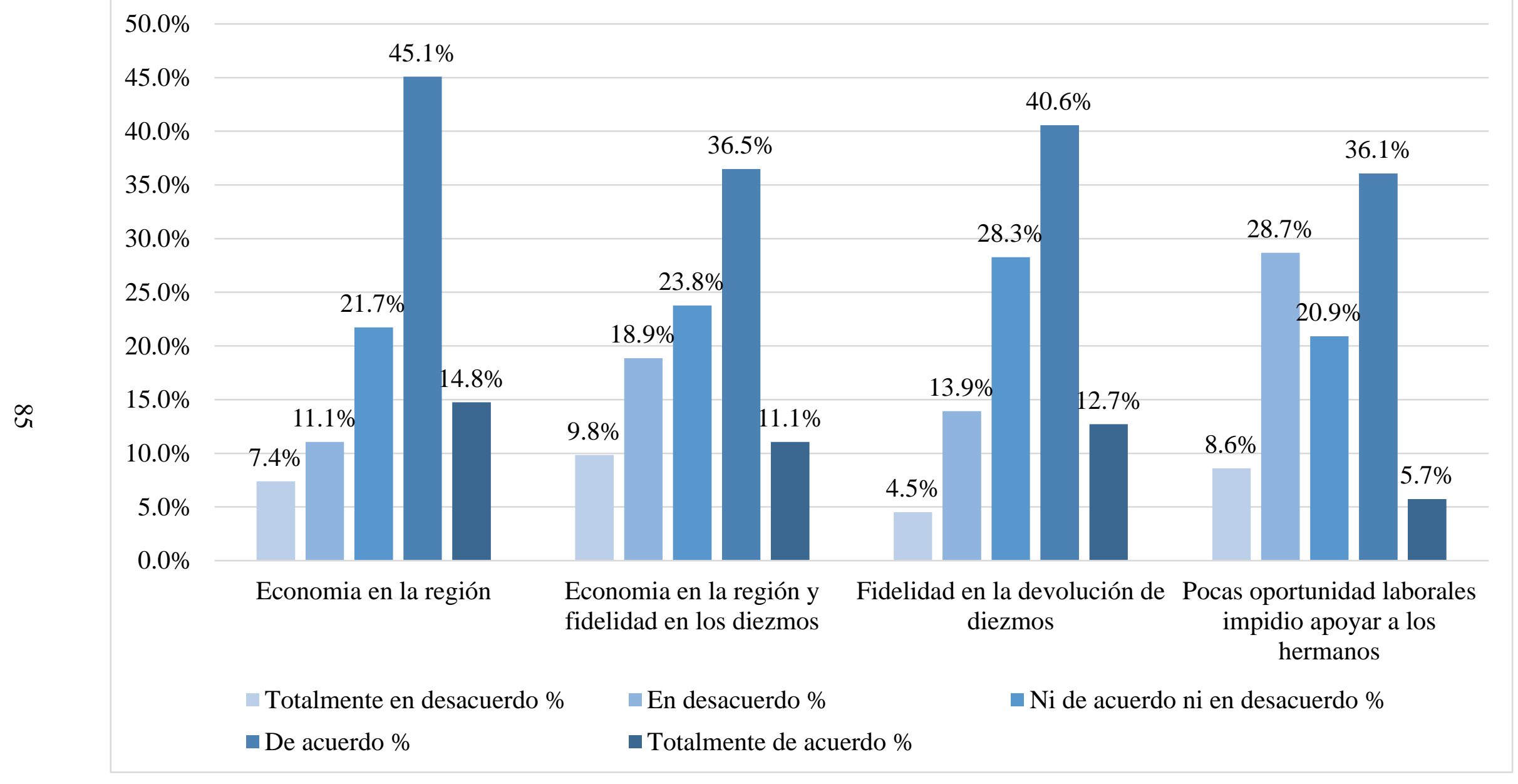

Figura 6. Cómo influyeron las condiciones económicas durante el período del 2001-2009 


\section{Factores evangelísticos}

Entre los factores evangelísticos, se consideró dos ítems que buscaron conocer si existió ese énfasis y qué tipos de campañas dieron mayor resultado en el período 2001 al 2009. El primer ítem preguntó: ¿Considera usted que hubo énfasis evangelístico entre los años 2001-2009? Los resultados son los siguientes: "De acuerdo" con un 60,7\% de las opiniones, el 23,0\% "Totalmente de acuerdo", el 10,2\% "Ni de acuerdo ni en desacuerdo", mientras que un 2,9\% y 3,3\% "En desacuerdo" y "Totalmente en desacuerdo", respectivamente.

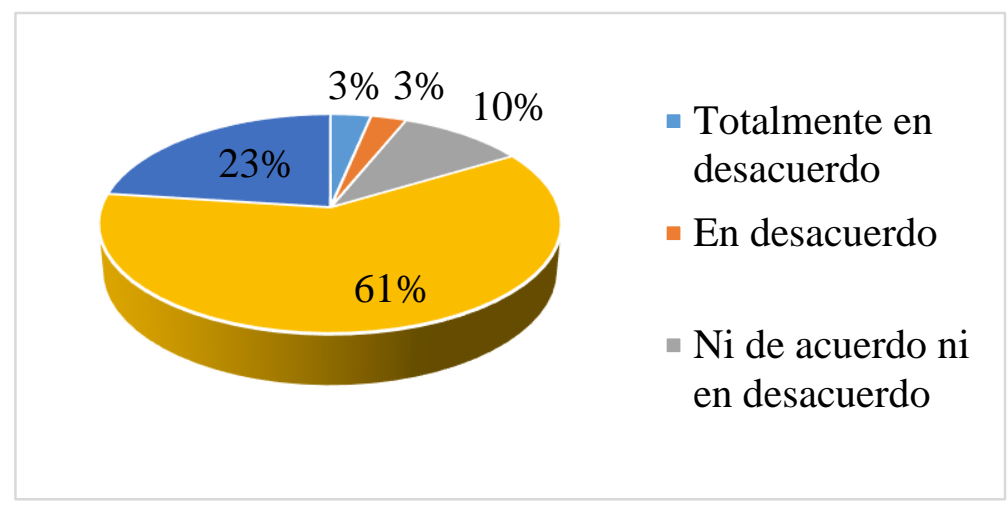

Figura 7. ¿Considera usted que hubo énfasis evangelístico entre los años 2001-2009?

El segundo ítem preguntó: ¿Qué tipo de campañas evangelísticas cree usted que dio mayor resultado en el crecimiento de la iglesia (se desarrolló más) en el periodo 2001-2009? Los resultados son los siguientes: el 41,0\% opinó que fue por el “Evangelismo personal", mientras que un 30,7\% le dio un realce al "Evangelismo público", también el 14,3\% mencionó las “Caravanas de la esperanza” y el 11,9\% opina que el "Evangelismo laico" y finalmente un 2,0\% mencionó “Otras actividades". 


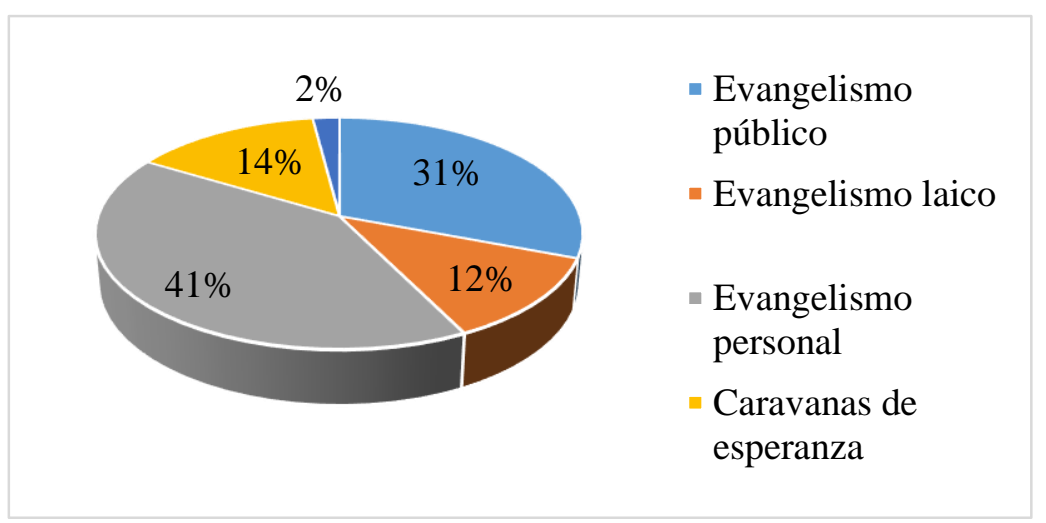

Figura 8. Campañas evangelísticas que se desarrollaron más durante el período del 20012009

\section{Liderazgo pastoral}

El liderazgo pastoral es otro factor importante para conocer si existe relación con el crecimiento de la iglesia en esos años. La primera pregunta que se formuló fue: ¿Del 1 al 5 en qué lugar ubicaría el liderazgo del pastor distrital como uno de los factores claves en el crecimiento de los distritos misioneros de Trujillo durante el período del 20012009? Los resultados son los siguientes:

E1 50,8\% lo ubicó en el nivel 4 (“De acuerdo"), el 24,2\% lo ubicó en el nivel 5, que es "Totalmente de acuerdo". Entre ambas opciones se puede tomar la conclusión de que el $75 \%$ de las opiniones son favorables con respecto al liderazgo del pastor distrital, mientras que un $20.1 \%$ mencionó que no está "Ni de acuerdo ni en desacuerdo", y sólo el 1,6 \% y 3,3 \% están "En desacuerdo" y "Totalmente en desacuerdo" respectivamente. 


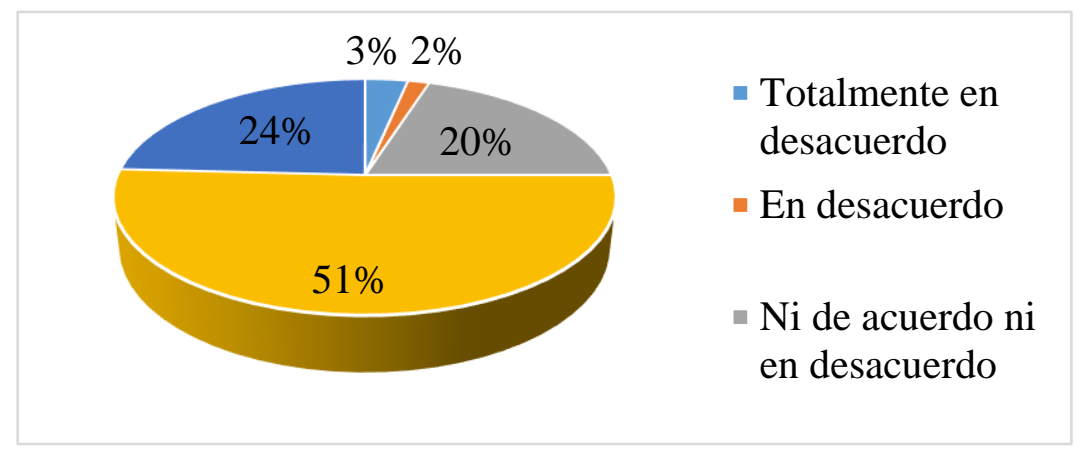

Figura 9. ¿Del 1 al 5 en qué lugar ubicaría el liderazgo del pastor distrital como uno de los factores claves en el crecimiento de los distritos misioneros de Trujillo durante el período del 2001-2009?

El segundo ítem que se ha medido fue el siguiente: ¿Qué característica en el liderazgo espiritual se manifestó con mayor realce en el periodo 2001-2009? Las respuestas tienen el siguiente orden: el "Liderazgo motivador" un 44,7 \%, seguido de un "Liderazgo capacitador" con un 22,1\%, también el "Liderazgo responsable" con un 17,2 $\%$, en cuarto lugar el "Liderazgo visionario" con un 10,7\% y finalmente el "Liderazgo innovador" con un 5,3\%.

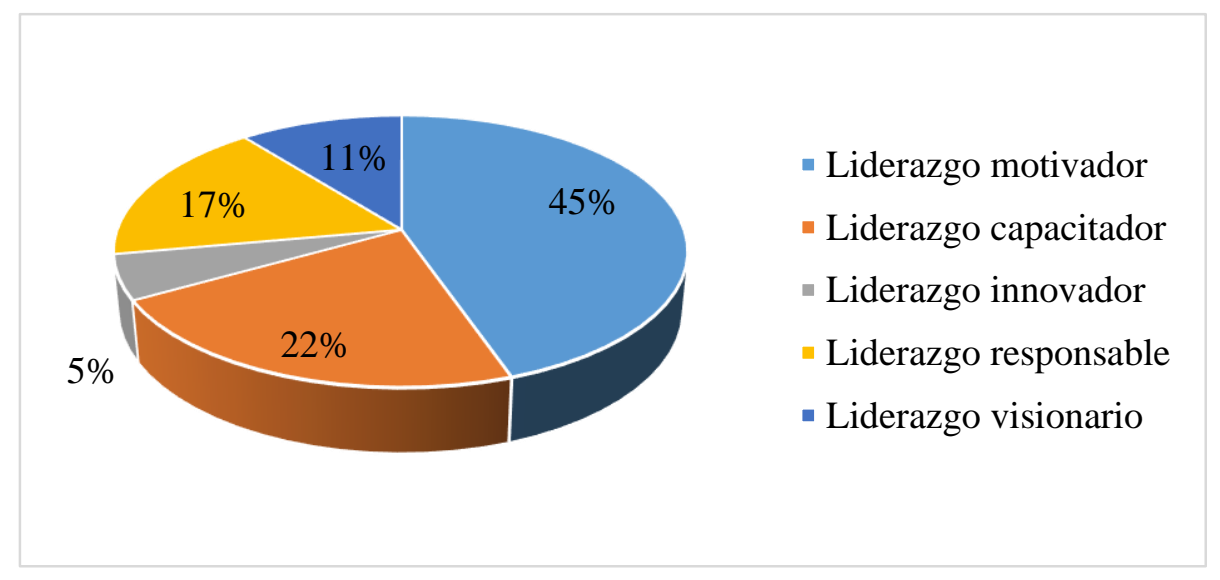

Figura 10. ¿Qué característica en el liderazgo espiritual se manifestó mucho durante el período del 2001-2009? 


\section{Estructurales}

En estructurales se consideró Grupos pequeños y formación de discípulos.

\section{Grupos pequeños}

Los Grupos pequeños también fueron considerados para observar como influyó en el crecimiento de la iglesia. Se realizó la siguiente pregunta clave: ¿Considera que el rol que cumplieron los GP en el periodo 2001-2009 fueron fundamentales para el crecimiento de los distritos en la ciudad de Trujillo? Se obtuvieron los siguientes resultados: el 48,4 \% está “De acuerdo", seguido de un significante 34,4\% que está “Totalmente de acuerdo", a continuación un 10,2 \% que "No está de acuerdo ni en desacuerdo", seguido de pequeños 3,7 \% y 3,3 \% que están "En desacuerdo" y “Totalmente en desacuerdo" respectivamente.

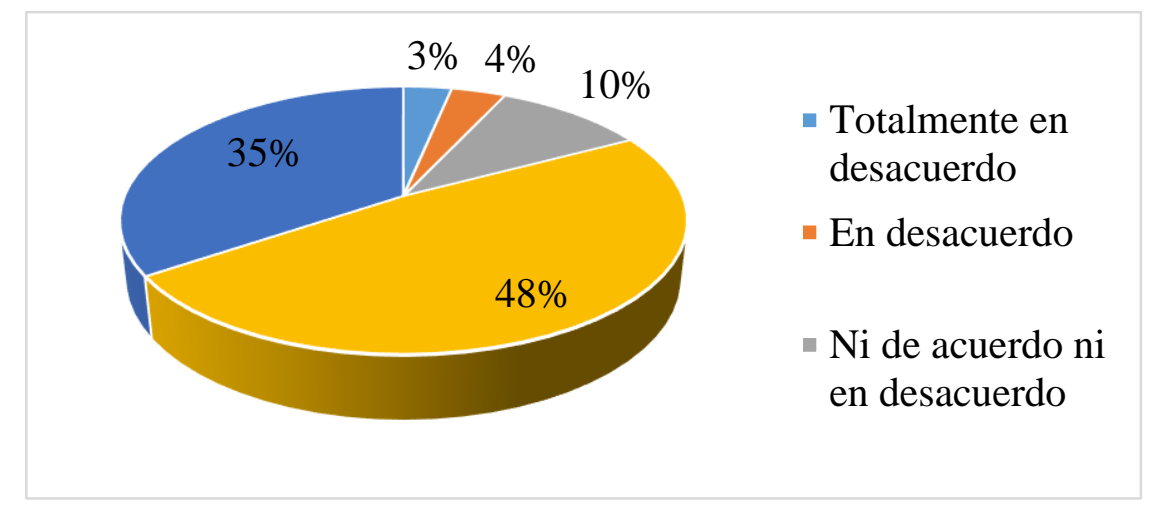

Figura 11. ¿Considera usted que el rol que cumplieron los GP durante el período del 2001-2009 fueron fundamentales para el crecimiento de los distritos misioneros en la ciudad de Trujillo?

\section{Formación de discípulos}

La formación de discípulos es importante en el cumplimiento de la misión como iglesia, de tal manera se formuló la siguiente pregunta: ¿Cree que la formación de nuevos 
discípulos contribuyó para el crecimiento de los distritos misioneros en Trujillo en el periodo 2001-2009? Se obtuvieron los siguientes resultados importantes: el 54,9\% está "De acuerdo", seguido de un 24,6 \% que está "Totalmente de acuerdo", mientras que un 14,8 \% está "Ni de acuerdo ni en desacuerdo", mientras que una pequeña proporción de respuestas con un 2,5\% y 3,3\% están "En desacuerdo" y en "Totalmente en desacuerdo", respectivamente.

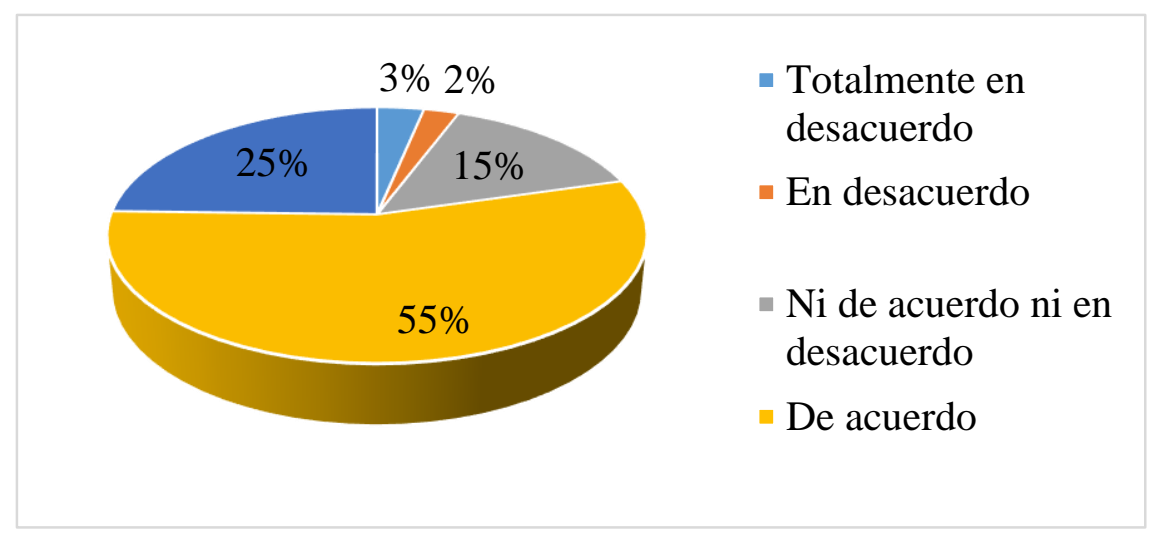

Figura 12. ¿Cree usted que la formación de nuevos discípulos contribuyó para el crecimiento de los distritos misioneros en Trujillo durante el período del 2001-2009?

\section{Otros}

En esta parte de la encuesta se realizó la siguiente pregunta ¿Cree que el ambiente social (estabilidad) contribuyó en el crecimiento de la iglesia en el periodo 2001 - 2009? Las respuestas tienen el siguiente orden: el 52,5 \% está "De acuerdo" con el ambiente social, seguido de un 21,3\% que está "Ni de acuerdo ni en desacuerdo", mientras que un 15,6 \% está "Totalmente de acuerdo", al final con un 6,1 \% y 4,5 \% están las opiniones "En desacuerdo" y "Totalmente en desacuerdo", respectivamente. 


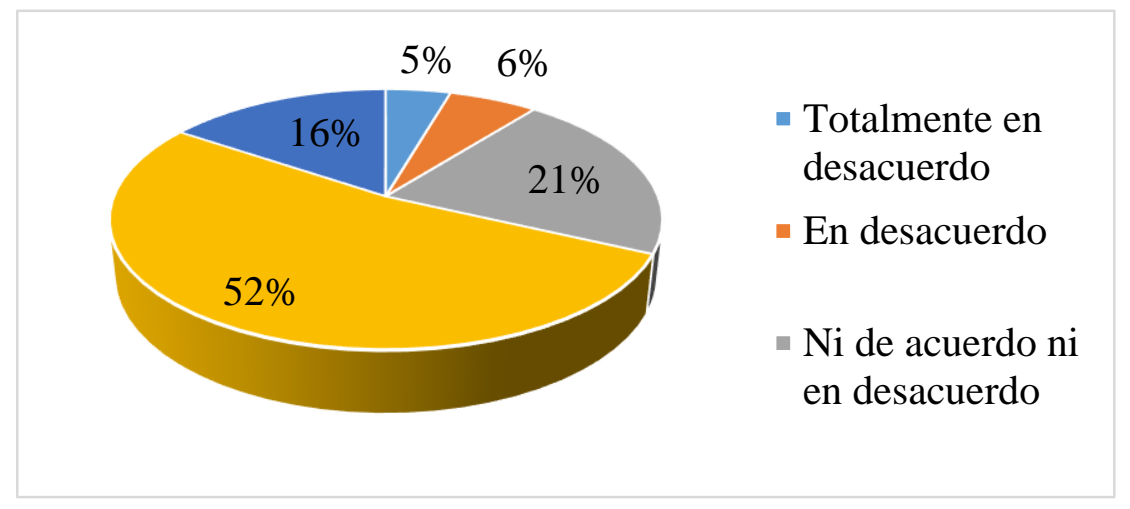

Figura 13. ¿Cree usted que el ambiente social (estabilidad) contribuyó en el crecimiento de la iglesia durante el período del 2001-2009?

Los resultados muestran que los factores administrativos, evangelísticos, pastorales y estructurales han contribuido significativamente en el crecimiento distrital de la IASD en la ciudad de Trujillo, durante el período del 2001-2009.

En el factor administrativo, al considerar si la sede de la Misión contribuyó o no en el crecimiento de los distritos misioneros, un 53,28\% está de acuerdo, y un 29,51\% totalmente de acuerdo. Y al preguntar qué acciones administrativas influyeron más en el crecimiento durante el período del 2001-2009, un 34,4\% respondió que el "trabajo armonioso con hermanos y pastores". El trabajo armonioso tiene que ver con trabajo en equipo, buenas relaciones pastor y miembro de iglesia, esto es clave en el desarrollo de cualquier iglesia. El amor y la unidad favorecen el crecimiento de la iglesia. Asimismo, al observar que otras opciones se marcaron, se puede visualizar que el 34\% marcó "Liderazgo espiritual", también significativo para dirigir un distrito o una zona, sin ella no hay dirección divina. Finalmente, el 22,5\% marcó “Énfasis misionero y evangelístico".

Mario Veloso destaca que "la administración de los distintos niveles de la iglesia debe mantener siempre presente la necesidad de proveer los medios necesarios para el 
desarrollo espiritual de los miembros de iglesia". ${ }^{166}$ Entre los elementos que se pueden utilizar para el desarrollo espiritual corporativo de la iglesia, están los congresos, los retiros espirituales, las reuniones campales y otras.

En el factor evangelístico, se encuentra que el 60,7\% está de acuerdo en que hubo énfasis evangelístico durante el período del 2001-2009, y un 23,0\% está totalmente de acuerdo. Al preguntar qué tipo de campaña evangelística dio más resultados el 41\% marca "evangelismo personal" y el 30,7\% "evangelismo público". Se realizaron semanas intensas de cosecha, caravanas misioneras, concentraciones masivas en el Estadio Mansiche de Trujillo y el trabajo personal casa por casa dando estudios bíblicos.

Elena G. de White afirma claramente que es muy importante el trabajo de casa en casa, razonando y explicando la Palabra. Los obreros que sigan los métodos de Cristo ganarán almas como salario. ${ }^{167}$ La obra de Cristo se realizaba mayormente por medio de entrevistas personales. Eximía una fiel consideración al auditorio de un alma. Por medio de un alma, a menudo el evangelio se extendía a millares de personas. ${ }^{168}$

En el factor pastoral, se destaca en qué lugar ubicaría el liderazgo del pastor distrital. En la escala del 1 al 5 la gente responde: nivel 4 "de acuerdo" un 50,8\% y el nivel 5 "totalmente de acuerdo" un $24,2 \%$. Entre los dos, se puede ver que un $75 \%$ tiene opiniones favorables. Asimismo, al preguntar qué característica del liderazgo espiritual se manifestó con mayor realce durante el período del 2001-2009, se encuentra lo siguiente:

${ }^{166}$ Mario Veloso, Teología de la administración eclesiástica (Brasilia: Seminario Adventista Latinoamericano de Teología, 1982), 57.

${ }^{167}$ Elena G. de White, El ministerio de la bondad (Buenos Aires: Asociación Casa Editora Sudamericana, 1976), 64.

${ }^{168}$ Ibíd., 64-65. 
"Liderazgo motivador" un 44,7\%. "Liderazgo capacitador" un 22,1\% y "liderazgo responsable" un $17,2 \%$.

Schuller destaca que la dirección del pastor es primordial, y requiere mucha responsabilidad. No se la puede considerar a la ligera, ni dejar "en manos de quienes no estén dispuestos a considerar a la iglesia como el asunto más importante de su vida". ${ }^{169}$ Como sucede para el encendido de un motor, el pastor debe ser la bujía de encendido. "El capitán y estratega que conduzca a las tropas monte arriba". ${ }^{170}$

En los factores estructurales, frente a la pregunta: ¿El rol que cumplieron los Grupos Pequeños entre el 2001-2009 fueron fundamentales para el crecimiento de los distritos? La gente responde que un 48,4\% está "De acuerdo" y un 34,4\% "totalmente de acuerdo". Asimismo, a la pregunta si la formación de nuevos discípulos contribuyó para el crecimiento de los distritos misioneros en Trujillo, la gente responde que un 54,9\% está de acuerdo y un 24,6\% está totalmente de acuerdo. Los detalles conseguidos de cada factor van evidenciando el cumplimiento de la hipótesis planteada al comienzo de esta tesis.

Emilio Abdala, teólogo adventista, opina que la principal justificación para los grupos pequeños es un retorno a las prácticas de la iglesia primitiva. Dice que los grupos pequeños florecerán debido a un sistema de valores y base teológica que da sustento a su programa. Adoptar una estructura de grupos pequeños por razones meramente organizacionales es perder el foco. De la misma forma, hay que tener en cuenta que los

${ }^{169}$ Robert H. Schuller, Su iglesia tiene posibilidades (Barcelona: Editorial Clie, 1976), 72 .

${ }^{170}$ Ibíd. 
grupos pequeños ofrecen ventajas para el cumplimiento de la gran comisión y la salvación de las personas. ${ }^{171}$

Por otro lado, el Dr. Isidro Goma Civit, teólogo graduado en la Universidad Gregoriana, opina que "haced discípulos" tiene que ver con el resultado completo de la misión, no sólo con un aspecto de ella. Lo expresa de la siguiente manera: "Hacer discípulos señala el resultado completo de la Misión; no como otros términos del vocabulario misional que indican sólo un aspecto, o una fase incoactiva ("proclamar", “dar testimonio”, “evangelizar”, etc.). Hacer discípulos es hacer Comunidad cristiana, hacer iglesia". ${ }^{172}$

${ }^{171}$ Emílio Abdala, "Os pequenos grupos na história do cristianismo". Pequenos grupos, grandes solucoes (Brasilia: Seminaro Adventista Latinoamericano de Teología, 2007), 37.

${ }^{172}$ Isidro Goma Civit, El evangelio según San Mateo (Madrid: Ediciones Marova, 1976), 2:715. 


\title{
CAPÍTULO 6 RESUMEN, CONCLUSIONES Y RECOMENDACIONES
}

\begin{abstract}
Resumen
El objetivo de esta investigación fue determinar en qué medida los factores administrativos, evangelísticos, pastorales y estructurales influyeron en el crecimiento de la IASD en la ciudad de Trujillo entre los años 2001 al 2009.

En el capítulo 1, se da un marco de referencia de la iglesia adventista del séptimo día, desde datos estadísticos de la Asociación General hasta datos estadísticos de la Misión Nor Pacífico. Asimismo, se muestra un panorama general y específico de la IASD en el período 2001 al 2009, en la ciudad de Trujillo.

En el capítulo 2, se han presentado datos referenciales de Trujillo y una breve reseña histórica de la IASD en el Perú, su origen y progreso.

En el capítulo 3, se encuentran fundamentos teóricos de crecimiento iglesia. Cada autor presenta su punto de vista y experiencia en cuanto al iglecrecimiento. El detalle bíblico es clave en la comprensión de los designios de Dios.

El capítulo 4, es la metodología de la tesis. Es de tipo histórico sincrónicodescriptivo. Se utilizó el diseño no experimental, y la muestra estuvo constituida por 244 feligreses de las iglesias principales de la ciudad de Trujillo, miembros representativos de las juntas directivas que antecedieron y vivieron durante el período de estudio. El 56,1\% fueron varones y el 43,9 \% mujeres. Las edades varían entre los 17 años y los 84 años y la mayoría está en el grupo de 17 a 30 años de edad con un 26,6\%. La encuesta que
\end{abstract}


contestaron tuvo el objetivo de obtener información básica y fidedigna de los feligreses, en cuanto al crecimiento de los distritos misioneros en la ciudad de Trujillo, durante el período del 2001-2009.

El capítulo 5, es el análisis e interpretación de los resultados. Cada detalle obtenido, fortalecen la hipótesis que factores administrativos, evangelísticos, pastorales y estructurales influyeron en el crecimiento de la iglesia entre los años 2001-2009. La lectura de este capítulo, da un claro panorama de lo que sucedió en Trujillo en esos años. Todo crecimiento es guiado por Dios, y se debe tener en cuenta las cosas fundamentales que arroja la encuesta.

\section{Conclusiones}

De manera general se puede mencionar: 1. La expansión del adventismo en las diferentes regiones del Perú, y de manera particular en el norte peruano, fue el resultado del ímpetu misionero de los pioneros. 2. El establecimiento de unidades administrativas en los nuevos territorios, facilitó el crecimiento y desarrollo de la iglesia adventista. 3. También, los especialistas, en iglecrecimiento señalan entre otros factores que facilitan el desarrollo y expansión, a los administrativos, evangelísticos, pastorales y estructurales.

De manera específica, en esta investigación, también se puede concluir que estos factores han influido de la siguiente manera:

1. Los factores administrativos tuvieron una gran responsabilidad en el crecimiento de la iglesia en la ciudad de Trujillo durante el período 2001-2009. Tener la sede de la Misión en Trujillo facilitó el crecimiento de los distritos misioneros y así lo demuestran los resultados de la encuesta aplicada a los líderes de las diversas iglesias: 53,28 \% está "De acuerdo" y el 29,51 \% está “Totalmente de acuerdo", esto da un 82,79 
$\%$ de aceptación en la decisión de tener una misión en la ciudad de Trujillo y sobre todo que se asocia con el crecimiento de la iglesia.

Asimismo, tener la misión en la ciudad, permitió que la administración tomara decisiones en favor del desarrollo de la iglesia. Una de las decisiones de mayor crecimiento fue el "Trabajo armonioso con hermanos y pastores" con un $34.4 \%$. De igual manera se asocia el "Liderazgo espiritual" con un 34,0 \%, así también el Énfasis misionero y evangelístico con un 22,5\%. Estos tres abarcan el 90\% de la opinión de la iglesia.

2. Los factores evangelísticos que contribuyeron al crecimiento de la IASD de la ciudad de Trujillo entre los años 2001 y 2009. Los líderes de las iglesias encuestados dieron su opinión sobre el énfasis evangelístico durante los años mencionados: el 60,7\% está "De acuerdo" mientras que el 23,0\% está "Totalmente de acuerdo", el resultado sumado de ambos es del 83,7 \% el cual indica que el énfasis desarrollado en estos años fue causa del crecimiento de la iglesia en la ciudad de Trujillo. De esta manera, se llegó a conocer también qué tipos de campañas evangelísticas fueron las de mayor resultado en ese período, para mejorar y optimizar los programas. El Evangelismo personal va en primer lugar con un 41,0\%, seguido del Evangelismo público con un 30,7 \% y en tercer lugar, las Caravanas de esperanza con un 14,3\%.

3. El crecimiento de la iglesia también se debe a los factores pastorales. El resultado que se obtuvo con respecto al liderazgo del pastor distrital es del 75,0 \% que están "De acuerdo" y "Totalmente de acuerdo" con el liderazgo pastoral como un factor clave en el crecimiento de la iglesia. Asimismo, se ha conocido el tipo de liderazgo que se manifiesta de la mejor manera y la relación es la siguiente: un Liderazgo motivador 
44,7 \%, Liderazgo capacitador 22,1\%, y Liderazgo responsable 17,2 \%. Estos tres tipos de liderazgo ayudaron y contribuyeron al el crecimiento de la iglesia en la ciudad de Trujillo.

4. Los factores estructurales que involucra la formación de Grupos pequeños y la formación de discípulos cumplieron un rol muy significativo en el crecimiento de la iglesia en la ciudad de Trujillo. Con respecto a los Grupos Pequeños, el 82,8 \% opina que fue fundamental en el crecimiento de la iglesia, mientras que un 79,5\% ratifica la importancia de la formación de discípulos para el crecimiento de los distritos misioneros en la ciudad de Trujillo entre los años 2001 y 2009.

\section{Recomendaciones}

Realizar un estudio prospectivo del fenómeno de crecimiento y desarrollo, en otros campos de la UPN y del Perú, que sin duda fortalecerá el trabajo de administradores, departamentales y pastores de iglesia, conducente a mejorar la calidad del crecimiento de la iglesia.

Buscar otros factores que contribuyeron en el desarrollo y mejoramiento de la disciplina de crecimiento de iglesia y que se constituya en un material de consulta y referencia al crecimiento de la IASD en Trujillo.

Trabajar de manera permanente con los factores administrativos, evangelísticos, pastorales y estructurales en la ciudad de Trujillo y que la ANoP lo extienda para los demás lugares que atiende en su campo. Realizar un estudio cualitativo para encontrar la respuesta de los hermanos de iglesia no sólo en Trujillo sino en otras partes del Perú.

Desarrollar investigaciones acerca del liderazgo como tema general, del liderazgo pastoral en el Perú y qué tipos de liderazgo existen en la actualidad. 


\section{APÉNDICE A}

\section{ADMINISTRACIÓN DE LA TESIS}

Cronograma de actividades 2013-2015

\begin{tabular}{llll}
\hline Capítulo & Tema & Mes & Año \\
\hline 1 & Introducción & Mayo-junio & 2013 \\
2 & Marco referencial & Mayo-junio & 2013 \\
3 & Marco teórico & Junio & 2013 \\
4 & Metodología & Junio & 2013 \\
& Elaboración y validación de instrumento & Mayo-junio & 2013 \\
& Recolección de datos & Junio-Julio & 2013 \\
& Análisis de datos & Abril-junio & 2014 \\
& Análisis e interpretación de los resultados & Febrero-marzo & 2015 \\
6 & Resumen, conclusiones y recomendaciones & Abril & 2015 \\
\hline & Presentación final & Octubre & 2015 \\
\hline
\end{tabular}




\section{APÉNDICE B}

\section{ENCUESTA}

\section{"Factores que contribuyeron al crecimiento de los distritos misioneros en Trujillo (2001-2009)"}

Estimado participante:

La presente encuesta tiene por objetivo identificar qué factores contribuyeron más para que los distritos misioneros de la ciudad de Trujillo se duplicaran entre los años 20012009. Por favor responda con veracidad las siguientes preguntas según corresponda y llene los espacios.

Tome en cuenta por favor, los 5 niveles de respuesta:

1. Totalmente en desacuerdo

2. En desacuerdo

3. Ni de acuerdo ni en desacuerdo

4. De acuerdo

5. Totalmente de acuerdo

\section{INFORMACIÓN GENERAL}

1. Género: Femenino $1 \square$ Masculino $2 \square$

2. Edad:

3. Estado civil: Soltero 1

Casado 2

Otros 3

4. Ocupación: Empleado 1 Profesor 2 Empresario 3

Comerciante 4 Misionero 5 Otros 6

\section{INFORMACIÓN ESPECÍFICA}

\section{ADMINISTRATIVO}

5. A partir del año 2001 se inició la MNP en Trujillo, con 9 distritos misioneros en su sede. Se desarrolló hasta el año 2009, llegando a tener 18 distritos misioneros en Trujillo. Luego se convirtió en Asociación. ¿Cree usted que tener la sede de la Misión en Trujillo facilitó el crecimiento de los distritos misioneros?
$1 \square$
2
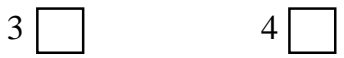
$5 \square$ 
6. ¿Cuál de las siguientes acciones administrativas considera usted que influyó mucho en el crecimiento de los distritos misioneros de Trujillo durante el período del 2001-2009?
a. Liderazgo espiritual
b. Pronta solución de problemas
c. Apoyo económico
d. Trabajo armonioso con hermanos y pastores
e. Énfasis misionero y evangelístico

\section{ECONÓMICO}

7. ¿Cree usted que las condiciones económicas de la región en los años 20012009 contribuyeron al crecimiento de la iglesia?
1
2
$3 \square$
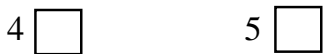

8. ¿Considera usted que la situación económica de la región en los años 20012009 ayudó a los miembros a ser más fieles en la devolución de los diezmos?
1
2
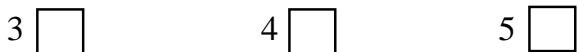

9. ¿Considera usted que los miembros de iglesia fueron más fieles en la devolución de los diezmos en ese período?
1
2
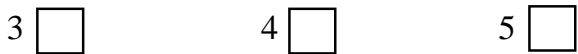

10. ¿Cree usted que las pocas oportunidades laborales impidió a los hermanos apoyar económicamente a la iglesia en ese período?

1

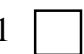

2
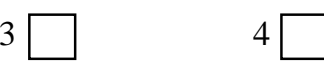

5

\section{EVANGELÍSTICOS}

11. ¿Considera usted que hubo énfasis evangelístico entre los años 2001-2009?

1

2
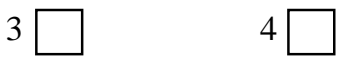

5

12. ¿Qué tipo de campañas evangelísticas cree usted que dio mayor resultado en el crecimiento de la iglesia (se desarrolló más) durante el período del 20012009 ?

Evangelismo público (evangelistas y pastores)

Evangelismo laico (predicadores laicos)

Evangelismo personal (estudios bíblicos en las casas) 
Caravanas de esperanza

Otros:

\section{LIDERAZGO DEL PASTOR}

13. ¿Del 1 al 5 en qué lugar ubicaría el liderazgo del pastor distrital como uno de los factores claves en el crecimiento de los distritos misioneros de Trujillo durante el período del 2001-2009?

1

2

3

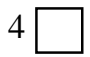

$5 \square$

14. ¿Qué característica en el liderazgo espiritual se manifestó mucho durante el período del 2001-2009?

Liderazgo motivador

Liderazgo capacitador

Liderazgo innovador

Liderazgo responsable

Liderazgo visionario

Otros:

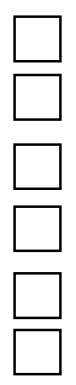

15. Mencione a algunos pastores que los recuerda por su buen liderazgo. Anote nombres y apellidos:

\section{LOS GRUPOS PEQUEÑOS}

16. ¿Considera usted que el rol que cumplieron los GP durante el período del 2001-2009 fueron fundamentales para el crecimiento de los distritos misioneros en la ciudad de Trujillo?

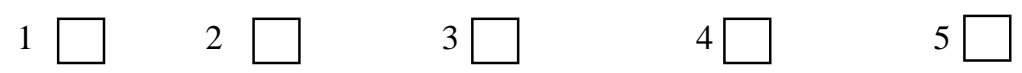

17. ¿Qué actividad de los GP considera usted que incidió más en el crecimiento de los distritos misioneros en Trujillo durante el período del 2001-2009? 
Estudio de la Biblia

Confraternización

Organización misionera en parejas

Evangelismo por amistad

Visitación

\section{FORMACIÓN DE DISCÍPULOS}

18. ¿Cree usted que la formación de nuevos discípulos contribuyó para el crecimiento de los distritos misioneros en Trujillo durante el período del 2001-2009?

1

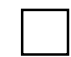

2
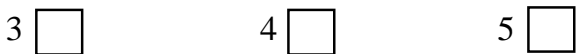

19. ¿Qué seminario considera usted que ayudó más a los miembros de iglesia para promover el crecimiento de la misma durante el período del 2001-2009?

Cómo dar estudios bíblicos

El arte de la visitación

Cómo captar estudiantes de la Biblia

El arte de la predicación

El discipulado

Otros

\section{OTROS}

20. ¿Cree usted que el ambiente social (estabilidad) contribuyó en el crecimiento de la iglesia durante el período del 2001-2009?

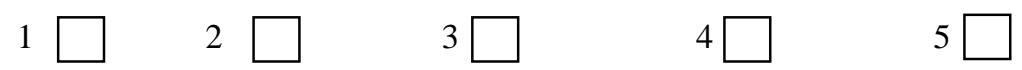

21. Quizás usted conoce otros factores que impulsaron el crecimiento de los distritos misioneros en Trujillo durante el período del 2001-2009.

Menciónelos por favor (en orden de prioridad):

1. Primero:

2. Segundo:

3. Tercero:

4. Cuarto:

¡Agradecemos su participación! 


\section{APÉNDICE C}

\section{PRUEBA DE CONFIABILIDAD ALFA DE CRONBACH}

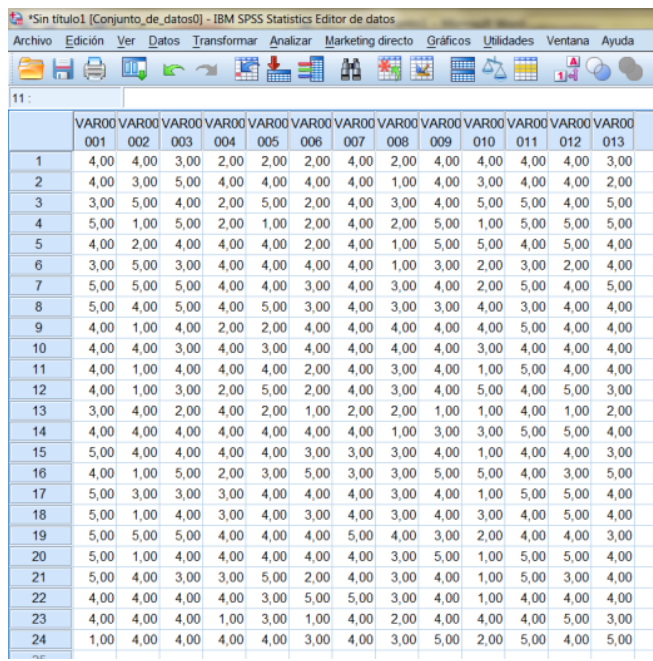

\begin{tabular}{rrr}
\hline \multicolumn{3}{c}{ Estadísticos de fiabilidad } \\
\hline $\begin{array}{r}\text { Alfa de } \\
\text { Cronbach }\end{array}$ & $\begin{array}{r}\text { Alfa de Cronbach } \\
\text { basada en los } \\
\text { elementos } \\
\text { tipificados }\end{array}$ & $\begin{array}{r}\text { N de } \\
\text { elementos }\end{array}$ \\
\hline, 654 &, 678 & 11 \\
\hline
\end{tabular}

\begin{tabular}{lrrrrr}
\hline \multicolumn{7}{c}{ Estadísticos total-elemento } & \\
\hline & $\begin{array}{r}\text { Media de } \\
\text { la escala si } \\
\text { se elimina } \\
\text { el elemento }\end{array}$ & $\begin{array}{r}\text { Varianza de } \\
\text { la escala si } \\
\text { se elimina el } \\
\text { elemento }\end{array}$ & $\begin{array}{r}\text { Correlación } \\
\text { elemento- } \\
\text { total } \\
\text { corregida }\end{array}$ & $\begin{array}{r}\text { Correlación } \\
\text { múltiple al } \\
\text { cuadrado }\end{array}$ & $\begin{array}{r}\text { Alfa de } \\
\text { Cronbach si } \\
\text { se elimina el } \\
\text { elemento }\end{array}$ \\
\hline VAR00001 & 36,5000 & 19,739 &, 233 &, 293 &, 647 \\
VAR00003 & 36,7083 & 18,476 &, 481 &, 353 &, 602 \\
VAR00004 & 37,3750 & 21,636 &,- 002 &, 354 &, 691 \\
VAR00005 & 37,0000 & 19,739 &, 185 &, 206 &, 659 \\
VAR00006 & 37,5833 & 17,819 &, 350 &, 372 &, 624 \\
VAR00007 & 36,7083 & 19,520 &, 530 &, 425 &, 610 \\
VAR00008 & 38,0000 & 19,652 &, 255 &, 222 &, 642 \\
VAR00009 & 36,7083 & 18,389 &, 454 &, 597 &, 605 \\
VAR00011 & 36,2917 & 20,911 &, 219 &, 342 &, 646 \\
VAR00012 & 36,5833 & 17,819 &, 448 &, 645 &, 603 \\
VAR00013 & 36,7917 & 18,781 &, 406 &, 480 &, 614 \\
\hline
\end{tabular}

Por recomendación del programa se eliminarán las variables 2 y 10. 
APÉNDICE D

TABLAS DE ANÁLISIS E INTERPRETACIÓN DE LOS RESULTADOS

Tabla 14. ¿Cree usted que tener la sede de la Misión en Trujillo facilitó el crecimiento de los distritos misioneros?

\begin{tabular}{lrr}
\hline & Frecuencia & \% \\
\hline Totalmente en desacuerdo & 9 & $3,69 \%$ \\
En desacuerdo & 12 & $4,92 \%$ \\
Ni de acuerdo ni en desacuerdo & 21 & $8,61 \%$ \\
De acuerdo & 130 & $53,28 \%$ \\
Totalmente de acuerdo & 72 & $29,51 \%$ \\
\hline Total & 244 & $100,00 \%$ \\
\hline
\end{tabular}

Tabla 15. ¿Cuál de las siguientes acciones administrativas considera usted que influyó más en el crecimiento de los distritos misioneros de Trujillo durante el período del 2001-2009?

\begin{tabular}{lrr} 
& Frecuencia & \% \\
\hline Liderazgo espiritual & 83 & $34,0 \%$ \\
Pronta solución de problemas & 10 & $4,1 \%$ \\
Apoyo económico & 12 & $4,9 \%$ \\
Trabajo armonioso con hermanos y pastores & 84 & $34,4 \%$ \\
Énfasis misionero y evangelístico & 55 & $22,5 \%$ \\
\hline Total & 244 & $100,0 \%$ \\
\hline
\end{tabular}


Tabla 16. Cómo influyeron las condiciones económicas en el período 2001 - 2009

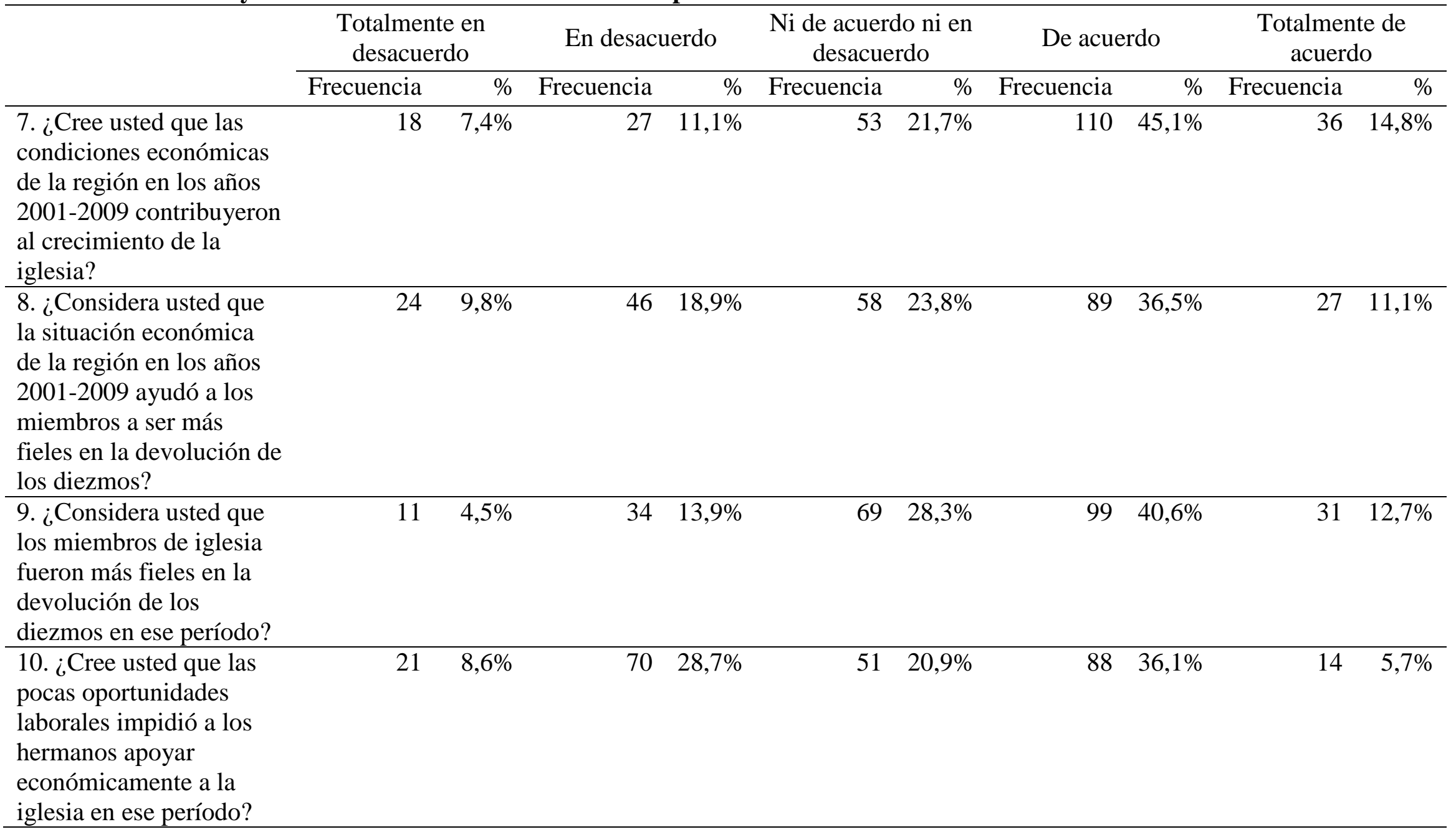


Tabla 17. ¿Considera usted que hubo énfasis evangelístico entre los años 2001-2009?

\begin{tabular}{lrr}
\hline & Frecuencia & \% \\
\hline Totalmente en desacuerdo & 8 & $3,3 \%$ \\
En desacuerdo & 7 & $2,9 \%$ \\
Ni de acuerdo ni en desacuerdo & 25 & $10,2 \%$ \\
De acuerdo & 148 & $60,7 \%$ \\
Totalmente de acuerdo & 56 & $23,0 \%$ \\
\hline Total & 244 & $100,0 \%$ \\
\hline
\end{tabular}

Tabla 18. ¿Qué tipo de campañas evangelísticas cree usted que dio mayor resultado en el crecimiento de la iglesia (se desarrolló más) durante el período del 2001-2009?

\begin{tabular}{lrr}
\hline & Frecuencia & \% \\
\hline Evangelismo público & 75 & $30,7 \%$ \\
Evangelismo laico & 29 & $11,9 \%$ \\
Evangelismo personal & 100 & $41,0 \%$ \\
Caravanas de esperanza & 35 & $14,3 \%$ \\
Otros & 5 & $2,0 \%$ \\
\hline Total & 244 & $100,0 \%$ \\
\hline
\end{tabular}

Tabla 19. ¿Del 1 al 5 en qué lugar ubicaría el liderazgo del pastor distrital como uno de los factores claves en el crecimiento de los distritos misioneros de Trujillo durante el período del 2001-2009?

\begin{tabular}{lrr}
\hline & Frecuencia & \% \\
\hline Totalmente en desacuerdo & 8 & $3,3 \%$ \\
En desacuerdo & 4 & $1,6 \%$ \\
Ni de acuerdo ni en desacuerdo & 49 & $20,1 \%$ \\
De acuerdo & 124 & $50,8 \%$ \\
Totalmente de acuerdo & 59 & $24,2 \%$ \\
\hline Total & 244 & $100,0 \%$ \\
\hline
\end{tabular}

Tabla 20. ¿Qué característica en el liderazgo espiritual se manifestó mucho durante el período del 2001-2009?

\begin{tabular}{lrr} 
& Frecuencia & \% \\
\hline Liderazgo motivador & 109 & $44,7 \%$ \\
Liderazgo capacitador & 54 & $22,1 \%$ \\
Liderazgo innovador & 13 & $5,3 \%$ \\
Liderazgo responsable & 42 & $17,2 \%$ \\
Liderazgo visionario & 26 & $10,7 \%$ \\
\hline Total & 244 & $100,0 \%$ \\
\hline
\end{tabular}


Tabla 21. ¿Considera usted que el rol que cumplieron los GP durante el período del 2001-2009 fueron fundamentales para el crecimiento de los distritos misioneros en la ciudad de Trujillo?

\begin{tabular}{lrr}
\hline & Frecuencia & \% \\
\hline Totalmente en desacuerdo & 8 & $3,3 \%$ \\
En desacuerdo & 9 & $3,7 \%$ \\
Ni de acuerdo ni en desacuerdo & 25 & $10,2 \%$ \\
De acuerdo & 118 & $48,4 \%$ \\
Totalmente de acuerdo & 84 & $34,4 \%$ \\
\hline Total & 244 & $100,0 \%$ \\
\hline
\end{tabular}

Tabla 22. ¿Cree usted que la formación de nuevos discípulos contribuyó para el crecimiento de los distritos misioneros en Trujillo durante el período del 2001-2009?

\begin{tabular}{lcc}
\hline & Frecuencia & \% \\
\hline Totalmente en desacuerdo & 8 & $3,3 \%$ \\
En desacuerdo & 6 & $2,5 \%$ \\
Ni de acuerdo ni en desacuerdo & 36 & $14,8 \%$ \\
De acuerdo & 134 & $54,9 \%$ \\
Totalmente de acuerdo & 60 & $24,6 \%$ \\
\hline Total & 244 & $100,0 \%$ \\
\hline
\end{tabular}

Tabla 23. ¿Cree usted que el ambiente social (estabilidad) contribuyó en el crecimiento de la iglesia durante el período del 2001-2009?

\begin{tabular}{lrr} 
& Frecuencia & $\mathbf{\%}$ \\
\hline Totalmente en desacuerdo & 11 & $4,5 \%$ \\
En desacuerdo & 15 & $6,1 \%$ \\
Ni de acuerdo ni en desacuerdo & 52 & $21,3 \%$ \\
De acuerdo & 128 & $52,5 \%$ \\
Totalmente de acuerdo & 38 & $15,6 \%$ \\
\hline Total & 244 & $100,0 \%$ \\
\hline
\end{tabular}


APÉNDICE E

ARQUEOLOGÍA DE TRUJILLO

Ciudadela de Chan Chan
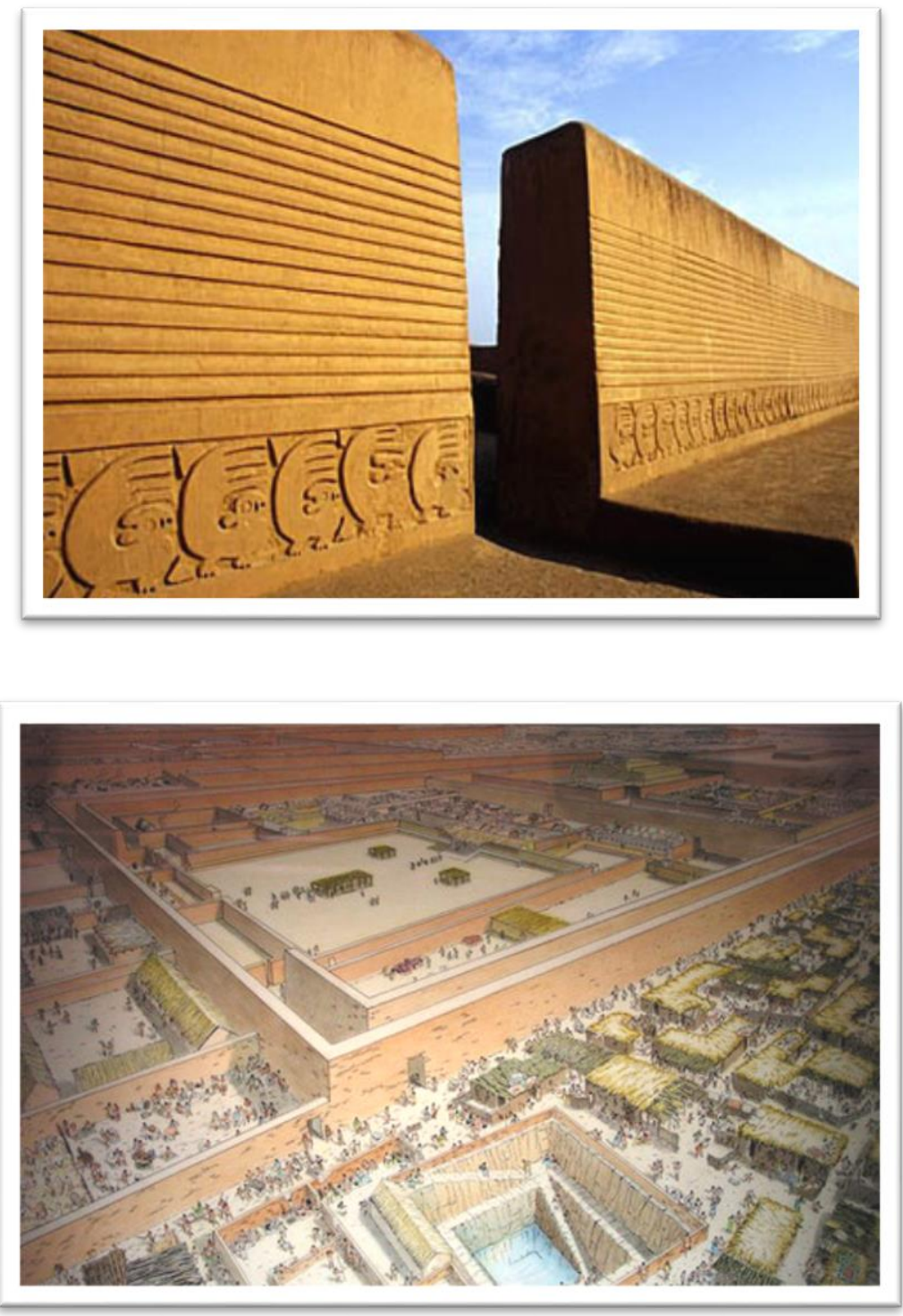


\section{Huaca EI Dragón o Arco Iris}

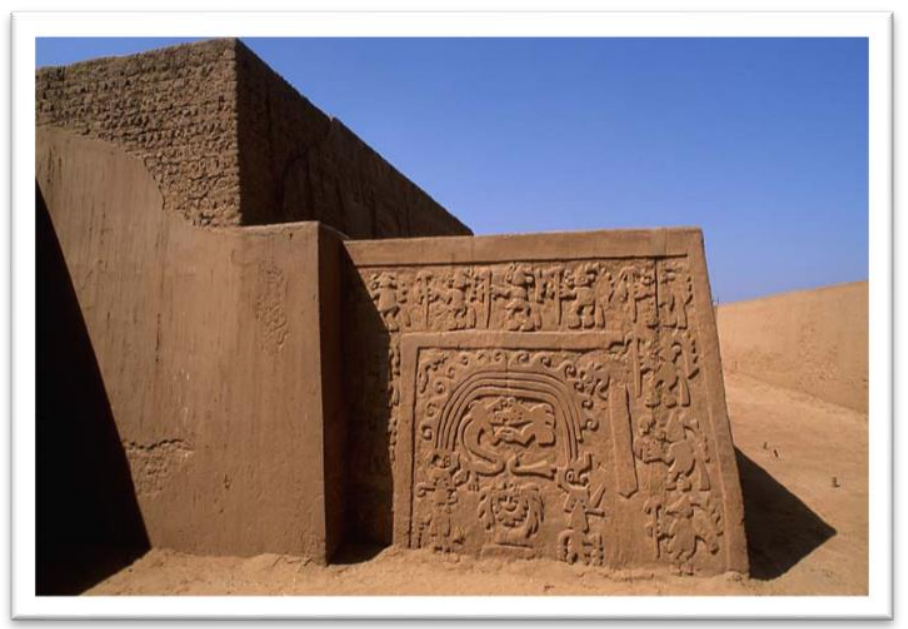

Huaca del Sol y Huaca de la Luna

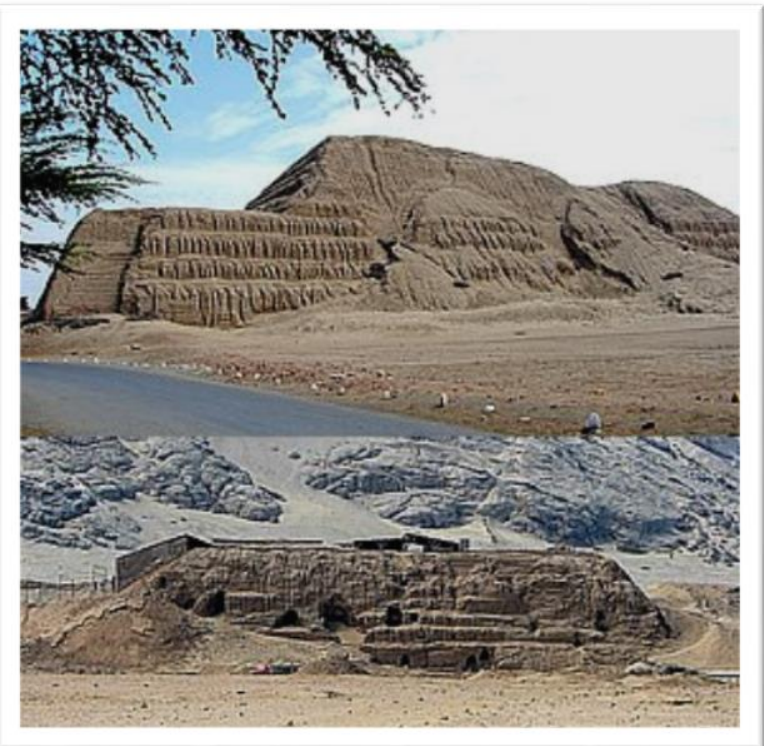




\section{Huaca La Esmeralda}

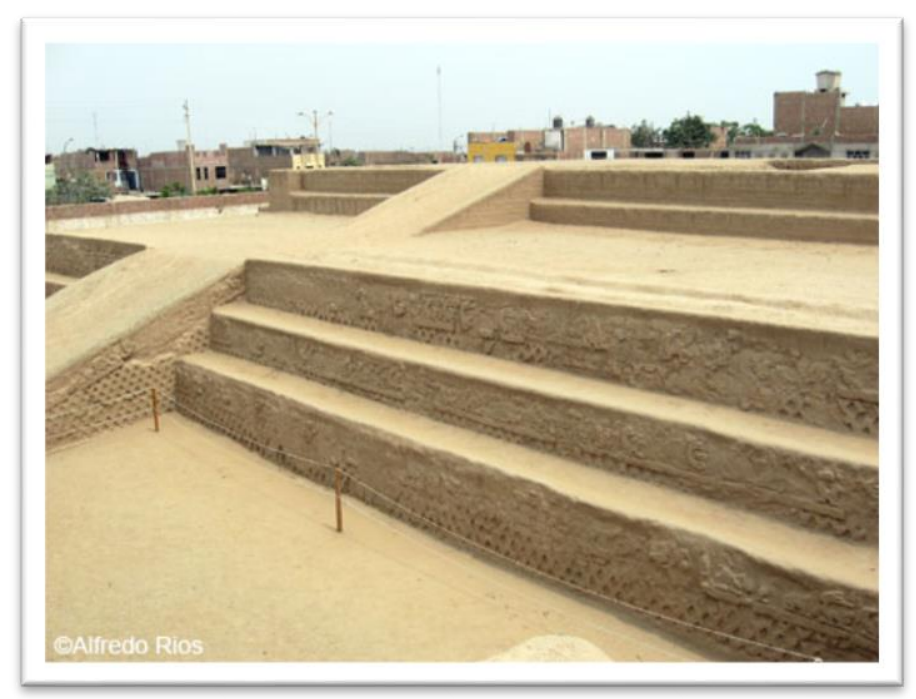

Museo de Arqueología José Cassinelli

Alberga finas piezas arqueológicas de la cultura Mochica, Chimú y Recuay.

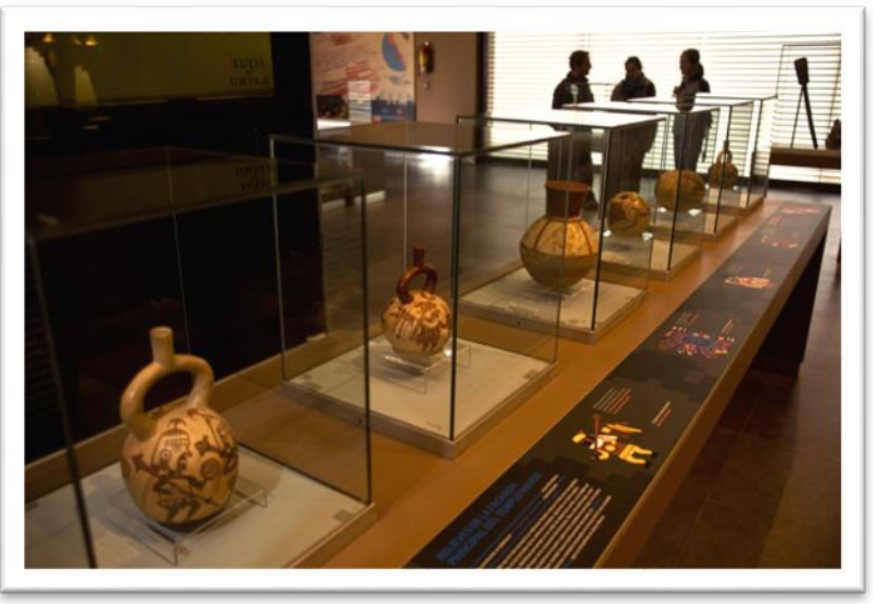




\section{BIBLIOGRAFÍA}

Abdala, Emilio. "Os pequenos grupos na história do cristianismo". Pequeños grupos, grandes solucoes. Brasil: Seminaro Adventista Latinoamericano de Teología, 2007.

Asociación General de la Iglesia Adventista del $7^{\circ}$ Día, Manual de la iglesia. Buenos Aires: Asociación Casa Editora Sudamericana, 2010.

Besse, Jean-Pierre y Heredia, Esperanza. Células en casa para la iglesia en misión: Manual práctico. Barcelona: Editorial Clie, 2001.

Bosch, David J. Misión en transformación: Cambios de paradigma en la teología de la misión. Grand Rapids, MI: Libros Desafío, 2000.

Burrill, Russell. La iglesia revolucionada del siglo XXI. Buenos Aires: Asociación Casa Editora Sudamericana, 2007.

Cho, David Yonggi. Mucho más que números. Miami, FL: Editorial Vida, 1985.

Corrie, John. "Mateo 28:16-20: La misión y el discipulado". Kairós, julio-diciembre, 2002.

Dederen, Raoul. ed. Teología: Fundamentos bíblicos de nuestra fe. Tomo 5. Miami, FL: Asociación Publicadora Interamericana, 2007.

División Sudamericana de la Asociación General de los Adventistas del Séptimo Día. Reglamentos eclesiástico-administrativos. Buenos Aires: Asociación Casa Editora Sudamericana, 2011.

Documental del Perú, Enciclopedia Nacional Básica. Tomo XIII. Barcelona: Cronion S.A. 1988.

Eims, LeRoy. El arte perdido de discipular. El Paso, TX: Editorial Mundo Hispano, 2008.

General Conference of Seventh-day Adventists, 147th Annual Statistical Report-2009. Silver Spring, MD: Compiled by the Office of Archives and Statistics, 2009.

Goma Civit, Isidro. El evangelio según San Mateo. Vol. 2. Madrid: Ediciones Marova, 1976. 
Gran Enciclopedia del Perú. Barcelona: Lexus Editores, 1998.

Greathouse, William M; Metz, Donald S; Carver, Frank G. ed. Comentario Bíblico BEACOM. Kansas City, MO: Casa Nazarena de Publicaciones, 1968.

Grubbs, Bruce. Mi iglesia puede crecer. El Paso, TX: Casa Bautista de Publicaciones, 1985.

Guthrie, D; Motyer, J.A. ed. Nuevo comentario bíblico. El Paso, TX: Casa Bautista de Publicaciones, 1977.

Keener Craig S. Comentario del contexto cultural de la Biblia. El Paso, TX: Editorial Mundo Hispano, 2006.

Larson, Pedro A. Crecimiento de la Iglesia. El Paso, TX: Casa Bautista de Publicaciones, 1989.

Maquera Sosa, Jorge P. Operación Andes Libres: Construyendo la "Utopía”. Lima: Editorial Imprenta Unión, 2014.

Miranda, Juan Carlos. Manual de iglecrecimiento. Miami, FL: Editorial Vida, 1985.

Municipalidad Provincial de Trujillo, Atlas Ambiental de la ciudad de Trujillo. Trujillo: se, 2002.

Nichol, Francis D, Cottrell, Raymond F y Neufeld, Don F., eds. Comentario bíblico adventista. Tomo 6. Buenos Aires: Asociación Casa Editora Sudamericana, 1996.

Orrego, Aldo D. Nuestra herencia: Historia de la Iglesia Adventista para el Ministerio Joven. Buenos Aires: Asociación Casa Editora Sudamericana, 2005.

Plenc, Daniel Oscar. Misioneros en Sudamérica. Buenos Aires: Asociación Casa Editora Sudamericana, 2008.

Prescott, W. W. Review and Herald. 13 de junio, 1907.

Raso, Bruno A. "Un estudio de factores personales, eclesiásticos, pastorales y comunitarios que inciden sobre la misión de hacer discípulos". Tesis doctoral, Seminario Adventista Latinoamericano de Teología, 2004.

Rode, Daniel Julio. Estrategias de crecimiento de iglesia. Buenos Aires: SALT, 2006.

Rode, Isabel y Daniel. Crecimiento: Claves para revolucionar su iglesia. Buenos Aires: Asociación Casa Editora Sudamericana, 2003.

Santana, Samuel. Renovación, transición y fortalecimiento de las iglesias hispanas en Norte América. Connecticut: Fiel USA, 2007.

Schuller, Robert H. Su iglesia tiene posibilidades. Barcelona: Editorial Clie, 1976. 
Schwarz, Christian A. Desarrollo Natural de la Iglesia: Ocho características básicas de una iglesia saludable. Barcelona: Editorial Clie, 1996.

Stedman, Ray C. La iglesia resucita. Barcelona: Editorial Clie, 1978.

The General Conference Corporation of Seventh-day Adventists. Yearbook 2008. Hagerstown: Review and Herald Publishing Association, 2008.

Veloso, Mario Teología de la administración eclesiástica. Seminario Adventista Latinoamericano de Teología, 1982.

Wagenveld, Juan. Iglecrecimiento integral. Miami, FL: Editorial Unilit, 2000.

Wagner, C. Peter. Su iglesia puede crecer. Barcelona: Editorial Clie, 1980. . Sus dones espirituales pueden ayudar a crecer a su iglesia. Barcelona: Editorial Clie, 1980.

Warren, Rick. Una iglesia con propósito. Miami: Editorial Vida, 1998.

Westphal, F. H.“The Opening of Our Work in Western South America”, $R H, 16$ de mayo de 1907.

White, Elena G. de. Cada día con Dios. Buenos Aires: Asociación Casa Editora Sudamericana, 1979.

. Consejos sobre el régimen alimenticio. Buenos Aires: Asociación Casa Editora Sudamericana, 2008.

. El Evangelismo. Buenos Aires: Asociación Casa Editora Sudamericana, 1975.

. El ministerio de la bondad. Buenos Aires: Asociación Casa Editora Sudamericana, 1976.

. Eventos de los últimos días. Buenos Aires: Asociación Casa Editora Sudamericana, 1992.

. Hechos de los Apóstoles. Buenos Aires: Asociación Casa Editora Sudamericana, 1977.

. Joya de los Testimonios. Tomo 2. Buenos Aires: Asociación Casa Editora Sudamericana, 1975.

. Joya de los Testimonios Tomo 3. Miami, FL: Publicaciones Interamericanas, 1953.

Testimonios selectos. Tomo 5. Buenos Aires: Casa Editora Sudamericana, 1932. 